\title{
DISSERTATION
}

THERMAL MONITORING OF NATURAL SOURCE ZONE DEPLETION

\author{
Submitted by \\ Kayvan Karimi Askarani \\ Department of Civil and Environmental Engineering
}

In partial fulfillment of the requirements

For the Degree of Doctor of Philosophy

Colorado State University

Fort Collins, Colorado

Summer 2019

Doctoral Committee:

Advisor: Thomas Sale

Jay Ham

Joseph Scalia

Ryan Bailey 
Copyright by Kayvan Karimi Askarani

All Rights Reserved 


\section{ABSTRACT \\ THERMAL MONITORING OF NATURAL SOURCE ZONE DEPLETION}

Natural Source Zone Depletion (NSZD) has emerged as a viable remedial approach for mature releases of petroleum liquids in soils and groundwater. Herein, petroleum liquids in soils and groundwater are referred to as LNAPL. In recent years, gradient, dynamic chamber, and carbon trap methods have been developed to quantify NSZD rates based on measuring the consumption of $\mathrm{O}_{2}$ or the generation of $\mathrm{CO}_{2}$ associated with biodegradation of LNAPL. A promising alternative approach to resolving LNAPL NSZD rates is real-time monitoring of subsurface temperatures. Transformation of temperature data to NSZD rates involves use of background-corrected temperature data, energy balances to resolve NSZD energy, and an estimate of heat produced through NSZD. All current computational methods for quantifying NSZD rates using temperature data have the drawbacks of: 1) incomplete energy balances 2) ignoring the effect of water table fluctuation, and 3) using linear extrapolations of temperature profiles to calculate thermal gradients.

A regression algorithm is advanced to overcome the primary drawbacks of current computational methods that convert subsurface temperature data to NSZD rates using background correction. The regression algorithm is demonstrated using 42 million temperature measurements from a fuel terminal. An $8 \%$ difference between NSZD rates from the $\mathrm{CO}_{2}$ Trap method and the regression algorithm supported the validity of regression algorithm for estimation of NSZD rates using subsurface temperatures. In addition, seasonal behavior of NSZD rates is captured and correlated water content in shallow soils and depth to the water 
table. It is concluded that as the water table rises, the apparent NSZD rates increase, while larger water content in shallow soil causes a reduction in the apparent NSZD rates.

Imperfection with background-correction approaches can be attributed to many factors, including differing infiltration of precipitation, vegetative cover, soil properties, and net solar radiation, at background versus impacted locations. Differences between the background location and the impacted area cause anomalous background-corrected temperatures leading to over/under estimation of NSZD rates. A new computational model is developed to eliminate the need for background correction of temperature data in calculating NSZD rates. Since the new model uses only the temperature data collected from the temperature sensors attached to a single solid stick, the model is referred to as the "single stick" method.

The validity of the single stick model is evaluated using a numerical model and field temperature data. Agreement between the results from a numerical model with imposed heat fluxes, and estimated heat fluxes using temperature data derived from the numerical model, supports the validity of single stick model. In addition, a close match between single stick simulated temperatures using estimated heat fluxes and actual measure temperatures supports the validity of the single stick model. Furthermore, comparison of NSZD rates from the single stick model with the rates from background correction methods at background locations shows that the single stick model is the only algorithm that consistently provides near zero NSZD rates in clean areas. Lastly, per thermodynamic calculations and preliminary lab studies, it is observed that negative NSZD rates may be due to endothermic methanogenic process.

Thermal conductivity is one of the key input parameters for all computational methods converting temperature data to NSZD rates. An integrated Internet of Things (IoT) instrument and computational model is developed to measure real-time in-situ thermal conductivity of soils. 
Favorable agreement between measure ex-situ and in- situ thermal conductivities values supports the validity of the demonstrated in-situ techniques for estimating thermal conductivities. Favorable attributes of the new in-situ methods include lower cost, automated data acquisition and an ability to acquire in-situ estimates of thermal conductivities through time.

Overall, this work demonstrated that monitoring subsurface temperature is a viable technique to resolve NSZD rates for LNAPLs. A promising next step for evaluating the validity of thermal NSZD rates is to periodically collect and analyze cryogenic cores from field sites to independently validate NSZD rates. Also, further work is needed to better resolve NSZD thermodynamics. 


\section{ACKNOWLEDGMENTS}

I would like to thank my advisor, Professor Tom Sale, for providing me with this great opportunity to pursue my Ph.D. at Colorado State University (CSU). His knowledge and deep understanding in the field of contaminant hydrology were greatly influential and helpful for me to conduct my Ph.D. research over the last four years. Without his comprehensive support and encouragement, I would have not been able to finish this journey. I would also like to thank my committee member, Dr. Jay Ham, who provided continuous support and guidance during development of my research. I would like to thank my committee members, Drs. Joseph Scalia and Ryan Bailey, for their valuable feedback and insightful comments.

My friends and colleagues at the Center for Contaminant Hydrology $(\mathrm{CCH})$ at $\mathrm{CSU}$ have all been very supportive and kind to me over the last few years. I would like to thank all of them and for their help, support, and friendship.

Without years of funding and support from the ExxonMobil, Suncor Energy USA Inc., BP Corporation North America Inc., and TRC Companies Inc., the work presented in this dissertation would have not been possible. Also, I would like to thank Dr. Charles Newell (GSI Environmental, Inc.), Emily Stockwell (Geosyntec Consultants, Inc.), and Keith Piontek (TRC Companies Inc.) for sharing their valuable thoughts and ideas that greatly influenced the work presented in this dissertation. I would like to thank many people from Chevron Energy Technology Company, GSI Environmental, Inc., and TriHydro who have supported me to implement the research presented in this dissertation. 
I would like to thank Dr. David McWhorter, emeritus professor at Colorado State University, Dr. Paul DuChateau, emeritus professor at Colorado State University, and Dr. Gerard Kluitenberg, professor at Kansas State University, for their useful advice and support.

I would also like to thank my parents who have always supported and respected my decisions throughout my life and have always been there for me through thick and thin. Last but not least, I would like to thank my wife, Mona, for her continuous and unconditional love and support throughout the completion of this program and dedicate this dissertation to her as a gesture of my appreciation and gratitude towards her kindness and support. 


\section{TABLE OF CONTENTS}

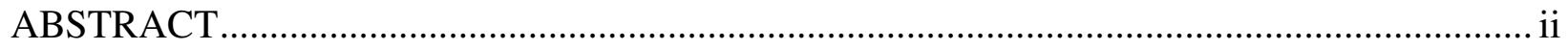

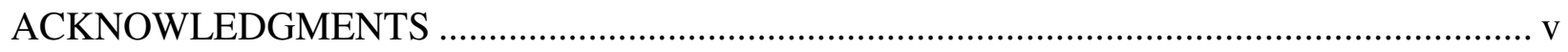

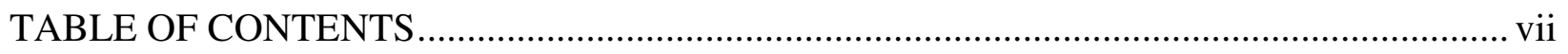

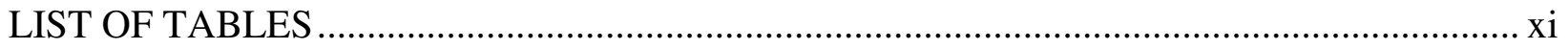

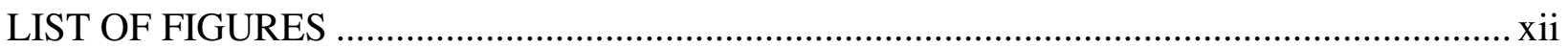

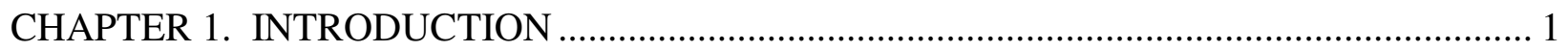

1.1. Research Objective and Rational.............................................................. 1

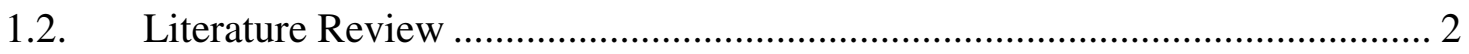

1.2.1. Governing Processes ………………………........................................ 2

1.2.2. Methods for Measuring NSZD Rates ……………....................................... 4

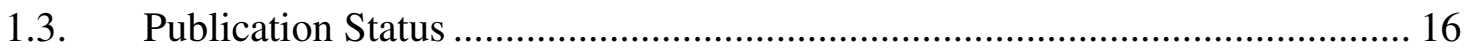

CHAPTER 2. THERMAL MONITORING OF NATURAL SOURCE ZONE DEPLETION... 17

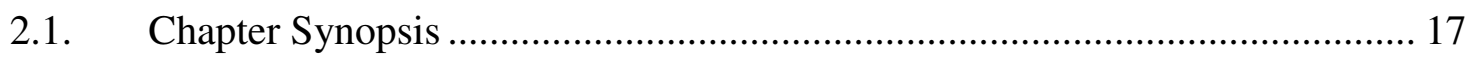

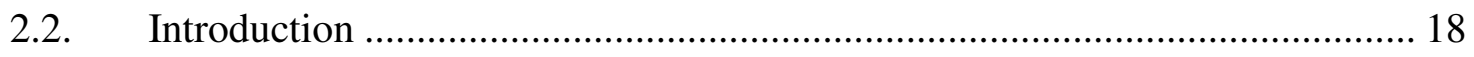

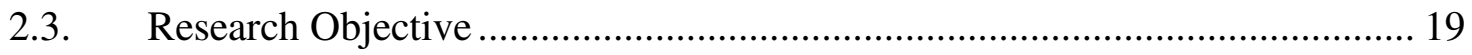

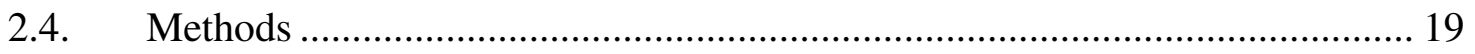

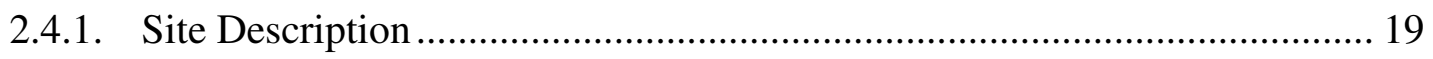

2.4.2. Temperature Data Collection ................................................................... 20

2.4.3. Computational Method........................................................................... 22 


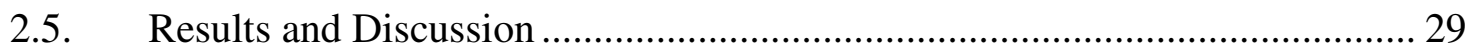

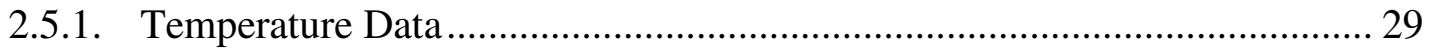

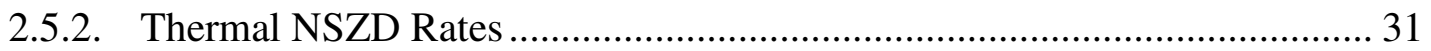

2.5.3. Comparison of Thermal and $\mathrm{CO}_{2}$ Trap NSZD Rates ............................... 36

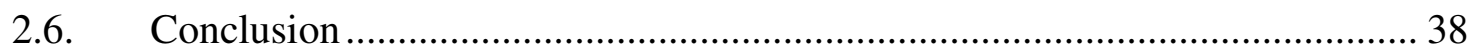

CHAPTER 3. ESTIMATION OF NATURAL SOURCE ZONE DEPLETION WITHOUT

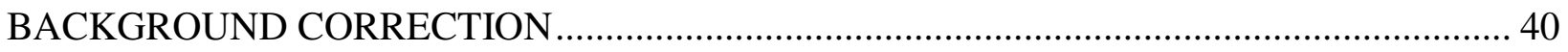

3.1. Chapter Synopsis ........................................................................... 40

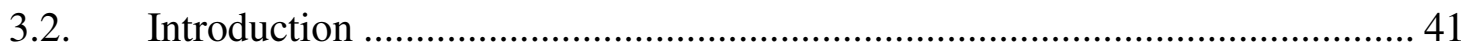

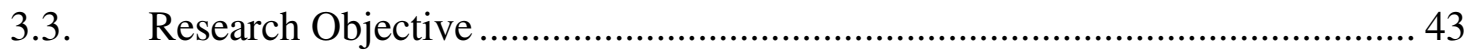

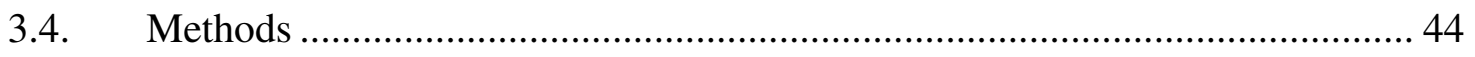

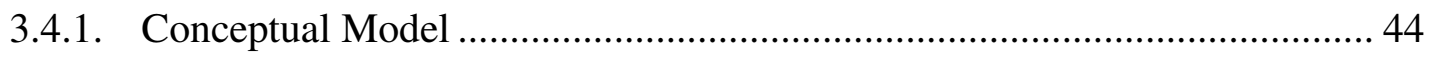

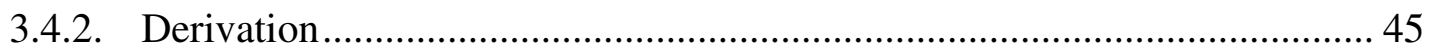

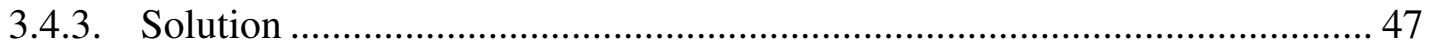

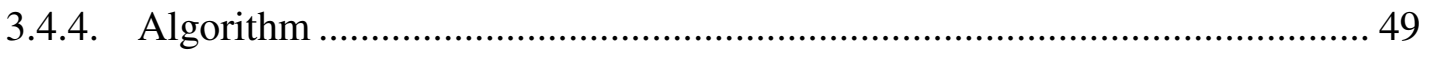

3.4.5. Confirmation of Solution and Algorithm .............................................. 51

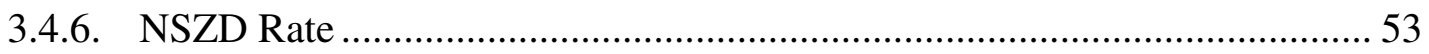

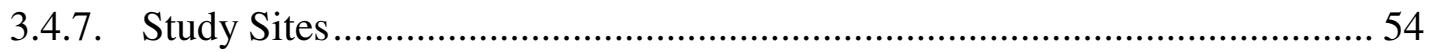

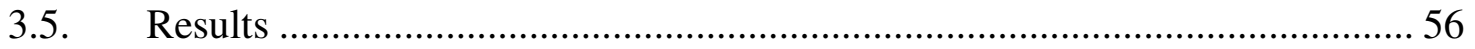

3.5.1. Confirmation of Solution and Algorithm ............................................. 56 


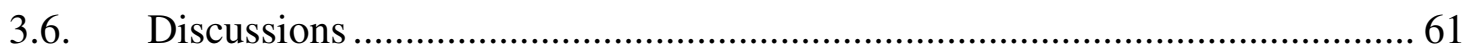

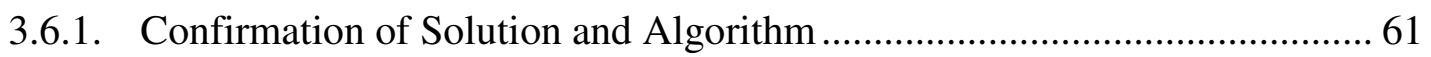

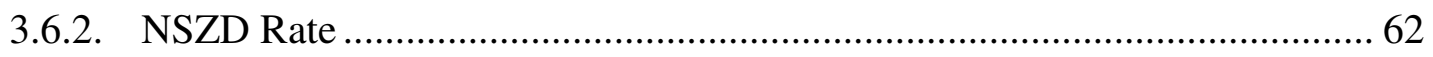

3.6.3. Merits-Limitation of the Single Stick Method .............................................. 65

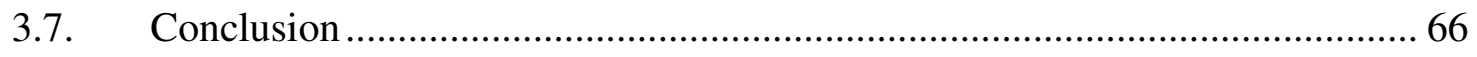

CHAPTER 4. REAL-TIME, IN-SITU THERMAL CONDUCTIVITY MEASUREMENT OF

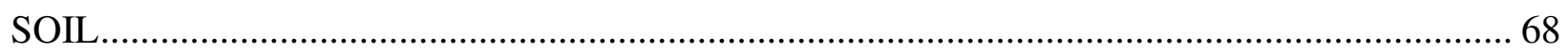

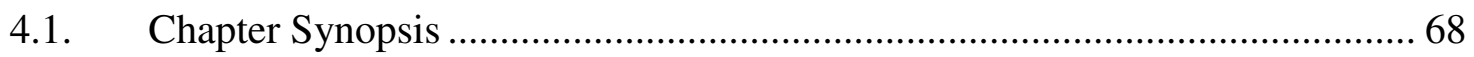

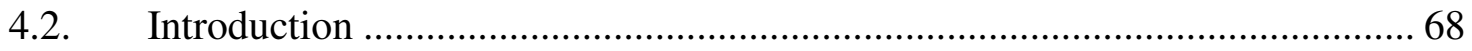

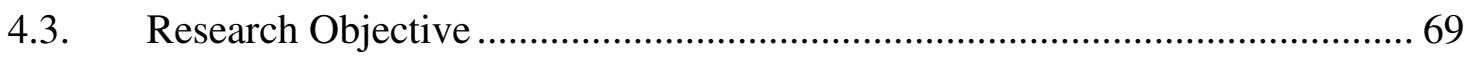

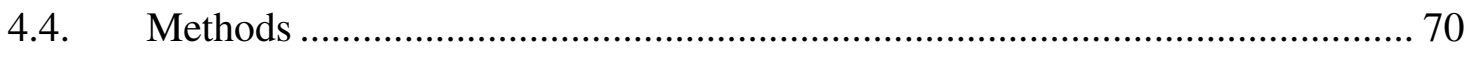

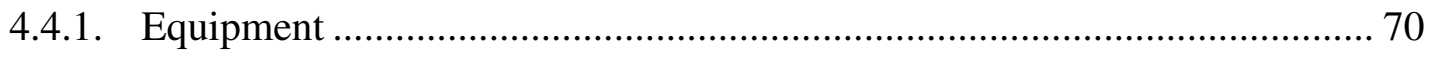

4.4.2. Temperature Data Collection ........................................................................ 72

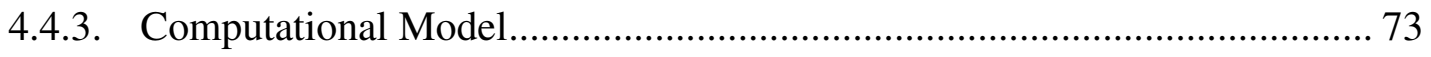

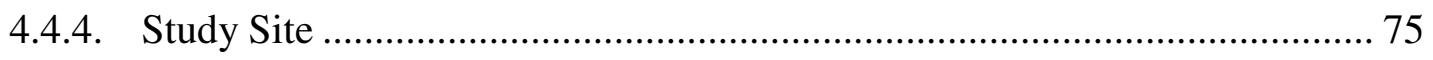

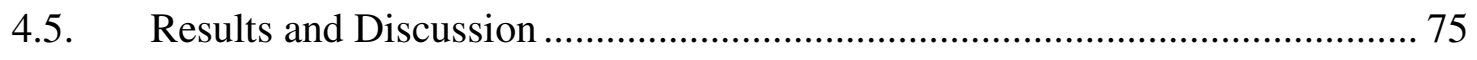

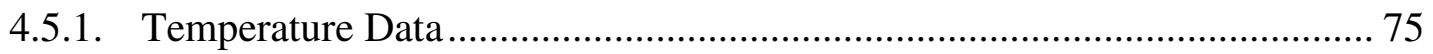

4.5.2. Heating and Cooling Period ...................................................................... 76

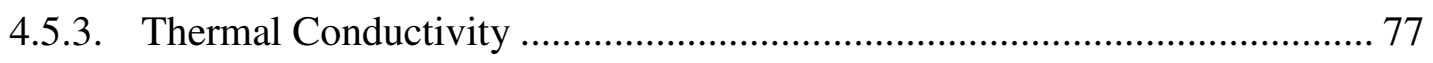




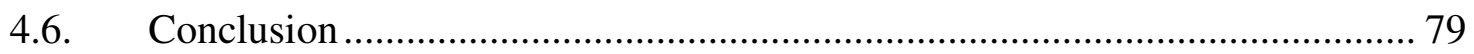

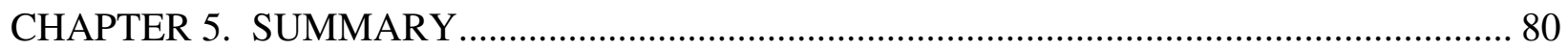

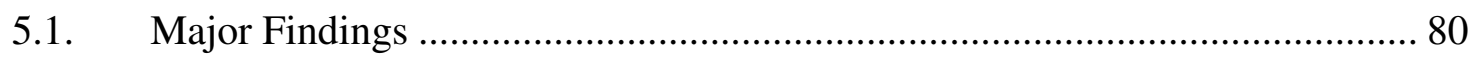

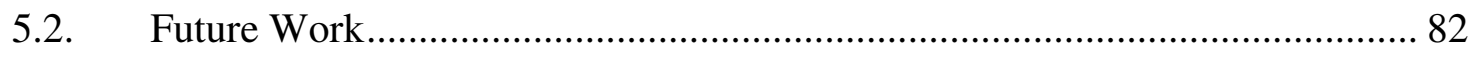

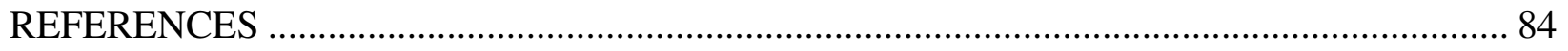

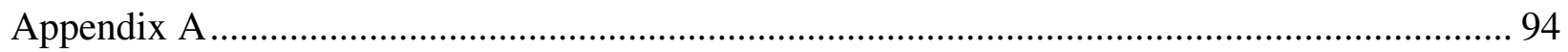

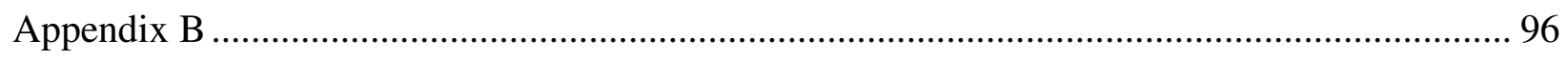




\section{LIST OF TABLES}

Table 1.1. Summary of characteristics of methods ........................................................... 12

Table 2.1. Results from $\mathrm{CO}_{2}$ traps deployed from 2012 through 2014 ................................ 28

Table 3.1. Transformation of decane as a representative of petroleum hydrocarbon compound through NSZD process with change in free Gibbs energy and enthalpy. The values of change in Gibbs free energy $\Delta \boldsymbol{G r} \boldsymbol{r}$ and enthalpy $\Delta \boldsymbol{H} \boldsymbol{r o}$ under standard conditions for each reaction in Table

3.1 are calculated based on the values tabulated in Appendix A......................................... 45

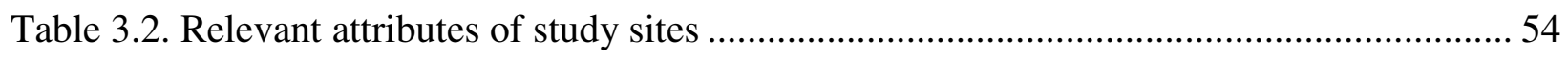

Table 3.3. Statistical evaluation of the performance of the single stick model ........................56

Table 3.4. Statistical evaluation of the agreement between measured and simulated temperature

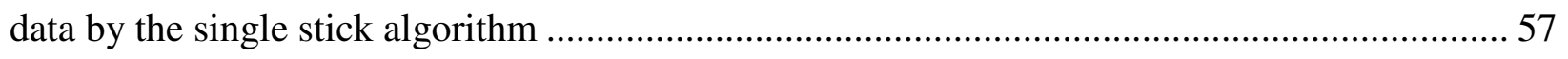

Table 3.5. Triplicate NSZD rates from $\mathrm{CO}_{2}$ trap and the single stick method for a 42-day period

Table A-1. Free energy and enthalpy of formation for reaction components .......................... 95 


\section{LIST OF FIGURES}

Figure 1.1. Conceptual model of NSZD process (Stockwell, 2015) ........................................ 3

Figure 1.2. Schematic cross section showing multilevel soil-gas probes .............................. 5

Figure 1.3. Scheme of soil-gas concentration profiles..................................................... 6

Figure 1.4. Conceptualization of thermal monitoring system......................................... 10

Figure 2.1. Conceptual model of processes governing NSZD. Region 2 is the primary zone of

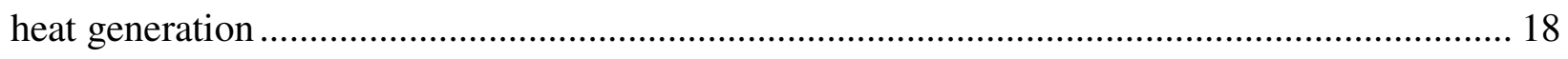

Figure 2.2. Study site with location of temperature monitoring sticks N1-N4 ....................... 20

Figure 2.3. Thermal monitoring system: A) thermocouple, B) installation using direct-push drilling methods, C) solar power supply and weatherproof box containing data-logging and communications software. 22

Figure 2.4. An example of regressed background-corrected temperature data on two consecutive

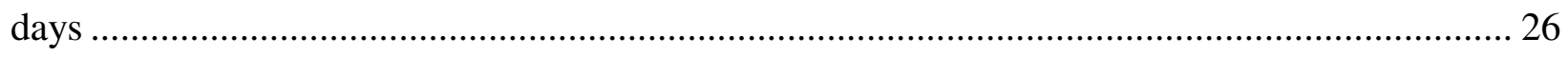

Figure 2.5. Temperature data measured on May 10, 2014. A) Raw temperature data and B) background-corrected temperature data. Lines are best-fit regressions of the data developed using

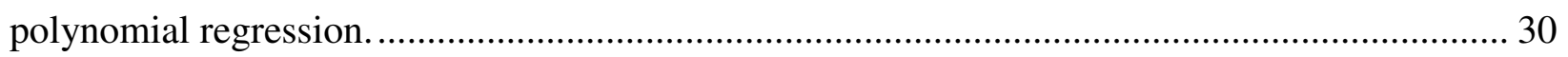
Figure 2.6. Cumulative LNAPL losses for May 2014 to November 2016 at N1 through N3 and

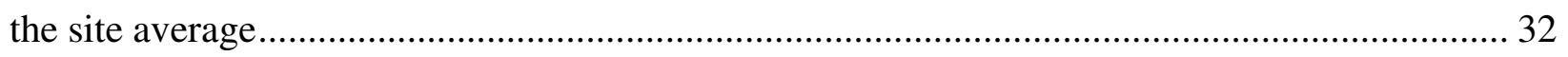
Figure 2.7. A) Average monthly NSZD rates based on temperature data, B) average water level measured along the transect and simulated soil moisture data, and C) average $\mathrm{CO}_{2}$ trap NSZD rates 34 
Figure 2.8. Comparison of $\mathrm{CO}_{2}$ trap and thermal monitoring estimates of NSZD rates during three two-week periods of concurrent data collection at the same locations. Broad bars reflect $\mathrm{CO}_{2}$ trap NSZD values based on total sorbed $\mathrm{CO}_{2}$ over two week deployment periods. Narrow bars reflect NSZD values without energy storage obtained from average daily temperature data.

Figure 3.1. a) Extent of glacial ice limited by melting ice and b) Extent of LNAPL limited by NSZD 41

Figure 3.2. Conceptual model for primary heat sources in a LNAPL-impacted area 46

Figure 3.3. Flowchart of the single stick model. 51

Figure 3.4. Finite element approach: (a) physical model of soil profile, (b) discretization of soil profile, and (c) temperature distribution. 52

Figure 3.5. a) Prescribed values (black circles) and predicted values (red line) of $\boldsymbol{q}_{s}$, b) prescribed values (black squares) and predicted values (red line) of $\boldsymbol{q}_{\boldsymbol{s}}$ 56

Figure 3.6. Measured subsurface temperature profile (squares) in a LNAPL-impacted location at Site-1 and simulated subsurface temperatures (solid line) from the single stick algorithm ...... 57 Figure 3.7. Annual average NSZD rate in background and LNAPL-impacted areas at a) Site-1, b) Site-2, and c) Site-3. 59

Figure 3.8. Average monthly NSZD rates by the single stick method in an LNAPL-impacted area at Site-5 60

Figure 3.9. Average of evapotranspiration, shallow soil moisture, and site-wide monthly average of NSZD rates calculated by the single stick method in Site-3 61

Figure 3.10. Average of NSZD rates calculated by the single stick method and background correction method for all background locations. 63 
Figure 4.1. Scheme of a sensor in a stick with attached heating strip

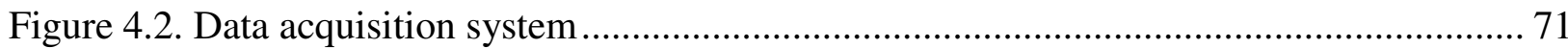

Figure 4.3. Study site with location of temperature monitoring stick .................................. 72

Figure 4.4. Measured subsurface temperatures at multiple positions during and after heating test

Figure 4.5. a) Change in subsurface temperature through the heating and dissipation of heat at $0.61 \mathrm{~m}(\mathrm{bgs})$ and b) semi-log of residual temperature versus $(\boldsymbol{t} / \boldsymbol{t})$ at $0.61 \mathrm{~m}(\mathrm{bgs}) \ldots \ldots \ldots \ldots \ldots . . . . . . .77$

Figure 4.6. In-situ thermal conductivity of the soil profile ................................................ 78

Figure B-1. Change in subsurface temperature through the heating and dissipation of heat and residual temperature versus $(\boldsymbol{t} / \boldsymbol{t})$ at $0.30 \mathrm{~m}(\mathrm{bgs})$ 97

Figure B-2. Change in subsurface temperature through the heating and dissipation of heat and residual temperature versus $(\boldsymbol{t} / \boldsymbol{t})$ at $0.91 \mathrm{~m}(\mathrm{bgs})$ 97

Figure B-3. Change in subsurface temperature through the heating and dissipation of heat and residual temperature versus $(\boldsymbol{t} / \boldsymbol{t})$ at $1.22 \mathrm{~m}(\mathrm{bgs})$ 97

Figure B-4. Change in subsurface temperature through the heating and dissipation of heat and residual temperature versus $(\boldsymbol{t} / \boldsymbol{t})$ at $1.83 \mathrm{~m}(\mathrm{bgs})$ 98 Figure B-5. Change in subsurface temperature through the heating and dissipation of heat and residual temperature versus $(\boldsymbol{t} / \boldsymbol{t})$ at $2.44 \mathrm{~m}(\mathrm{bgs})$ 98 Figure B-6. Change in subsurface temperature through the heating and dissipation of heat and residual temperature versus $(\boldsymbol{t} / \boldsymbol{t})$ at $3.05 \mathrm{~m}(\mathrm{bgs})$ 98 Figure B-7. Change in subsurface temperature through the heating and dissipation of heat and residual temperature versus $(\boldsymbol{t} / \boldsymbol{t})$ at $3.66 \mathrm{~m}(\mathrm{bgs})$ 99 
Figure B-8. Change in subsurface temperature through the heating and dissipation of heat and residual temperature versus $(\boldsymbol{t} / \boldsymbol{t})$ at $4.27 \mathrm{~m}(\mathrm{bgs})$

Figure B-9. Change in subsurface temperature through the heating and dissipation of heat and residual temperature versus $(\boldsymbol{t} / \boldsymbol{t})$ at $4.88 \mathrm{~m}(\mathrm{bgs})$

Figure B-10. Change in subsurface temperature through the heating and dissipation of heat and residual temperature versus $(\boldsymbol{t} / \boldsymbol{t})$ at $5.49 \mathrm{~m}(\mathrm{bgs})$ 100

Figure B-11. Change in subsurface temperature through the heating and dissipation of heat and residual temperature versus $(\boldsymbol{t} / \boldsymbol{t})$ at $6.07 \mathrm{~m}(\mathrm{bgs})$ 100

Figure B-12. Change in subsurface temperature through the heating and dissipation of heat and residual temperature versus $(\boldsymbol{t} / \boldsymbol{t})$ at $6.71 \mathrm{~m}(\mathrm{bgs})$ 100

Figure B-13. Change in subsurface temperature through the heating and dissipation of heat and residual temperature versus $(\boldsymbol{t} / \boldsymbol{t})$ at $7.32 \mathrm{~m}(\mathrm{bgs})$ 101 


\section{CHAPTER 1.}

\section{INTRODUCTION}

The following section provides an introduction to this Ph.D. dissertation. Contents include research objective, research rational, literature review, and the status of related publications.

\subsection{Research Objective and Rational}

Many sites in the industrialized world are impacted by petroleum hydrocarbon in the form of light, nonaqueous-phase liquids (LNAPLs). The presence of LNAPL in the subsurface can pose a threat to human health and the environment. Based on the concerns, implementation of remedies that remove and/or restore the source zone are typically required to manage threats to human health and the environment.

Since the mid-2000s, recognition has been growing that Natural Source Zone Depletion (NSZD) processes can deplete subsurface releases of petroleum-based Light Nonaqueous Phase Liquid (LNAPL) at rates on the order of 1,000s to 10,000s liters/hectare/year (Amos et al., 2005; Johnson et al., 2006; McCoy et al., 2015; Sihota et al., 2016; Palaia, 2016). Impressively, NSZD rates of this magnitude can rival depletion rates that can be achieved with active remedies at mature sites (McCoy et al., 2015) and hold the promise of fully depleting LNAPL over periods of decades (Skinner, 2013).

To date, the methods for measuring NSZD rates can be divided into two main categories: 1) the methods that rely on the flux of gases produced or consumed through NSZD process including gradient, chamber, and trap methods and 2) the methods that rely on the heat

associated with natural degradation. The resulting NSZD rates based on gas flux measurement 
can be biased by temporally variable environmental factors governing the mechanisms of gas fluxes in the subsurface. In addition, measured NSZD rates derived from gas fluxes are typically limited to the short time period of measurement. The limitations of gradient, chamber, and trap methods have provided the motivation for development of the techniques that quantify NSZD rates by monitoring subsurface temperatures.

Computational approaches for converting temperature data into NSZD rates have also limitations including not taking into consideration 1) a complete energy balances, 2) the influence of variable water table elevation, 3) nonlinear temperature profile in the subsurface, 4) non uniform thermal properties of soils, and 5) the influence of an imperfect background location. The overarching objectives of this work are to overcome the shortcomings of current thermal NSZD estimation methods by advancing 1) an improved computational method relying on the background-correction approach, 2) a novel method for transforming temperature data to NSZD rates that eliminates the need for background correction, and 3) field procedure for measuring in-situ thermal conductivity of soil.

\subsection{Literature Review}

\subsubsection{Governing Processes}

Petroleum liquids are commonly found beneath petroleum facilities due to surface spills and leakage from buried infrastructures. Typically, released LNAPL migrates downward to the water table. Small portions of LNAPL may be trapped in the vadose zone before reaching the water table. Accumulated LNAPL at the water table can spread across the water table surface, mostly in the direction of groundwater flow. LNAPL constituents are depleted over time through natural processes. Commonly, subsurface LNAPL can persist as a source of groundwater contaminants for decades. Following ITRC (2009), LNAPL bodies are referred to "source 
zones." Furthermore, the source zones are naturally depleted at a rate which is referred to as the Natural Source Zone Depletion (NSZD) rate.

Natural loss mechanisms include sorption, volatilization, dissolution, and biodegradation (aerobic and anaerobic). Biodegradation accounts for the majority of natural losses (Lundegard and Johnson, 2006). Remediation of LNAPL in contaminated media is often a default remedial objective in regulatory programs. For mature LNAPL release, NSZD should be considered as a viable remedial approach managing risks associated with subsurface LNAPL.

In anaerobic zones, biodegradation of LNAPLs leads to formation of hydrogen and acetate. As shown in Figure 1.1, through the methanogenic process, hydrogen and acetate are used to produce methane (Gieg et al., 2014). As the $\mathrm{CO}_{2}$ and $\mathrm{CH}_{4}$ gas bubbles formed in saturated zone exceed the gas-solubility capacity of groundwater, they move upward to the unsaturated zone (Garg et al., 2017). $\mathrm{CO}_{2}$ and $\mathrm{CH}_{4}$ can also be produced through NSZD processes in the vadose zone. Typically, the upward flux of $\mathrm{CH}_{4}$ in the vadose zone is met by a downward diffusing $\mathrm{O}_{2}$ (Amos et al., 2005). Following Stockwell (2015), methanotrophs convert $\mathrm{CH}_{4}$ and $\mathrm{O}_{2}$ into $\mathrm{CO}_{2}, \mathrm{H}_{2} \mathrm{O}$, and heat.

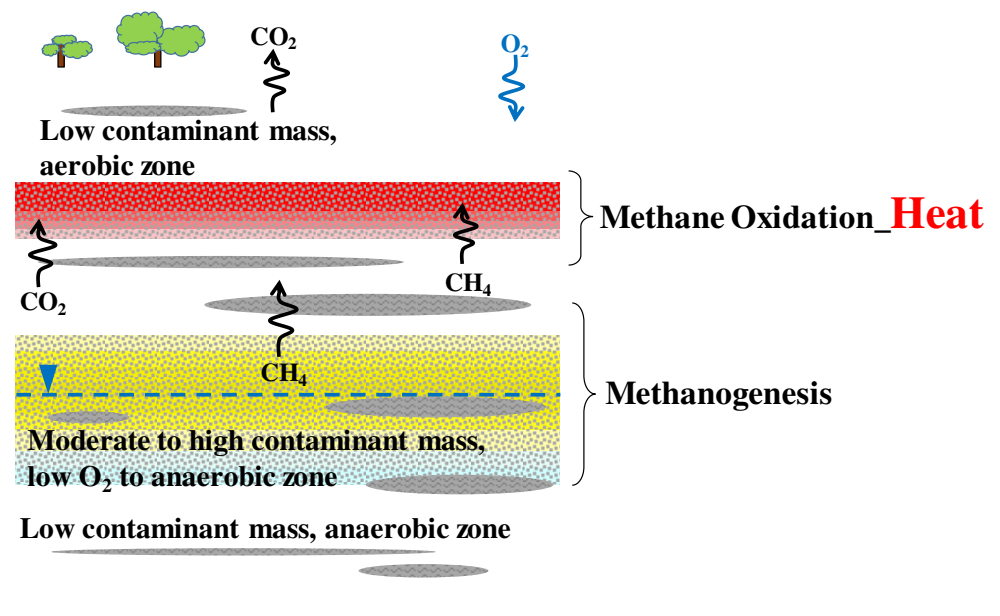

Figure 1.1. Conceptual model of NSZD process (Stockwell, 2015) 


\subsubsection{Methods for Measuring NSZD Rates}

Methods for quantifying NSZD rates using gas fluxes and soil temperatures are documented in the following sections to provide a point of embarkation for research advanced in this dissertation.

Gradient method. Vertical soil gas concentration profiles are used to estimate NSZD rate (Johnson et al., 2006). Multi-level soil gas samples are collected along a vertical profile as illustrated in Figure 1.2. By coupling soil gas profiles with effective diffusion coefficients in Fick's first law, subsurface LNAPL depletion rate can be estimated. If reactions and volatilization are assumed negligible, NSZD rate estimation can be simply computed using $\mathrm{CO}_{2}$ concentration gradients by:

$J_{\mathrm{CO}_{2}}=-D_{\mathrm{CO}_{2}} \frac{\partial \mathrm{CO}_{2}}{\partial z}$

where $D_{\mathrm{CO}_{2}}$ is the effective gas-phase diffusion of carbon dioxide at the depth of measurement $\left[\mathrm{L}^{2} / \mathrm{T}\right]$, and $\frac{\partial \mathrm{CO}_{2}}{\partial z}$ is the vertical concentration gradient of carbon dioxide gas $\left[\mathrm{M} / \mathrm{L}^{4}\right]$. Analogously, inward diffusion of oxygen can also be used to resolve NSZD rates. The gradient method was first applied on a 3000-acre former oil field in California by Lundegard and Johnson (2006). Supporting data, obtained from geochemical profiles of continuous cores, nested ground water wells, and soil-gas probes, were used to determine mass loss rates. 


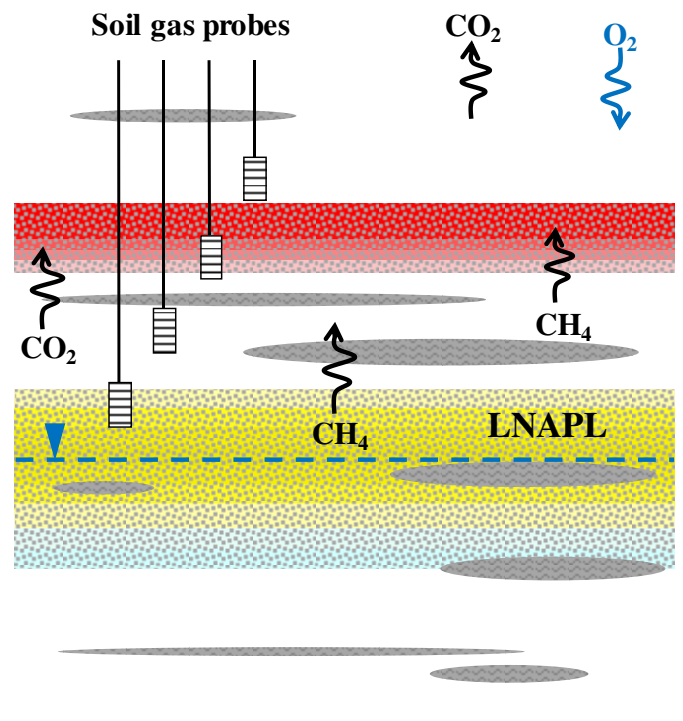

Figure 1.2. Schematic cross section showing multilevel soil-gas probes

Based on soil-gas profiles over source zones (Figure 1.3), Lundegard and Johnson (2006) observed that increasing depth causes a reduction in $\mathrm{O}_{2}$, increase in $\mathrm{CO}_{2}$, and appearance of $\mathrm{CH}_{4}$. As a result, occurrence of an aerobic and anaerobic biodegradation in the source zones was demonstrated. Dissolution is the other process involved in Source Zone Natural Attenuation (SZNA). The process responsible for the most significant rate of mass loss is the downward diffusing oxygen. By using the oxygen flux at just above the depth where all hydrocarbon concentrations reduce to zero, SZNA rates can be estimated (Equation 1.2):

$S Z N A \approx L_{\text {source }} W_{\text {source }}\left\{S_{O_{2}} D_{O_{2}}^{T}\left(\frac{C_{O_{2}}^{a t m}-C_{O_{2}}(d)}{d}\right)\right\}$

where $L_{\text {source }}$ is the source length parallel to groundwater flow; $W_{\text {source }}$ is the width of the dissolved plume leaving the down gradient edge of the source zone [L]; $S_{\mathrm{O}_{2}}$ is the stoichiometric coefficient for the aerobic oxidation of hydrocarbons and methane ranging from approximately 0.25 to $0.29 ; D_{\mathrm{O}_{2}}^{T}$ is the overall effective vapor-phase diffusion coefficient for oxygen vapor between ground surface and a depth $\mathrm{d}\left[\mathrm{L}^{2} / \mathrm{T}\right] ; C_{\mathrm{O}_{2}}^{a t m}$ is the atmospheric oxygen concentration 
$\left[\mathrm{M} / \mathrm{L}^{3}\right] ; C_{\mathrm{O}_{2}}(d)$ is the oxygen concentration at depth $d$ (usually $<<C_{\mathrm{O}_{2}}^{a t m}$ ) $\left[\mathrm{M} / \mathrm{L}^{3}\right]$. Strong inverse correlation between $\mathrm{CO}_{2}$ and $\mathrm{O}_{2}$ concentration results in a similar degradation rate obtained using either $\mathrm{CO}_{2}$ gradient or $\mathrm{O}_{2}$ gradient. Estimated SZNA rate ranged from 1000 to $10000 \mathrm{~L} / \mathrm{Ha} /$ year.

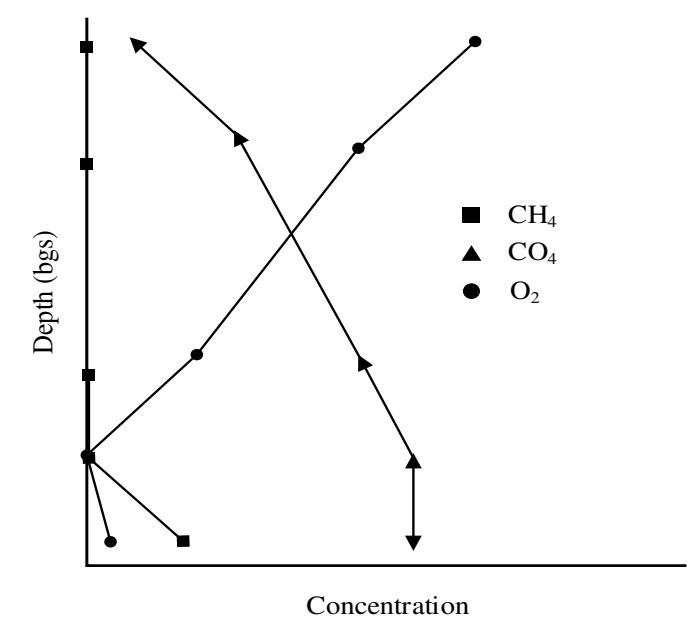

Figure 1.3. Scheme of soil-gas concentration profiles

This method provides instantaneous NSZD rates based on a period of measurement where a high level of effort is required for installation and collection of samples, determination of diffusion coefficient, and data reduction. Factors that can cause errors in the rates obtained from the gradient method include: correction for natural soil respiration, barometric pumping, surface wind, precipitation and/or soil moisture, artificial surfaces, and heterogeneities in diffusion coefficients.

Dynamic chamber method. In this method, total $\mathrm{CO}_{2}$ efflux is measured using an infrared gas analyzer (IRGA) within a soil gas chamber placed on a PVC collar at grade (LICOR, 2010). A direct correlation exists between increasing $\mathrm{CO}_{2}$ in the chamber headspace and absorption of infrared light. $\mathrm{CO}_{2}$ concentration is computed based on reduction in the 
transmission of infrared light. The change in $\mathrm{CO}_{2}$ concentration with respect to time is used to estimate $\mathrm{CO}_{2}$ efflux by:

$J_{\mathrm{CO}_{2}}=\frac{10 V P_{0}\left(1-\frac{W_{0}}{1000}\right)}{R S\left(T_{0}+273.15\right)} \frac{\partial C}{\partial t}$

where $J_{\mathrm{CO}_{2}}$ is the efflux of $\mathrm{CO}_{2}\left[\mathrm{M} / \mathrm{L}^{2} / \mathrm{T}\right], V$ is volume of the chamber headspace $\left[\mathrm{L}^{3}\right], P_{0}$ is the initial atmospheric pressure $\left[\mathrm{M} / \mathrm{L} / \mathrm{T}^{2}\right], W_{0}$ is the initial water vapor mole fraction, $S$ is the soil surface area $\left[\mathrm{L}^{2}\right], T_{0}$ is the initial air temperature $[\theta]$, and $\frac{\partial C}{\partial t}$ is the initial rate of change in watercorrected $\mathrm{CO}_{2}$ mole fraction [M/L]. The first application of the closed chamber method (DCC) is described in Sihota et al. (2011). DCC instruments were installed along a transect, near an existing vadose zone multilevel gas monitoring system.

$\mathrm{CO}_{2}$ efflux measurements were conducted at impacted and unimpacted LNAPL locations to compute $\mathrm{CO}_{2}$ efflux deviation from background values. At selected locations, $\mathrm{CO}_{2}$ efflux was quantified based on Fick's first law as:

$J=D_{e f f} \frac{C_{s}-C_{a}}{\Delta z}$

where $J$ is $\mathrm{CO}_{2}$ efflux $\left[\mathrm{M} / \mathrm{L}^{2} / \mathrm{T}\right], C_{s}\left[\mathrm{M} / \mathrm{L}^{3}\right]$ is the subsurface concentration, $C_{a}\left[\mathrm{M} / \mathrm{L}^{3}\right]$ is the atmospheric concentration, $\Delta z$ is the soil monitoring point depth in relation to the ground surface, and $D_{e f f}$ is the effective diffusion coefficient $\left[\mathrm{L}^{2} / \mathrm{T}\right]$. At the locations above the LNAPL body, the most significant $\mathrm{CO}_{2}$ effluxes were observed, while the smallest effluxes were observed in the unimpacted LNAPL locations.

The slight difference between $\mathrm{CO}_{2}$ effluxes obtained from each method (i.e., survey and long-term) suggested the effect of environmental factors. The $\mathrm{CO}_{2}$ efflux associated with contaminated soil respiration $\left(J_{C S R}\right)$ was computed using a background-correction method 
(Equation 1.5). Estimated source zone natural attenuation rate using the $\mathrm{CO}_{2}$ efflux associated with contaminated soil respiration yielded a 12,000 ( $\mathrm{L} / \mathrm{Ha} / \mathrm{year})$ rate of mass loss.

$J_{C S R}=J_{T S R}-J_{N S R}$

$J_{T S R}$ is $\mathrm{CO}_{2}$ efflux at the impacted area $\left[\mathrm{M} / \mathrm{L}^{2} / \mathrm{T}\right]$, and $J_{N S R}$ is $\mathrm{CO}_{2}$ efflux at the unimpacted area $\left[\mathrm{M} / \mathrm{L}^{2} / \mathrm{T}\right]$.

This method provides instantaneous NSZD rates based on a period of measurement, where it is assumed all degraded NAPL is converted to $\mathrm{CO}_{2}$. In this method, a moderate level of effort is required for fabrication and installation of the instruments. The factors that may cause variation in the rates obtained from this method include: correction for natural soil respiration, barometric pumping, surface wind, precipitation and/or soil moisture, artificial surfaces, and heterogeneities in subsurface diffusion coefficients.

Trap method. In this method, a PVC pipe at grade with two soda lime absorbent elements is used (Zimbron et al., 2014; McCoy et al., 2015). $\mathrm{CO}_{2}$ efflux from the subsurface is absorbed to the bottom element and is converted into solid phase carbonate. The top element captures atmospheric carbon dioxide to prevent it from reaching the bottom element. $\mathrm{CO}_{2}$ efflux from the subsurface is quantified by analyzing the absorbent elements and is used to estimate NSZD rate (McCoy et al., 2015).

The mass of captured $\mathrm{CO}_{2}$ from subsurface divided by the cross-section area of the absorbent element and the deployment duration produces $\mathrm{CO}_{2}$ efflux as:

$J_{\mathrm{CO}_{2}}=\frac{m_{\mathrm{CO}_{2}}}{A t}$

where $\mathrm{JCO}_{2}$ is the efflux of $\mathrm{CO}_{2}\left[\mathrm{M} / \mathrm{L}^{2} / \mathrm{T}\right], m_{\mathrm{CO}_{2}}$ is the mass of $\mathrm{CO}_{2}$ captured in the bottom absorption element $[\mathrm{M}], A$ is the cross-sectional area of the trap $\left[\mathrm{L}^{2}\right]$, and $t$ is the deployment duration $[\mathrm{T}]$. 
McCoy et al. (2015) utilized the trap method to estimate NSZD rate based on captured $\mathrm{CO}_{2}$ associated with petroleum hydrocarbon degradation at a former petroleum refinery. The methods proposed by McCoy et al. (2015), based on the concept of using $\mathrm{CO}_{2}$ flux at grade to constrain models better for source zone natural attenuation (Molins et al., 2010), quantify both advective and diffusive fluxes of $\mathrm{CO}_{2}$. In this field investigation, $23 \mathrm{CO}_{2}$ traps were deployed at impacted and unimpacted LNAPL locations. To estimate $\mathrm{CO}_{2}$ flux associated with LNAPL degradation, a background correction method was utilized (Sihota et al., 2011). Decane, as an analog for all constituents in LNAPL, was used for conversion of $\mathrm{CO}_{2}$ flux to NSZD rate (L/Ha/year). McCoy et al. (2015) observed NSZD rates ranging from 13,400 to 130,000 (L/Ha/year) with a variation coefficient of $18 \%$.

This method provides NSZD rates based on an approximate 2-week period of measurement, where it is assumed that all degraded NAPL is converted to $\mathrm{CO}_{2}$. In this method, up to a month is required for trap deployment, sample analysis, and data reduction. Factors that bias measured trap NSZD rates include: correction for natural soil respiration, surface wind, precipitation and/or soil moisture, artificial surfaces, and heterogeneities in the subsurface.

Thermal method. Sale et al. (2015) developed devices and methods for measuring subsurface thermal fluxes and for estimating a rate of change in the amount of a reactive material within a subsurface formation using the measured thermal fluxes. In this method, temperature sensors are placed vertically into the ground to resolve temperatures as a function of depth and time (Figure 1.4). The steps employed to resolve NSZD rates include:

1) Using temperatures at a background location to separate surface heating and cooling from the heat associated with NSZD.

2) Performing an energy balance to estimate energy associated with NSZD. 
3) Dividing the heat associated with NSZD by the heat of reaction to produce a NSZD rate.

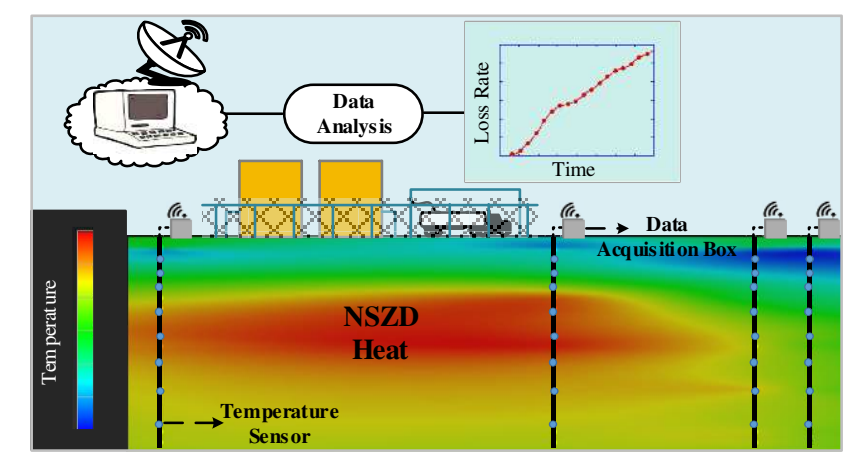

Figure 1.4. Conceptualization of thermal monitoring system

Based on the first law of heat conduction, known as Fourier's first law, the heat flux associated with NSZD process is expressed by:

$q=-\kappa \frac{\partial T}{\partial z}$

where $q$ is the heat flux due to conduction $\left[\mathrm{M} / \mathrm{T}^{3}\right], \kappa$ is the thermal conductivity $\left[\mathrm{ML} / \mathrm{T}^{3} \theta\right]$, and $\frac{\partial T}{\partial z}$ is the change in temperature with respect to distance in the vertical direction $[\theta / L]$. This equation assumes that convection and radiation are negligible with respect to conduction.

Warren et al. (2015) deployed temperature measurement systems in a petroleum spill site in Minnesota. Two background locations were considered for this study, one of which is needed to account for the heat from the pipeline. Through the vadose zone, the temperature profile associated with the natural depletion process was obtained by using a background correction method. At each location, using the maximum annual temperature, the heat generated through NSZD process was quantified (Equation 1.7).

In comparison with background locations, higher observed temperature through the depth at LNAPL locations reflected the effect of microbial heating. Using the maximum temperature 
change divided by the distance as thermal gradient, the heat flux was calculated. Estimated heat fluxes ranged from 0.38 to $0.76\left(\mathrm{~W} / \mathrm{m}^{2}\right)$. Hexadecane, as an analog for methanogenic enthalpy of crude oil, was used to convert heat flux to an NSZD rate. As a result, the NSZD rate ranged from 53,000 to 106,000 (L/Ha/year).

Observed temperature from the site in Minnesota provided evidence of increase in temperature due to heat generated by methane oxidation. The thermal NSZD method can provide continuous NSZD rates as data acquisition begins. An $11 \%$ difference between NSZD rates obtained from the temperature method and the $\mathrm{CO} 2$ data suggests validation for using temperature to estimate NSZD rates. The biggest challenge with the thermal method is that imperfection of the background-correction method causes inaccuracies in estimated NSZD rate. The key attributes of soil gas flux method, based on Tracy (2015), as well as key attributes of thermal method are summarized in Table1.1. 
Table 1.1. Summary of characteristics of methods

\begin{tabular}{|c|c|c|c|c|}
\hline \multirow[b]{2}{*}{ Characteristics } & \multicolumn{4}{|c|}{ Method } \\
\hline & Gradient & $\begin{array}{c}\text { Dynamic Closed } \\
\text { Chamber }\end{array}$ & Trap & Temperature \\
\hline 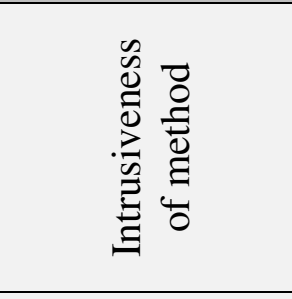 & $\begin{array}{l}\text { Intrusive. Subsurface sampling } \\
\text { required. }\end{array}$ & $\begin{array}{l}\text { Minimal. System is } \\
\text { deployed at ground } \\
\text { surface, and soil collar } \\
\text { is inserted centimeters } \\
\text { into the soil }{ }^{[\mathrm{e}]} \text {. }\end{array}$ & $\begin{array}{l}\text { Minimal. System is } \\
\text { deployed at ground } \\
\text { surface, and trap } \\
\text { receiver is inserted up to } \\
18 \text { centimeters into the } \\
\text { soil }^{[\mathrm{i}]} \text {. }\end{array}$ & $\begin{array}{l}\text { Intrusive. } \\
\text { Subsurface } \\
\text { temperature } \\
\text { required. }\end{array}$ \\
\hline 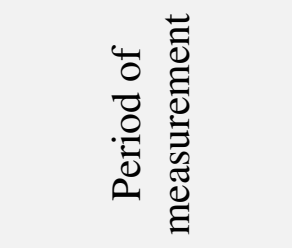 & Instantaneous & $\begin{array}{l}\text { Typically instantaneous. } \\
\text { Long-term is } \\
\text { constrained by } \\
\text { equipment cost. }\end{array}$ & $\begin{array}{l}\text { Time averaged integral } \\
\text { value }^{[\mathrm{j}, \mathrm{k}]}\end{array}$ & $\begin{array}{l}\text { Continuous or } \\
\text { instantaneous }\end{array}$ \\
\hline 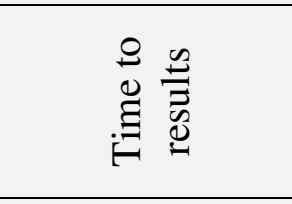 & $\begin{array}{l}\text { Weeks. Time includes sample } \\
\text { analysis and data reduction. }\end{array}$ & Real time field values & $\begin{array}{l}\text { Weeks. Time is required } \\
\text { for trap deployment, } \\
\text { sample analysis, and } \\
\text { data reduction }{ }^{[\mathrm{i}, \mathrm{j}, \mathrm{k}]} \text {. }\end{array}$ & $\begin{array}{l}\text { Once measuring is } \\
\text { started }\end{array}$ \\
\hline 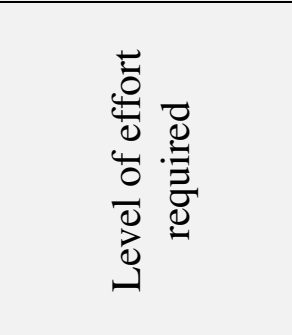 & $\begin{array}{l}\text { High. Requires installation of } \\
\text { sampling systems, collection of } \\
\text { gas samples, determination of } \\
\text { effective diffusion coefficients, } \\
\text { and data reduction }{ }^{[a]} \text {. }\end{array}$ & $\begin{array}{l}\text { Moderate. Requires } \\
\text { training to use properly. } \\
\text { Method is easy to } \\
\text { transport and capable of } \\
\text { making multiple } \\
\text { measurements in a short } \\
\text { time period. }\end{array}$ & $\begin{array}{l}\text { Low. Placement of traps } \\
\text { at field sites requires } \\
\text { minimal effort. Traps } \\
\text { are sent to an } \\
\text { independent lab for } \\
\text { analysis. }\end{array}$ & $\begin{array}{l}\text { Moderate. Requires } \\
\text { installation of } \\
\text { thermal monitoring } \\
\text { system at field site. }\end{array}$ \\
\hline
\end{tabular}




\begin{tabular}{|c|c|c|c|c|}
\hline 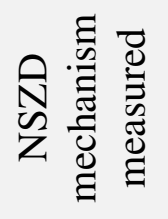 & $\begin{array}{l}\text { Volatilization and } \\
\text { biodegradation }^{[\mathrm{a}]}\end{array}$ & $\begin{array}{l}\text { Biodegradation, } \\
\text { assuming } \mathrm{CH}_{4} \\
\text { oxidation }^{[\mathrm{f}]}\end{array}$ & $\begin{array}{l}\text { Biodegradation, } \\
\text { assuming } \mathrm{CH}_{4} \\
\text { oxidation }^{[\mathrm{f}]}\end{array}$ & $\begin{array}{l}\text { Biodegradation, } \\
\text { assuming } \mathrm{CH}_{4} \\
\text { oxidation }^{[1, \mathrm{~m}]}\end{array}$ \\
\hline 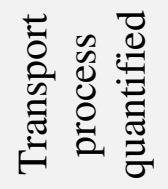 & Diffusion of gas ${ }^{[\mathrm{a}]}$ & $\begin{array}{l}\text { Advection and diffusion } \\
\text { of gas }{ }^{[\mathrm{f}]}\end{array}$ & $\begin{array}{l}\text { Advection and diffusion } \\
\text { of gas }{ }^{[\mathrm{f}, \mathrm{k}]}\end{array}$ & $\begin{array}{l}\text { Conduction and } \\
\text { convection of heat } \\
{[1, \mathrm{~m}]}\end{array}$ \\
\hline 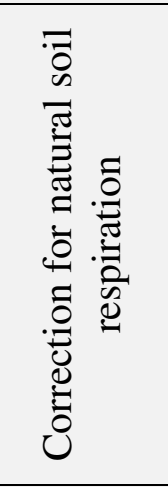 & $\begin{array}{l}\text { Depends on location of gas } \\
\text { sampling ports. Measurements } \\
\text { can be made below depth of } \\
\text { background } \mathrm{O}_{2} \text { utilization and } \\
\mathrm{CH}_{4} \text { production, eliminating } \\
\text { need to correct for natural soil } \\
\text { respiration }{ }^{[\mathrm{a}]} \text {. }\end{array}$ & $\begin{array}{l}\text { Required. Can be } \\
\text { corrected for using } \\
\text { stable carbon and } \\
\text { radiocarbon isotope } \\
\text { analysis }^{[\mathrm{d}]} \text { or } \\
\text { background correction } \\
\text { method }^{[\mathrm{g}]} \text {. Isotope } \\
\text { analysis requires } \\
\text { collection of gas } \\
\text { samples in the field. }\end{array}$ & $\begin{array}{l}\text { Required. Can be } \\
\text { corrected for using } \\
\text { stable carbon and } \\
\text { radiocarbon isotope } \\
\text { analysis }^{[\mathrm{d}]} \text { or } \\
\text { background correction } \\
\text { method }^{[\mathrm{g}]} \text {. Gas samples } \\
\text { for isotope analysis can } \\
\text { be obtained during trap } \\
\text { analysis }^{[\mathrm{k}]} \text {. }\end{array}$ & $\begin{array}{l}\text { Required for } \\
\text { separating NSZD } \\
\text { temperature from } \\
\text { that of associated } \\
\text { with surface heating } \\
\text { and cooling. }\end{array}$ \\
\hline 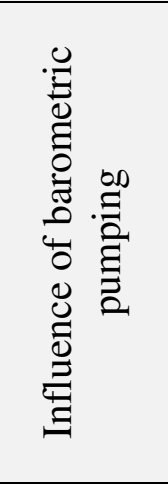 & $\begin{array}{l}\text { Method provides instantaneous } \\
\text { snapshot of subsurface gas } \\
\text { profiles which may be subject to } \\
\text { barometric pumping }^{[b]} \text {. }\end{array}$ & $\begin{array}{l}\text { Survey measurements } \\
\text { provide an } \\
\text { instantaneous snapshot } \\
\text { of } \mathrm{CO}_{2} \text { efflux which } \\
\text { may be subject to } \\
\text { barometric pumping }{ }^{[\mathrm{h}]} \text {. } \\
\text { Long-term } \\
\text { measurements provide } \\
\text { insight into variations } \\
\text { caused by changes in }\end{array}$ & $\begin{array}{l}\text { Method is an integral } \\
\text { measurement designed } \\
\text { to capture variation due } \\
\text { to barometric pumping } \\
{[\mathrm{k}] \text {. }}\end{array}$ & $\begin{array}{l}\text { Method is a } \\
\text { continuous } \\
\text { measurement } \\
\text { designed to capture } \\
\text { variation due to } \\
\text { barometric pumping. }\end{array}$ \\
\hline
\end{tabular}




\begin{tabular}{|c|c|c|c|c|}
\hline & & atmospheric pressure. & & \\
\hline 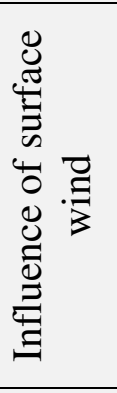 & $\begin{array}{l}\text { Low. Depends on soil texture } \\
\text { and moisture content }{ }^{[\mathrm{b}, \mathrm{c}]} \text {. } \\
\text { Surface wind may affect } \\
\text { subsurface gas distributions if } \\
\text { soil texture is relatively coarse } \\
\text { and moisture content is } \\
\text { relatively high. }\end{array}$ & $\begin{array}{l}\text { Potential influence. } \\
\text { Surface winds resulted } \\
\text { in underestimations of } \\
\text { the true flux in } \\
\text { laboratory studies. Field } \\
\text { studies are needed to } \\
\text { fully understand effect } \\
\text { of wind. }\end{array}$ & $\begin{array}{l}\text { Potential influence. } \\
\text { Surface winds resulted } \\
\text { in overestimations of } \\
\text { the true flux in } \\
\text { laboratory studies. Field } \\
\text { studies are needed to } \\
\text { fully understand effect } \\
\text { of wind. }\end{array}$ & $\begin{array}{l}\text { Low. } \\
\text { Depends on } \\
\text { difference in } \\
\text { building distribution } \\
\text { [n] and surface } \\
\text { elevation at } \\
\text { background and } \\
\text { impacted location. }\end{array}$ \\
\hline 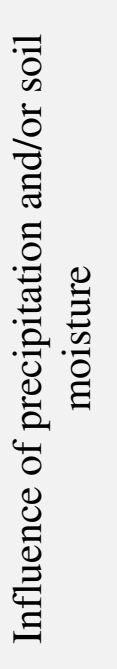 & $\begin{array}{l}\text { Method is not well suited for } \\
\text { shallow aquifer applications due } \\
\text { to difficulties estimating } \\
\text { effective diffusion coefficients } \\
\text { near the water table and } \\
\text { capillary fringe. Effective } \\
\text { diffusion coefficients are highly } \\
\text { sensitive to changes in soil } \\
\text { moisture }{ }^{[a, b]} \text {. }\end{array}$ & $\begin{array}{l}\text { Fully saturated soils can } \\
\text { shut down soil gas } \\
\text { efflux, making } \\
\text { measurements } \\
\text { impossible following } \\
\text { precipitation events. }\end{array}$ & $\begin{array}{l}\text { Rain cover may prevent } \\
\text { wetting of underlying } \\
\text { soil }{ }^{[j]} \text {, causing rain } \\
\text { shadow in which } \\
\text { preferential flow can } \\
\text { develop. More research } \\
\text { is needed to determine } \\
\text { effect of precipitation } \\
\text { on trap measurements. }\end{array}$ & $\begin{array}{l}\text { Difference in } \\
\text { recharges, associated } \\
\text { with precipitation } \\
\text { events, can cause } \\
\text { over/under } \\
\text { estimations of } \\
\text { NSZD temperature } \\
\text { [m]. Given high soil } \\
\text { moisture in shallow } \\
\text { soil, can affect } \\
\text { NSZD temperature } \\
\text { by constraining } \\
\text { inward diffusion of } \\
\text { oxygen. }\end{array}$ \\
\hline
\end{tabular}




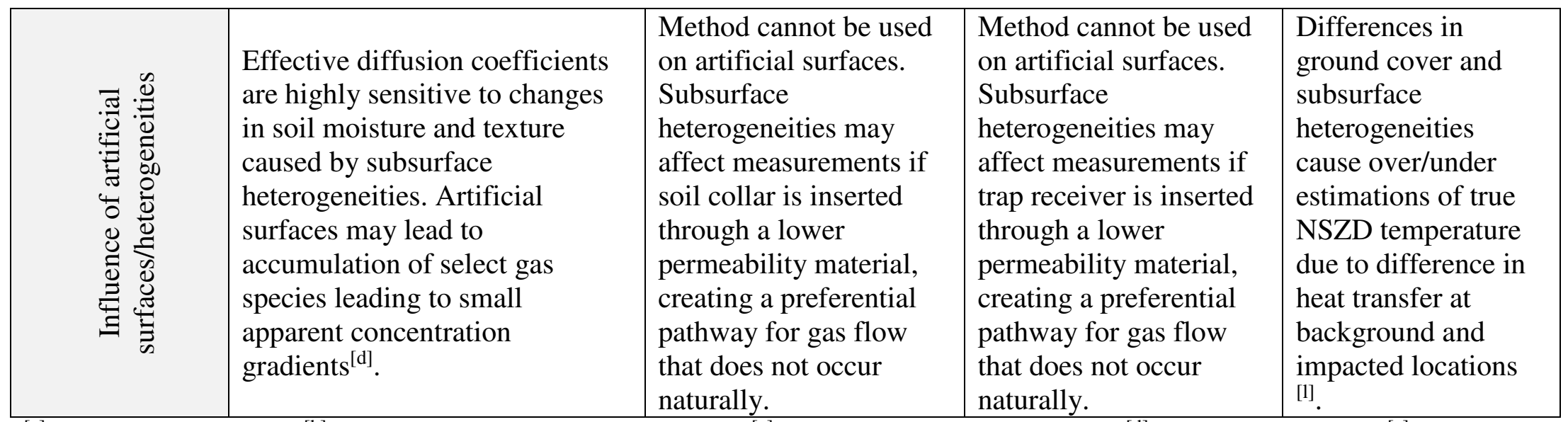

[a] Johnson et al., 2006; ${ }^{[b]}$ Maier and Schack-Kirchner, 2014; ${ }^{[\mathrm{cc}}$ Poulson and Møldrup, 2006; ${ }^{[\mathrm{d}]}$ Coffin et al., 2008; ${ }^{[\mathrm{e}]}$ LI-COR, 2010; ${ }^{[\mathrm{f}]}$ Molins et al., 2010; ${ }^{[\mathrm{g}]}$ Sihota et al., 2011; ${ }^{[\mathrm{h}]}$ Wyatt et al., 1995; ${ }^{\left[{ }^{[i]}\right.}$ McCoy, 2012; ${ }^{[j]}$ Zimbron et al., 2014; ${ }^{[\mathrm{k}]}$ McCoy et al., 2015; ${ }^{[1]}$ Stockwell, 2015; ${ }^{[\mathrm{m}]}$ Warren et al., 2015; ${ }^{[\mathrm{n}]}$ Luo et al., 2013. 


\subsection{Publication Status}

Chapter 1 presents introductory material that is not intended for publication outside of this dissertation. Chapter 2 was published in the National Groundwater Association Journal of Groundwater Monitoring and Remediation (May 2018), co-authors: Emily B. Stockwell, Keith R. Piontek, and Tom C. Sale. Chapter 3 was submitted to the Elsevier Journal of Water Research (June 2019), co-authors: Tom C. Sale. Chapter 4 is intended to be submitted to the National Groundwater Association Journal of Groundwater Monitoring and Remediation (August 2019), co-authors: Sam Gallo, Andrew Kirkman, Tom Sale. Chapter 5 presents a summary of the research and conclusions and is not intended for publication outside of this dissertation. 


\section{CHAPTER 2.}

\section{THERMAL MONITORING OF NATURAL SOURCE ZONE DEPLETION}

\subsection{Chapter Synopsis}

Natural depletion of subsurface petroleum liquids releases energy in the form of heat. The rate of Natural Source Zone Depletion (NSZD) can be derived from subsurface temperature data. An energy balance is performed to resolve NSZD-generated energy in terms of watts $/ \mathrm{m}^{2}$. Biodegradation rates are resolved by dividing the NSZD energy by the heat of reaction in joules/mole. Required temperature data are collected using data loggers, wireless connections, and automated data storage and analysis. Continuous thermal resolution of monthly NSZD rates at a field site indicates that apparent monthly NSZD rates vary through time, ranging from 10,000 to $77,000 \mathrm{~L} / \mathrm{hectare} /$ year. Temporal variations in observed apparent NSZD rates are

attributed to processes governing the conversion of $\mathrm{CH}_{4}$ to $\mathrm{CO}_{2}$, as opposed to the actual rates of NSZD. Given a year or more of continuous NSZD rate data, it is anticipated that positive and negative biases in apparent NSZD rates will average out and, averaged apparent NSZD rates will converge to true NSZD rates. An $8.4 \%$ difference between average apparent NSZD rates over a 31-month period using the thermal monitoring method and seven rounds of $\mathrm{CO}_{2}$ efflux measurements using $\mathrm{CO}_{2}$ traps supports the validity of both $\mathrm{CO}_{2}$ trap and thermal monitoring methods. A promising aspect of thermal monitoring methods is that continuous data provide a rigorous approach to resolving the true mean NSZD rates as compared to temporally sparse $\mathrm{CO}_{2}$ trap NSZD rate measurements. Overall, a vision is advanced of real-time sensor-based groundwater monitoring that can provide better data at lower costs and with greater safety, security, and sustainability. 


\subsection{Introduction}

Figure 2.1 conceptualizes processes governing NSZD in a setting where LNAPLs have been present for an extended period (Stockwell, 2015). Given mature LNAPL releases and transport constraints, preferred electron acceptors including $\mathrm{O}_{2}, \mathrm{Mn}^{+4}, \mathrm{NO}_{3}^{-}$, and $\mathrm{Fe}^{+3}$ are sufficiently depleted in LNAPL zones, such that sulfate reduction (when present) and methanogenesis become the primary process driving NSZD (Atekwana and Atekwana, 2010; Irianni Renno et al., 2016; Garg et al., 2017). Biologically mediated NSZD in mature LNAPL zones can be driven by $\mathrm{SO}_{4}^{-2}$ reduction (where sulfate is present) and/or methanogenesis. Produced $\mathrm{CO}_{2}$ and $\mathrm{CH}_{4}$ lead to local exceedances of aqueous-phase gas solubilities in the saturated zone, formation of gas bubbles, upward ebullition of gases in the saturated zones, and an upward flux of $\mathrm{CO}_{2}$ and $\mathrm{CH}_{4}$ into the unsaturated zone (Garg et al., 2017). Similarly, NSZD processes in the vadose zone can also produce $\mathrm{CO}_{2}$ and $\mathrm{CH}_{4}$.

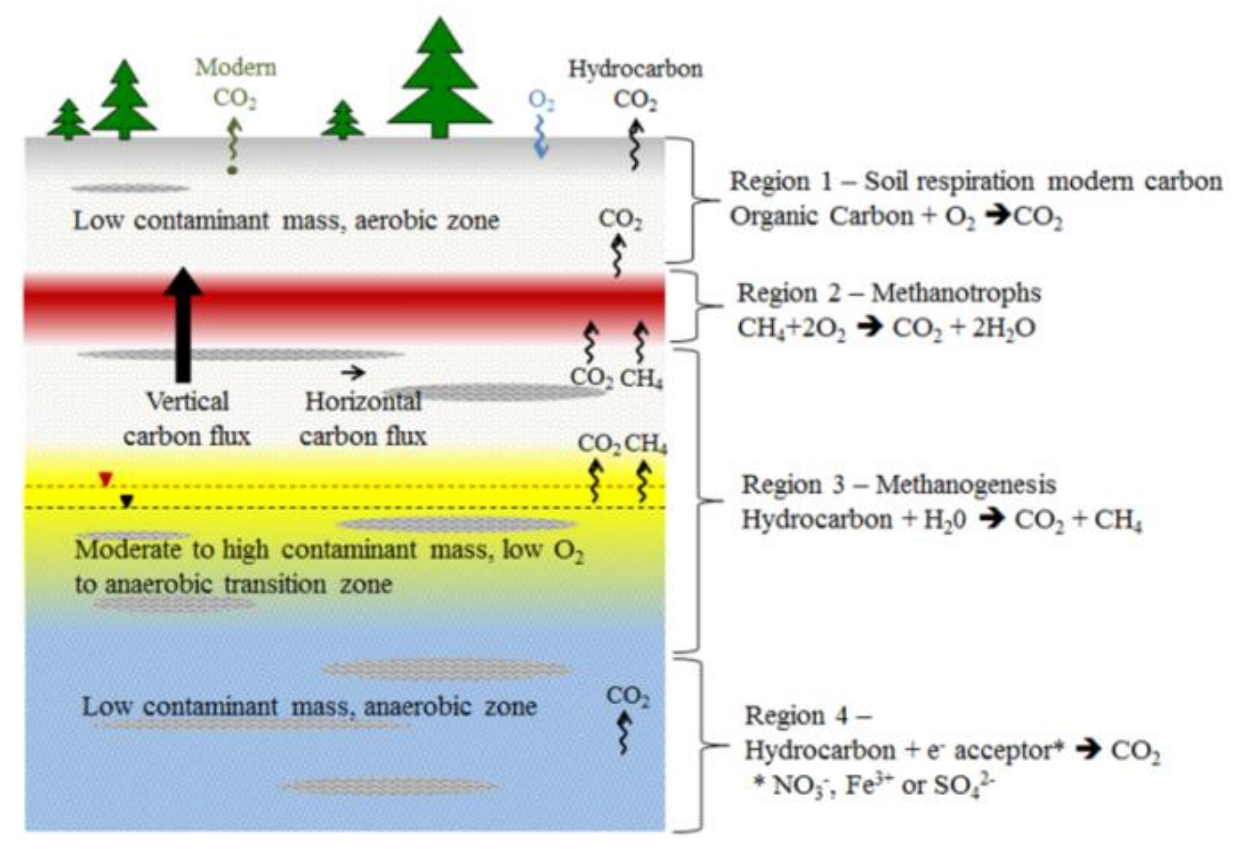

Figure 2.1. Conceptual model of processes governing NSZD. Region 2 is the primary zone of heat generation 
The upward diffusion-driven flux of $\mathrm{CH}_{4}$ is encountered by a downward flux of $\mathrm{O}_{2}$. At the $\mathrm{CH}_{4}-\mathrm{O}_{2}$ interface, $\mathrm{CH}_{4}$ is converted to $\mathrm{CO}_{2}$ before atmospheric discharge (Amos et al., 2005; Garg et al., 2017). An additional product of biologically mediated NSZD is heat (Sweeney and Ririe, 2014; Stockwell, 2015; Warren and Bekins, 2015). As an example, complete conversion of decane to $\mathrm{CO}_{2}$ and $\mathrm{H}_{2} \mathrm{O}$, under standard conditions, absent of other energy sinks or sources, produces 6,797 kJ/mole (Haynes, 2014). Heat of reactions associated with common NSZD reactions are presented in Wiedemeier et al. (1996). The reaction in the NSZD process that produces the most heat is the conversion of $\mathrm{CH}_{4}$ and $\mathrm{O}_{2}$ to $\mathrm{CO}_{2}$ and $\mathrm{H}_{2} \mathrm{O}$ in the vadose zone as shown in Fig 2.1.

\subsection{Research Objective}

The objectives of this chapter are to advance 1) the use of heat produced from NSZD to provide continuous, real-time NSZD rates at petroleum LNAPL sites and 2) a vision of real-time sensor-based groundwater monitoring that can provide better data at lower costs and with greater safety, security, and sustainability.

\subsection{Methods}

The following section describes the study site, methods for collecting data, and the computational approach for converting temperature data into NSZD rates.

\subsubsection{Site Description}

The study site is a refined petroleum products terminal located in the flood plain of a major river in the central United States (Figure 2.2). Storage of refined petroleum products has been ongoing at the facility since the early 1930s. Following typical fluvial sediment stratigraphy, the vadose zone (upper 5 meters) is comprised of fine-grained overbank silt and fine-grained sand. Sediments in the upper saturated zone (2 meters) are comprised of fine- to 
medium-grained point bar sand deposits. Both overbank and point bars sand deposits are laterally continuous beneath the site (TRC, 2012). Depths to groundwater are controlled by nearby river stage that varies seasonally and year to year. Except when the river is in flood stage, depth to groundwater ranges from 4.5 to 7.5 meters below ground surface (bgs) with low water table elevations occurring in the fall/winter and high water table elevations in the spring. The primary direction of groundwater flow beneath the site is to the east-southeast. The average horizontal seepage velocity at the site is estimated to range from 0.022 to $0.031 \mathrm{~m} /$ day $(T R C, 2013)$.

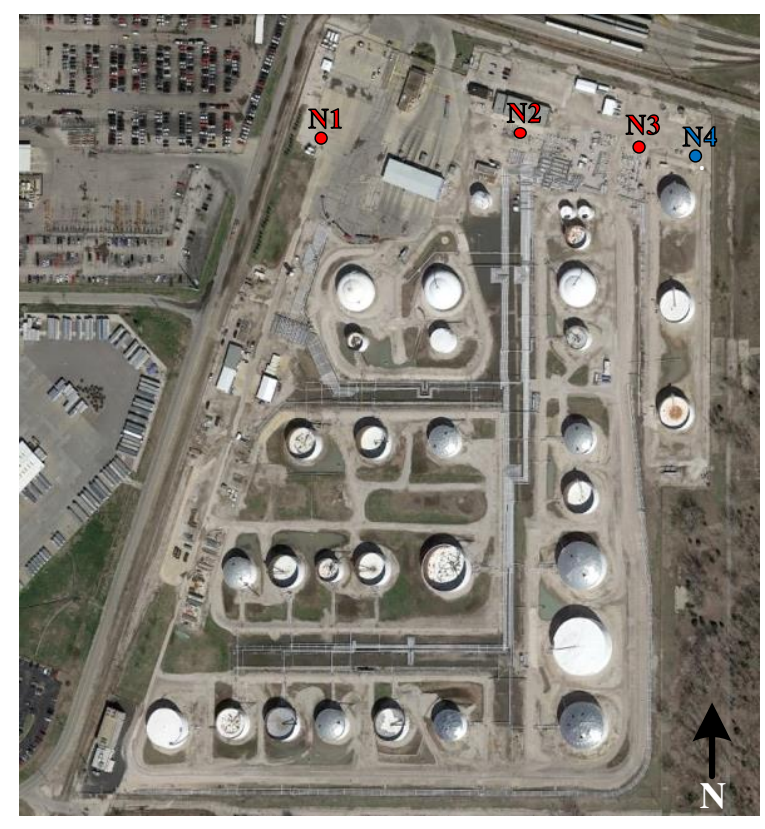

Figure 2.2. Study site with location of temperature monitoring sticks N1-N4

\subsubsection{Temperature Data Collection}

Locations of four thermal monitoring systems (referred to as "sticks") are shown in Figure 2.2. As defined through a Laser Induced Fluoresces (LIF) investigation, N1, N2, and N3 are located in LNAPL-impacted sediments (TRC, 2012). LNAPL is absent at location N4.

Each stick consists of eight type-T copper-constantan thermocouples installed at depth of $0.15,0.30,3.05,3.66,5.79,8.23,10.67$, and 11.28 meters (bgs). Thermocouples were fabricated 
using PFA-coated thermocouple wire (TC Direct, Hillside, IL); copper and constantan wires were spot-welded together at the end of the wire; the spot welds were enclosed in epoxy-filled glass caps; thermocouples were attached to $9.5 \mathrm{~mm}$ OD PVC rods to control the depth of installation (Figure 2.3A). The estimated accuracy of the combined thermocouples and dataloggers based on laboratory tests is $\pm 0.1^{\circ} \mathrm{C}$. The PVC rods with attached thermocouples were installed using a direct-push drilling rig, the annular space for each rod was backfilled with medium sand, and a bentonite seal was placed in the annular space at grade (Figure 2.3B).

The thermocouples on each stick are connected to a datalogger (CR1000, Campbell Scientific, Logan, UT). The dataloggers are powered by a 12-volt DC, 24 amp-hour sealed rechargeable battery (BP24, Campbell Scientific, Logan, UT), which is charged by a 20-watt solar panel (SP20, Campbell Scientific, Logan, UT). A 12-volt charge regulator (CH100, Campbell Scientific, Logan, UT) regulates the current between the solar panel, battery, and datalogger. A cellular digital modem (Airlink Raven XT, Sierra Wireless, Richmond, British Columbia) connected to the datalogger transmits via a cellular network. Subsurface temperatures are recorded by the datalogger every minute, and data are automatically downloaded daily to a computer that is backed up on a daily basis. The datalogger, battery, charge regulator, and cellular digital modem are housed in a protective, weather-resistant enclosure (ENC14/16, Campbell Scientific, Logan, UT), as shown in Figure 2.3C. 


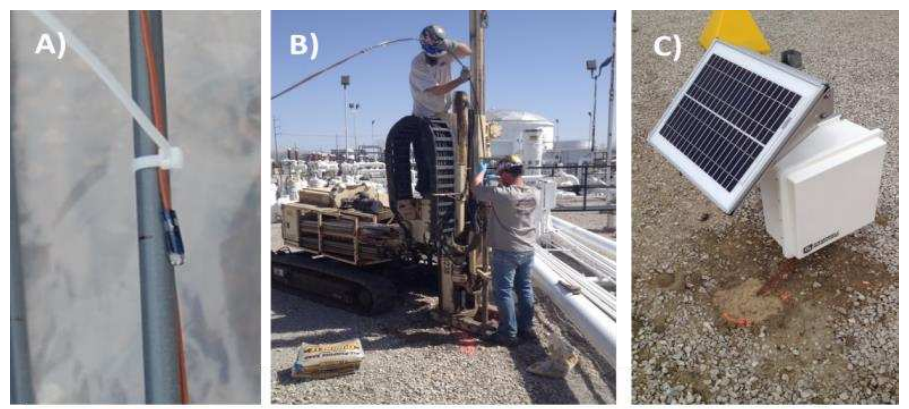

Figure 2.3. Thermal monitoring system: A) thermocouple, B) installation using direct-push drilling methods, C) solar power supply and weatherproof box containing data-logging and communications software.

Collection of temperature data at the site began on April 25, 2014. This manuscript considers data collected, without interruption, through November 1, 2016. In total, this manuscript considers more than 56 million temperature measurements collected at one-minute intervals and converted into average daily temperatures values. The regulatory agency-approved cleanup plan for the site incorporates NSZD as tracked through thermal monitoring as the remedy for depletion of residual LNAPL.

\subsubsection{Computational Method}

Background Correction. Computational methods are predicated on an energy balance performed on a one-dimensional vertical reference volume beginning at grade (upper boundary) and extending past the LNAPL zone to the deepest thermocouple at $11.28 \mathrm{~m}$ (lower boundary). Horizontal transport of heat generated by NSZD through the movement of water (convection) is considered to be negligible based on heat primarily being generated in the vadose zone at the $\mathrm{CH}_{4}-\mathrm{O}_{2}$ interface as shown in Figure 2.1. It is assumed that vertical heat transfer occurs solely through conduction - the transfer of energy by molecular collisions of particles. Other heat transfer processes, including black body radiation and heat transfer associated with vertical movement of water and or soil gas, are assumed to be negligible. 
Temperature at any vertical position in the reference volume is a function of heat generated through NSZD processes and heat from "other sources," including surface heating and cooling. Building on Stockwell (2015), it is assumed that "other sources" are similar at impacted and background locations. Applying the principle of superposition, temperatures associated with NSZD are estimated as:

$\left.T_{N S Z D}\right|_{z} ^{i}=\left.T_{I m p}\right|_{z} ^{i}-\left.T_{B a c k}\right|_{z} ^{i}$

where $\left.T_{N S Z D}\right|_{z} ^{i}$ is the component of temperatures associated with NSZD, $\left.T_{I m p}\right|_{z} ^{i}$ is the temperatures observed at an impacted location, and $\left.T_{B a c k}\right|_{z} ^{i}$ is the temperatures observed at the background location at a fixed time (i) and vertical position $(z)$.

Assumptions. Key assumptions employed in the energy balance include:

1. All factors controlling surface heating and cooling at impacted and background locations (incident radiation, infiltration of precipitation, albedo, etc.) are sufficiently similar, so that reasonable estimates of $T_{N S Z D}$ can be obtained.

2. The primary factor controlling temperatures at grade, at impacted and background locations, is surface heating and cooling and, correspondingly, the upper boundary condition for $T_{N S Z D}$ at grade is zero for all time.

3. Thermal conductivities and heat capacities of soil are constant through time with uniform unique values above and below the water table, reflecting differences in water content.

4. Fluctuation in water table levels through time are accounted for using daily water level data.

5. The only process leading to vertical flow of energy associated with NSZD in or out of the reference volume is conduction (Carslaw and Jaeger, 1959; Jury and Horton, 2004; Hillel, 2013). 
6. Horizontal flow of energy through the one-dimensional vertical reference volume is negligible.

7. Net gain or of loss of biomass, precipitation or dissolution of minerals, or changes in thermodynamic states do not act as a significant energy sink or source.

8. The energy produced from complete mineralization of decane is representative of the energy produced through NSZD of the hydrocarbons of concern (Johnson et. al., 2006).

As with all models, care is needed to avoid employing the model in situations where foundational assumptions do not apply. As an example, there may situations where horizontal flow of energy may be consequential.

Energy Balance. Employing the noted assumptions, Equation (2.2) provides a general energy balance for a one-dimensional vertical reference volume:

$\dot{E}_{\text {Bottom }}-\dot{E}_{\text {Top }}+\dot{E}_{N S Z D}=\frac{d E_{S t o}}{d t}$

where $\dot{\mathrm{E}}_{\text {Top }}$ is energy flux at the top of the reference volume $\left(\mathrm{W} / \mathrm{m}^{2}\right), \dot{\mathrm{E}}_{\mathrm{Bottom}}$ is energy flux at the bottom of the reference volume $\left(\mathrm{W} / \mathrm{m}^{2}\right), \dot{\mathrm{E}}_{\mathrm{NSZD}}$ is vertically-integrated energy produced through NSZD over the height of energy balance element $\left(\mathrm{W} / \mathrm{m}^{2}\right)$, and $E_{\text {Sto }}$ is verticallyintegrated stored energy over the height of energy balance element $\left(\mathrm{J} / \mathrm{m}^{2}\right)$.

Conductive energy fluxes at the top and bottom of the reference volume are estimated using Fourier's Law:

$\dot{E}_{\text {Top }}=-\left.\kappa_{\text {unsat }} \frac{d T_{N S Z D}}{d z}\right|_{T o p}$

$\dot{E}_{\text {Bottom }}=-\left.\kappa_{\text {sat }} \frac{d T_{N S Z D}}{d z}\right|_{\text {Bottom }}$

where $\kappa_{\text {unsat }}$ and $\kappa_{\text {sat }}$ are unsaturated and saturated thermal conductivity, respectively $(\mathrm{W} / \mathrm{m} / \mathrm{K})$.

The change in NSZD-related energy storage through the reference volume with respect to time is: 


$$
\begin{aligned}
& \frac{d E_{S t o}}{d t}=\frac{\left[\left(c_{\text {unsat }} \int_{T o p}^{z W T} T_{N S Z D} d z\right)+\left(c_{s a t} \int_{Z_{W T}}^{z_{b o t t o m}} T_{N S Z D} d z\right)\right]^{i}}{t^{i}-t^{i-1}}- \\
& \frac{\left[\left(c_{\text {unsat }} \int_{T o p}^{Z}{ }_{T T} T_{N S Z D} d z\right)+\left(c_{\text {sat }} \int_{Z_{W T}}^{z \text { bottom }} T_{N S Z D} d z\right)\right]^{i-1}}{t^{i-t^{i-1}}}
\end{aligned}
$$

where $C_{\text {unsat }}$ and $C_{\text {sat }}$ are unsaturated and saturated heat capacity, respectively $\left(\mathrm{J} / \mathrm{m}^{3} / \mathrm{K}\right), t$ is time (sec), and $z_{W T}$ is elevation of the water table $(\mathrm{m})$.

Energy produced through NSZD $\left(\mathrm{W} / \mathrm{m}^{2}\right)$ over the period $t^{i}-t^{i-1}$ is obtained by substituting Equations (2.3) through (2.5) into Equation (2.2):

$$
\begin{aligned}
& \left.\dot{E}_{N S Z D}\right|^{i}=-\left.\kappa_{\text {unsat }} \frac{d T_{N S Z D}}{d z}\right|_{\text {Top }} ^{i}+\left.\kappa_{\text {Sat }} \frac{d T_{N S Z D}}{d z}\right|_{\text {Bottom }} ^{i}+ \\
& \frac{\left[\left(c_{\text {unsat }} \int_{T o p}^{Z W T} T_{N S Z D} d z\right)+\left(c_{\text {sat }} \int_{Z_{W T}}^{z_{b o t t o m}} T_{N S Z D} d z\right)\right]^{i}}{t^{i}-t^{i-1}}- \\
& \frac{\left[\left(c_{\text {unsat }} \int_{T o p}^{Z} T_{N S Z D} d z\right)+\left(c_{s a t} \int_{Z_{W T}}^{z_{b o t t o m}} T_{N S Z D} d z\right)\right]^{i-1}}{t^{i}-t^{i-1}}
\end{aligned}
$$

NSZD rates, on a volumetric basis, are estimated as:

$N \dot{S Z D}=\frac{-\dot{\mathrm{E}}_{N S Z D}}{\Delta \mathrm{H}_{\text {Decane }} \rho_{\text {Decane }}}$

where NSZD is rate of NSZD $\left(\mathrm{L} / \mathrm{m}^{2} / \mathrm{sec}\right), \Delta \mathrm{H}_{\text {Decane }}$ is enthalpy of complete mineralization (J/mole), and $\rho_{\text {Decane }}$ is molar density of decane equal to 5.14 (moles/L).

Calculation Methods. Estimates of NSZD rates (NSZD) through time are obtained using an algorithm programmed in MATLAB ${ }^{\circledR} 2015 b$ (The MathWorks Inc., USA). Key concepts associated with data transformation are illustrated in Figure 2.4. The first step in calculating NSZD is to regress the average daily background-corrected temperature data with the regression forced through $T_{N S Z D}=0$ at $z=0$. Seven different polynomial regressions $\left(2^{\text {nd }}\right.$ through $8^{\text {th }}$ degree) are evaluated through eight data points (thermocouples) in the subsurface as well as one point at grade $\left(T_{N S Z D}=0\right.$ at $\left.z=0\right)$. The regression with the largest $R^{2}$ value is selected. The 
evaluation of multiple regression options, and selection of the regression with the best fit, provides optimal answers as reflected by minimized noise in the results. The derivative of the polynomial function $\left(T_{N S Z D}\right)$ with respect to vertical position, at $z=0$ and $z=$ bottom, yields the NSZD-related thermal gradient at the top and bottom of the reference volume.

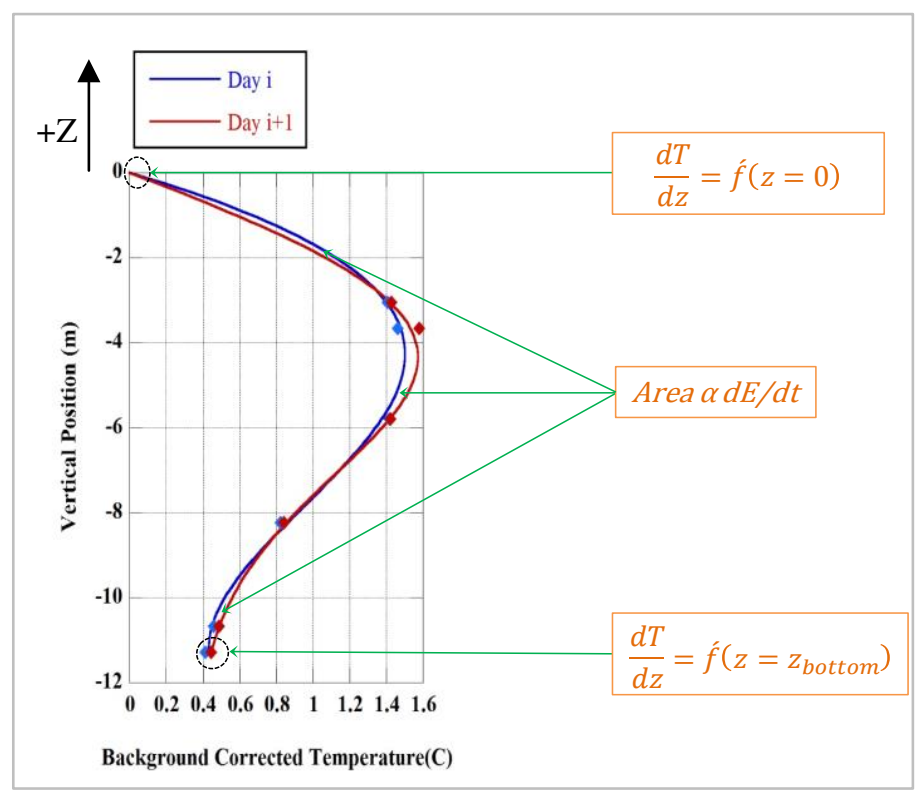

Figure 2.4. An example of regressed background-corrected temperature data on two consecutive days

The second step is to evaluate the change in $\mathrm{E}_{\text {Sto }}$ through time. This evaluation is accomplished by integrating the selected polynomial at time $(i)$ and $(i-1)$ over the height of the reference volume with respect to saturated and unsaturated intervals, subtracting the results, and multiplying the difference by the heat capacities for saturated and unsaturated media. Results of the first and second steps are used in Equations (2.6) and (2.7) to obtain NSZD rates for fixed time steps. Continuous NSZD rates are obtained by sequentially stepping the solution through time in one-day steps. 
At select times, including after precipitation events, the assumption that conditions at the background location are representative of non-NSZD sources of heat at the impacted locations fails. Non-representative background corrections are manifested by apparent loss of NSZDrelated energy and the illogical results that hydrocarbons are being produced. As an example, non-uniform precipitation/infiltration at background and impacted locations can lead to temporarily anomalous temperatures associated with evaporative cooling, infiltration of warm or cold meteoric water, and/or constraints to inward diffusing $\mathrm{O}_{2}$. All estimates of NSZD rates that suggest hydrocarbon production are corrected by excluding the negative background-corrected temperature data. Negative background-corrected temperatures were only found at 0.15 and 0.30 m. Through the study period, the frequency of excluding shallow background-corrected data was $12 \%$. Experience at other sites indicates this frequency, excluding negative backgroundcorrected temperature data, can be greatly reduced by increasing the number of shallow temperature monitoring points.

Input Parameters for Thermal NSZD Rates. In 2014, a continuous soil core was collected using a direct push GeoProbe ${ }^{\mathrm{TM}}$ drilling system, adjacent to N3, from 0.6 to $9.7 \mathrm{~m}$ bgs. Soil thermal conductivity and heat capacity were measured using a thermal properties analyzer (KD2 Pro, Decagon Device, Pullman, WA) at intervals of 0.30 to $0.61 \mathrm{~m}$ over a total length of $9.1 \mathrm{~m}$. Measured thermal conductivity and heat capacities in the unsaturated zone were 0.96 $\pm 0.18(\mathrm{~W} / \mathrm{m} / \mathrm{K})$ and $1.57 \pm 0.55\left(\mathrm{MJ} / \mathrm{m}^{3} / \mathrm{K}\right)$, respectively $(n=13)$. Measured thermal conductivity and heat capacities in the in the saturated zone were $1.46 \pm 0.31(\mathrm{~W} / \mathrm{m} / \mathrm{K})$ and $2.51 \pm 0.52$ $\left(\mathrm{MJ} / \mathrm{m}^{3} / \mathrm{K}\right)$, respectively $(n=15)$. Measured thermal conductivities and heat capacities were substituted in the computational method with no adjustment based on soil water content or temperature. Site-wide daily water levels were obtained using Solinst Level Logger ${ }^{\mathrm{TM}}$ pressure $^{\mathrm{N}}$ 
transducers and Barologger ${ }^{\mathrm{TM}}$ (Solinst Canada Ltd.) installed in monitoring wells. As previously stated, the heat of full oxidation of decane is used to convert NSZD energy into estimates of LNAPL depletion rates. The use of decane as generic hydrocarbon for NSZD rates calculations follows a precedent set in Johnson et al. (2006).

$\mathrm{CO}_{2}$ Trap Data. Prior to and during part of the thermal monitoring study, NSZD rates were measured at locations $\mathrm{N} 1$ through $\mathrm{N} 4$ using $\mathrm{CO}_{2}$ traps. $\mathrm{CO}_{2}$ traps 1) employ porous alkaline solids to trap gas-phase $\mathrm{CO}_{2}$ discharging at grade, 2) use ${ }^{14} \mathrm{C}$ to differentiate between $\mathrm{CO}_{2}$ associated with natural soil respiration and degradation of petroleum, and 3) were deployed at ground surface for approximate two week periods seven times between September 2012 and December 2014. A summary of observed $\mathrm{CO}_{2}$ trap NSZD rates is presented in Table 2.1. Comprehensive information regarding $\mathrm{CO}_{2}$ traps is presented in Zimbron et al. (2014), McCoy (2015), and API (2017). $\mathrm{CO}_{2}$ trap data are included in this manuscript as an independent check for NSZD rates determined from temperature data and as a basis for comparing the two methods for resolving NSZD rates.

Table 2.1. Results from $\mathrm{CO}_{2}$ traps deployed from 2012 through 2014

\begin{tabular}{|c|c|c|c|c|}
\hline \multirow[t]{2}{*}{ Event } & \multicolumn{4}{|c|}{$\begin{array}{l}\mathrm{CO}_{2} \text { Flux Rate (liter LNAPL per hectare-year) } \\
\text { Locations within LNAPL Zone }\end{array}$} \\
\hline & N1 & $\mathbf{N 2}$ & N3 & Average \\
\hline September 2012 & & & 17,900 & 17,900 \\
\hline December 2012 & 10,900 & 7,400 & 19,400 & 12,600 \\
\hline April 2013 & 67,300 & 8,000 & 13,700 & 29,700 \\
\hline August 2013 & 43,100 & 75,900 & 16,700 & 45,200 \\
\hline April 2014 & 97,700 & 100,100 & 92,800 & 96,900 \\
\hline September 2014 & 87,600 & 50,800 & 104,300 & 80,900 \\
\hline December 2014 & 2,400 & 4,500 & 14,200 & 7,000 \\
\hline Average & 51,500 & 41,100 & 39,900 & 41,500 \\
\hline
\end{tabular}

${ }^{1}$ Values reflect ${ }^{14} \mathrm{C}$ correction method. 
Soil Moisture Simulation. HYDRUS-1D (Simunek et al., 2013) was used to simulate soil moisture through time for the study period. The input meteorological data (e.g., precipitation ( $\mathrm{cm} /$ day), daily net radiation $\left(\mathrm{MJ} / \mathrm{m}^{2} / \mathrm{d}\right)$, maximum and minimum temperature $\left({ }^{\circ} \mathrm{C}\right)$, humidity $(\%)$, and wind $(\mathrm{km} / \mathrm{d}))$ were obtained from Kansas City Downtown Airport (MKC) station, five miles from the study site, and Olathe station, 20 miles from the study site. The input soil hydraulic parameters were also estimated by HYDRUS-1D using the HYDRUS-1D soil property database. Note that simulated soil moisture by HYDRUS-1D for the study period is only used to evaluate the effects of soil moisture on NSZD rate.

\subsection{Results and Discussion}

The following section documents the results including temperature data, temperaturebased estimates of NSZD rates, comparison of NSZD rates obtained using thermal monitoring and $\mathrm{CO}_{2}$ trap methods, avenues for further development of thermal NSZD monitoring, and a perspective on the future of real-time, sensor-based subsurface monitoring.

\subsubsection{Temperature Data}

The thermal monitoring systems proved to be effective and reliable for remote acquisition of subsurface temperature data. The systems began generating data immediately after installation, and no interruption in the ability to remotely acquire data from any individual thermocouple was experienced over the 31 months of thermal monitoring discussed herein.

Figure 2.5A presents average daily temperature data for a typical day (May 10, 2014), as a function of depth, for N1 through N4 (background). Per common spring conditions in the central United States, measured shallow soil temperatures decrease with depth to a depth of approximately $2 \mathrm{~m}$ and increase in temperature from 2 to $10 \mathrm{~m}$. At depths below $10 \mathrm{~m}$, temperatures are largely steady, independent of depth and season. 


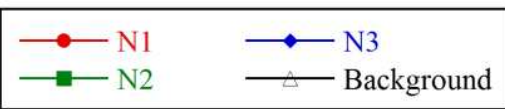

Raw temperatures

(A)

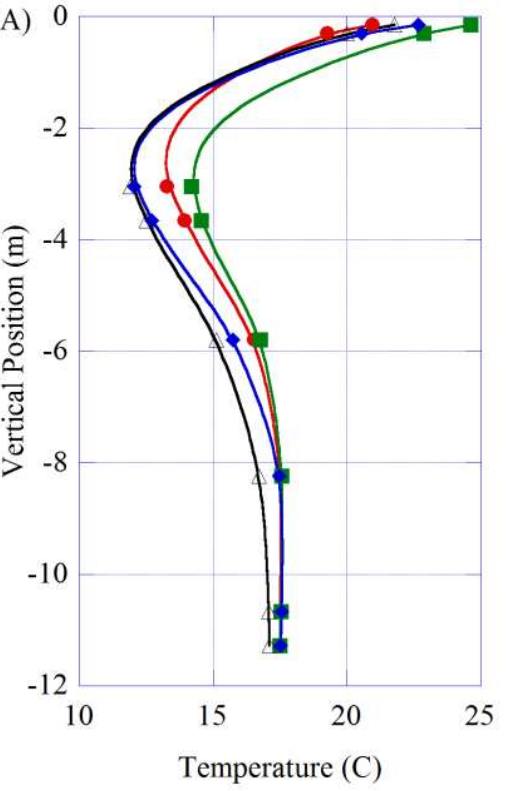

Background corrected temperatures

(B)

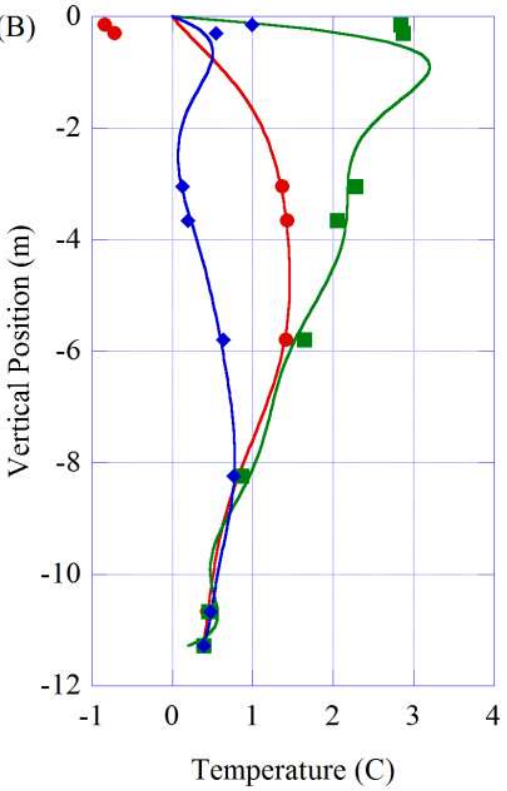

Figure 2.5. Temperature data measured on May 10, 2014. A) Raw temperature data and B) background-corrected temperature data. Lines are best-fit regressions of the data developed using polynomial regression.

Figure 2.5B presents background-corrected temperature data for the impacted locations for N1 through N3. Consistent with the finding of others (Sweeney and Ririe, 2014; Stockwell, 2015; Warren and Bekins, 2015; Garg et al., 2017; Kulkarni et al., 2017), subsurface temperatures are warmer at the impacted locations (N1 through N3), due to heat associated with NSZD, by as much as $3{ }^{\circ} \mathrm{C}$. Also shown with the background-corrected data are the best-fit regressions forced through zero. The regressions indicate maximum background-corrected temperatures at $4.2,0.8$, and $0.7 \mathrm{~m}$ bgs for $\mathrm{N} 1-\mathrm{N} 3$, respectively. It is hypothesized that the maximum background-corrected temperatures occur about the interval where $\mathrm{CH}_{4}$ and $\mathrm{O}_{2}$ are reacting to form $\mathrm{CO}_{2}$ and $\mathrm{H}_{2} \mathrm{O}$, as shown in Figure 2.1. 


\subsubsection{Thermal NSZD Rates}

Figure 2.6 presents cumulative LNAPL losses derived from daily temperature data. Previous computational methods have used an incomplete energy balance that causes the accuracy of NSZD rate estimation to be a concern (Sweeney and Ririe, 2014; Warren and Bekins, 2015). In Figure 2.6, each graph documents results with and without accounting for the changes in stored energy associated with NSZD to show the difference in NSZD rates from a complete and incomplete energy balance. Total losses of LNAPL over the 922-day study period are $114,600,104,400$, and $70,700 \mathrm{~L} /$ hectare for $\mathrm{N} 1$ through $\mathrm{N} 3$, respectively. The average cumulative loss for the study period is $96,500 \mathrm{~L} /$ hectare. The slope of the cumulative loss rate data suggests an apparent reduction in NSZD loss rates in the winter months and an increase in NSZD loss rates in the summer months. Minimum and maximum monthly average loss rates are 10,000 and 77,000 L/hectare/year. Using the average losses at N1 through $\mathrm{N} 3$ for the approximate 8.1-hectare LNAPL zone at the site suggests an overall loss of 781,650 liters of LNAPL for the study period. 


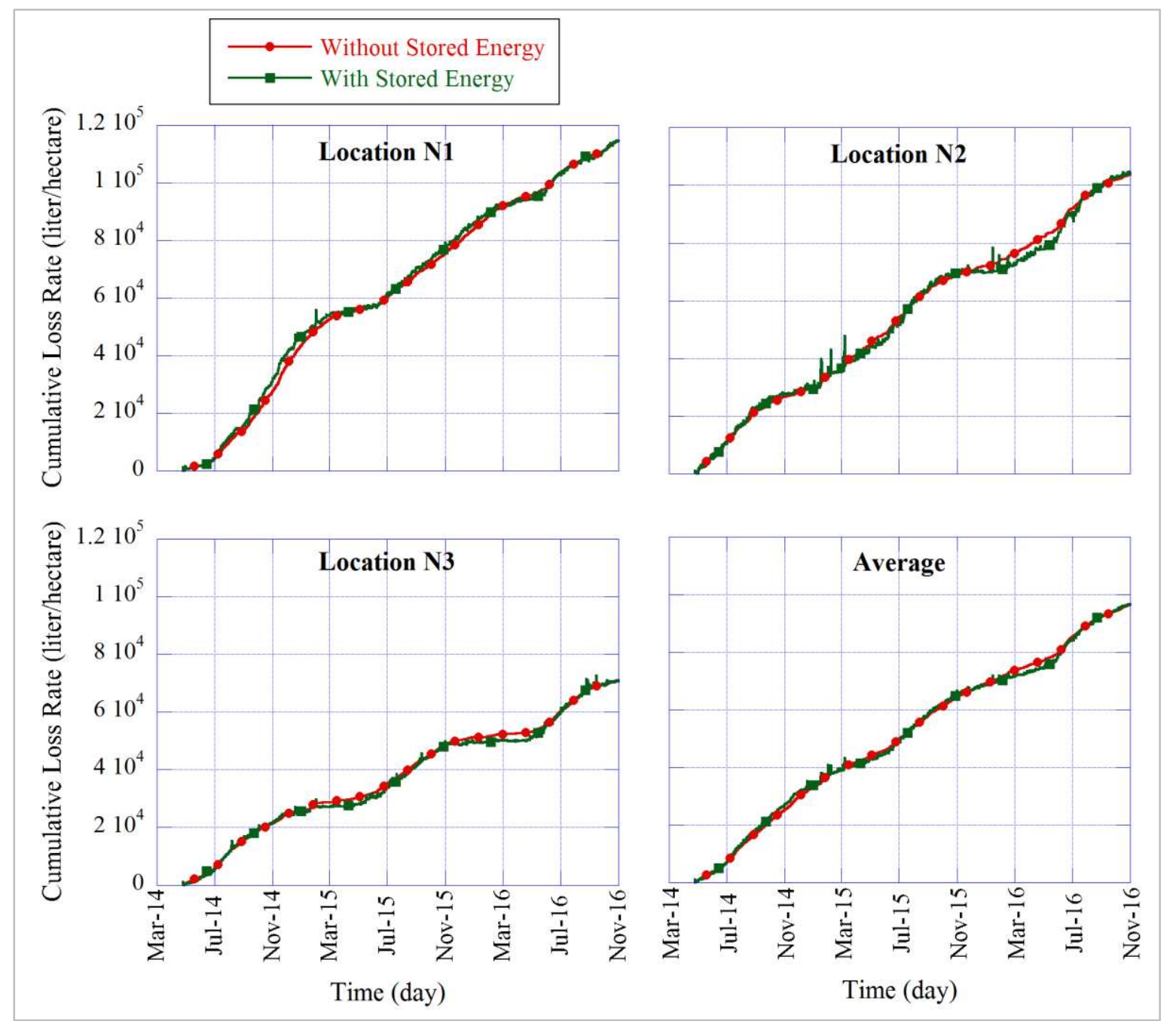

Figure 2.6. Cumulative LNAPL losses for May 2014 to November 2016 at N1 through N3 and the site average

Total LNAPL losses are similar with and without accounting for changes in the amount of NSZD heat in the reference volume. Occasional short-term increases and decreases in cumulative LNAPL losses (spikes) are seen when including changes in stored heat (primarily at N2). In general, spikes coinciding with rainfall events are attributed to short-term flaws in the background correction of the temperature data. Overall, Figure 2.6 indicates little difference resulting from including or neglecting stored energy. Nevertheless, the full energy balance may be useful for sites with shallower LNAPL zones. 
Figure 2.7A presents average monthly NSZD rates based on daily values (average of N1 through N3) derived from the thermal data. The errors bars reflect the $95 \%$ confidence interval of the measured thermal conductivity values. Alternatively, average monthly of the energy produced through NSZD is tabulated in supplement material. The mean NSZD rate for the study period is $38,200 \mathrm{~L} /$ hectare/year. The standard deviation of the monthly NSZD rates through time is $\pm 17,700 \mathrm{~L} / \mathrm{hectare} /$ year. As a check, $38,200 \mathrm{~L} / \mathrm{hectare} / \mathrm{year}$ is a vertical LNAPL flux of 3.8 mm/year. Given a specific LNAPL volume of $150 \mathrm{~mm}\left(0.15 \mathrm{~m}^{3} / \mathrm{m}^{2}\right.$ of impacted aquifer), a constant loss rate of 38,200 L/hectare/year could be sustained for 40 years.

As introduced in Figure 2.6, continuous thermal NSZD rate data in Figure 2.7 show periodic behavior with larger apparent NSZD rates occurring in the summer season and lower apparent NSZD rates in the winter. Temperatures in the LNAPL-impacted media are largely constant (Kulkarni et al., 2017). Therefore, seasonal variations in apparent NSZD rates cannot be explained by changing temperatures in the LNAPL zone at this site. Following developments in Sihota et al. (2016), regarding the lag time between actual NSZD and the expression of NSZD as $\mathrm{CO}_{2}$ efflux at grade, Thermal NSZD rates are referred to as "apparent," based on the fact that transport can result in actual NSZD and thermal expression of NSZD occurring at different times. Further review of temporal differences in the conversion of saturated-zone subsurface hydrocarbons to gases, and their release to the vadose zone, is presented in Ramirez et al. (2015) and Garg et al. (2017). 


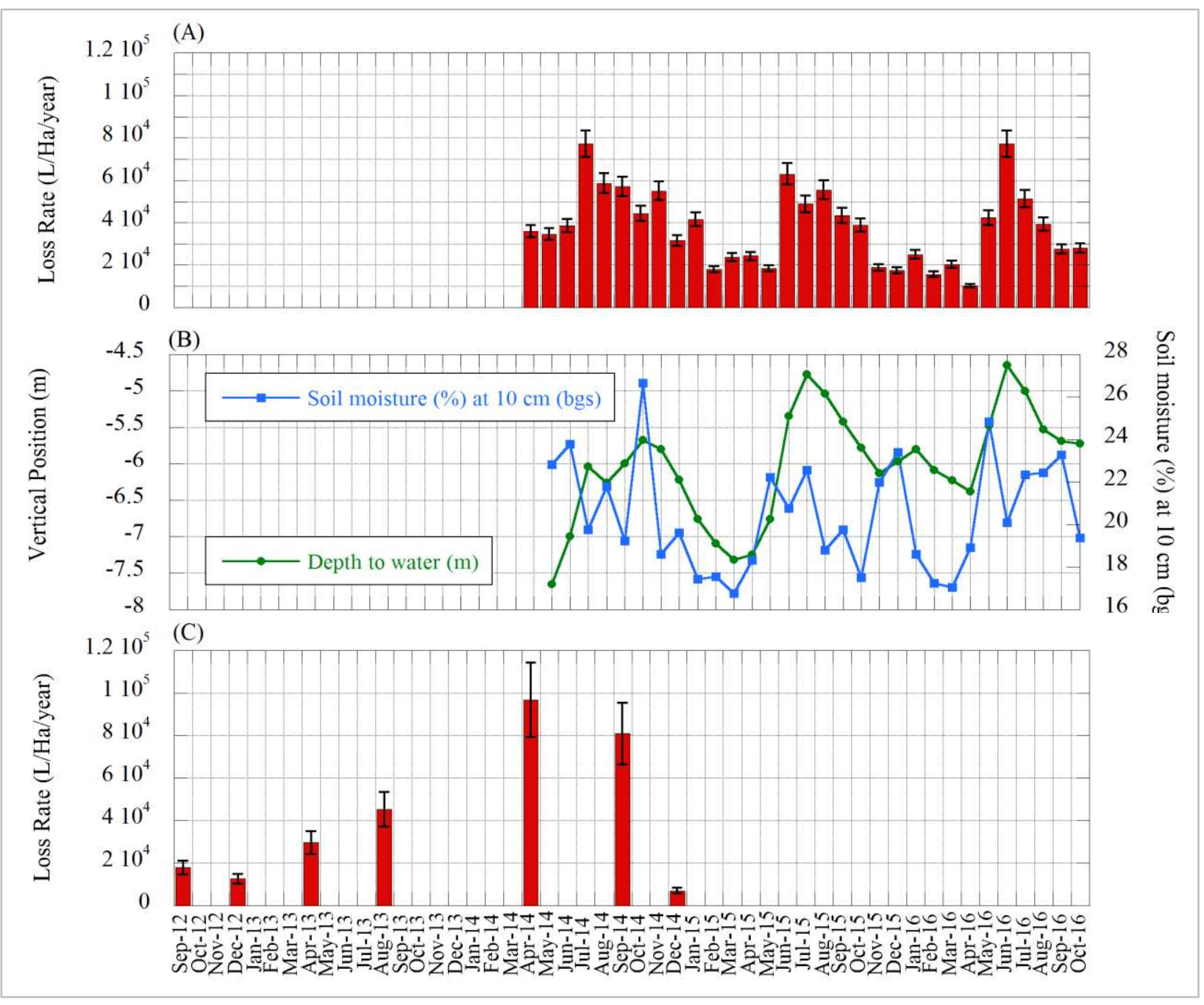

Figure 2.7. A) Average monthly NSZD rates based on temperature data, B) average water level measured along the transect and simulated soil moisture data, and $\mathrm{C}$ ) average $\mathrm{CO}_{2}$ trap NSZD rates

Building on the theme of transport effecting thermal expression of NSZD, it is hypothesized that the upward flux of $\mathrm{CH}_{4}$ to the interval of oxidation (Figure 2.1) in the shallow vadose zone can be increased by rising groundwater water levels (associated with rising river stage, up to $3 \mathrm{~m}$ ), increasing the flux of $\mathrm{CH}_{4}$ toward grade and, correspondingly, NSZD-related heat. Alternatively, given high water content in shallow soils associated with extended periods of high precipitation, frozen ground, and/or low transpiration, inward diffusion of $\mathrm{O}_{2}$ and heat 
produced from NSZD could be constrained. An analogy can be drawn to a woodstove, where the amount of heat generated by the stove is a function of both fuel and the air delivery rate.

To help elucidate the effects of water table fluctuation and soil moisture, Figure 2.7B presents depth-to-water and soil-moisture data for the study period. A multiple variable regression was performed using MATLAB $^{\circledR}$ Curve Fitting Toolbox ${ }^{\text {TM }} 2015$ b (The MathWorks Inc., USA) with changes in monthly average NSZD rates as the dependent variable and changes in depth to water and modeled soil moisture at $10 \mathrm{~cm}$ (bgs) as independent variables. The solution for the change in NSZD rate in L/hectare/year is:

$\triangle N \dot{S Z D}=-(2.70 E 4) \triangle D T W-(2.37 E 3) \Delta \theta_{10 \mathrm{~cm}}-2305$

$R^{2}=0.71$

where $\triangle D T W$ is change in depth to water along the transect (m),and $\Delta \theta_{10 \mathrm{~cm}}$ is change in estimated soil moisture (volumetric water content) at $10 \mathrm{~cm}$ bgs $(\%)$.

Similar work conducted at other sites suggests that a better correlation might be achieved using actual-versus-modeled soil moisture data. It is prudent to note 1) over time, short-term errors in equating apparent NSZD loss rates to actual NSZD rates average out, and 2) all techniques currently being employed to resolve NSZD rates (API 2017), including gradient (Johnson et al., 2006; ITRC, 2009), dynamic chamber (Sihota et al., 2011), and $\mathrm{CO}_{2}$ trap (McCoy et al., 2015) methods, are likely to be similarly biased by water table fluctuations and changes in the shallow soil moisture.

In general, there is a potential dependence of apparent thermal NSZD rates on soil moisture and depth to water. This dependence is not seen with the $\mathrm{CO}_{2}$ trap NSZD data. The lack 
of $\mathrm{CO}_{2}$ trap data correlation with soil moisture and depth to water is, in part, due to the sparse nature of the $\mathrm{CO}_{2}$ trap data.

\subsubsection{Comparison of Thermal and $\mathrm{CO}_{2}$ Trap NSZD Rates}

Figure 2.7C presents the average NSZD rates from $\mathrm{CO}_{2}$ traps located at N1 through N3 during seven two-week sampling events occurring between September 2012 and December 2014. Error bars for the $\mathrm{CO}_{2}$ trap data are based on an estimate of $\mathrm{CO}_{2}$ trap accuracy reported by McCoy et al. (2015). The average of all $19 \mathrm{CO}_{2}$ trap values for the study period is 41,500 \pm 35,000 L/hectare/year, versus 38,200 \pm 17,700 L/hectare/year for the thermal NSZD rates. The $8.4 \%$ difference between the mean results from the two methods falls within the confidence intervals of both methods. Again, standard deviations of NSZD rates reflect variations in apparent NSZD rates through time. The range of $\mathrm{CO}_{2}$ trap NSZD rates is $34 \%$ greater than the range of the thermal NSZD rates.

Figure 2.8 presents $\mathrm{CO}_{2}$ trap and thermal NSZD values collected concurrently over twoweek periods in April-May 2014, August-September 2014, and December 2014. $\mathrm{CO}_{2}$ trap and thermal monitoring methods provide similar results within a factor of two, at all location and times, with the exception of N1 from the December 2014 period. Insufficient data are available to resolve the larger temperature-derived NSZD rates at N1 from the December 2014 period. A plausible explanation for the low $\mathrm{CO}_{2}$ trap number in the December 2014 period, at N1-N-3, is frozen or water saturated soils inhibiting discharge of $\mathrm{CO}_{2}$ to the atmosphere. 


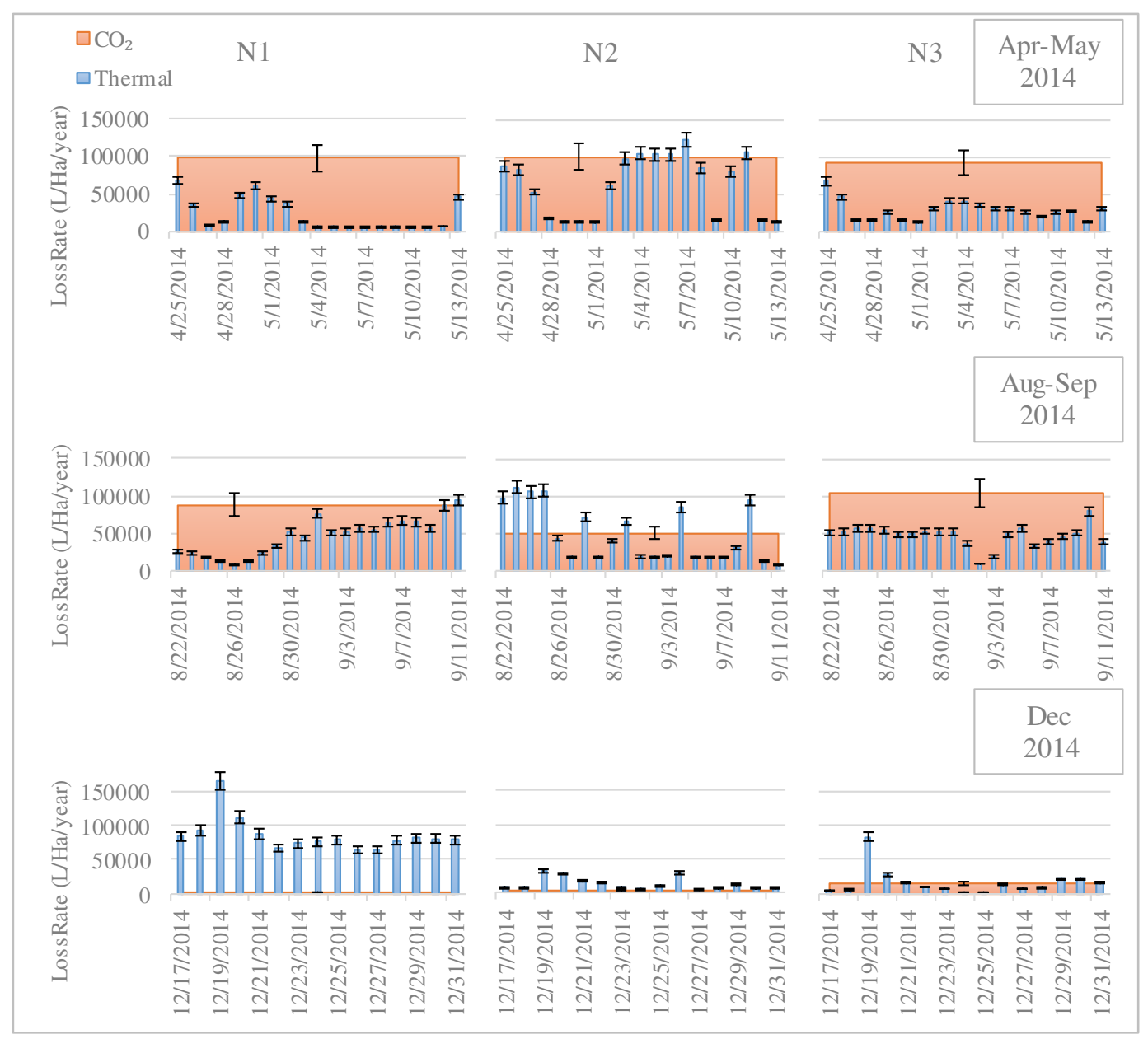

Figure 2.8. Comparison of $\mathrm{CO}_{2}$ trap and thermal monitoring estimates of NSZD rates during three two-week periods of concurrent data collection at the same locations. Broad bars reflect $\mathrm{CO}_{2}$ trap NSZD values based on total sorbed $\mathrm{CO}_{2}$ over two week deployment periods. Narrow bars reflect NSZD values without energy storage obtained from average daily temperature data.

Building on Figures 2.7 and 2.8, the variation in the average rates for the two methods are generally within the methods' confidence intervals. General agreement between results from both $\mathrm{CO}_{2}$ trap and thermal monitoring methods is encouraging with respect to the reasonableness of results derived from both methods. On one hand, data presented herein are insufficient to rigorously resolve which method is more accurate. On the other hand, generalizations as to the merits of both methods can be advanced. First, $\mathrm{CO}_{2}$ traps have comparatively low initial costs 
and high ongoing costs for long-term monitoring. In contrast, the thermal monitoring method has comparatively high initial costs (for hardware and installation) and low long-term cost due to remote data uploading and automated data processing. Second, thermal monitoring, over extended periods, has the additional benefit of fewer on site person-hours with corresponding advantages in terms of safety and security. Finally, the $\mathrm{CO}_{2}$ trap method presents the challenges of knowing when to sample and when enough measurements have been made to resolve annual average NSZD rates to a sufficient degree of accuracy. In contrast, given continuous monitoring with the thermal monitoring method, neither the timing nor the sufficiency of measurements is an issue.

\subsection{Conclusion}

Measuring subsurface temperatures as a function of depth at background and impacted locations, through time, provides a practical means for resolving apparent NSZD rates at petroleum sites. Favorable attributes of thermal NSZD monitoring include the simplicity of data collection and an ability to resolve NSZD rates continuously from temporally dynamic systems. A constraint to thermal NSZD monitoring at the study site is that reported instantaneous NSZD rates are apparent versus true values. At the study site, both large water table fluctuations and soil moisture appear to impact the timing of thermal expressions of NSZD. The challenge of apparent versus actual NSZD rates can be addressed by averaging continuous thermal NSZD results over annual cycles. It is worth noting that reporting apparent versus actual NSZD rates may be an even greater issue for methods that rely on infrequent NSZD rates measurements made over short periods (gradient, dynamic chamber, and $\mathrm{CO}_{2}$ trap methods).

A constraint to thermal monitoring of NSZD rates is the use of temperature data from background locations (background correction) to isolate heat associated with NSZD. 
Imperfection with background corrections can be attributed to many factors, including differing infiltration of precipitation and net solar radiation at background versus impacted locations. While background correction of temperature data is imperfect, this work suggests that it is a reasonable method based on close agreement between NSZD rates obtained using thermal monitoring and $\mathrm{CO}_{2}$ trap methods. A partial solution for background correction issues is to have multiple background locations, such that conditions at impacted locations are replicated as closely as possible by conditions at background locations. Going a step further, advancing computational methods that eliminate the need for background correction of temperature data is both enticing and a topic of ongoing research.

The remote data-acquisition methods described in this chapter, and their effectiveness in characterizing important subsurface processes, illustrate the potential of emerging Internet of Things (IoT) cloud-based analytics for subsurface monitoring. In addition to temperature, a host of other parameters can be measured (e.g., water levels, oxidation reduction potential, etc.) in groundwater. It seems we are on the verge of a future when the arduous process of collecting groundwater samples, conducting laboratory analyses, interpreting data, and reporting, may be largely supplanted by automated real-time, sensor-based data collection, analysis, and reporting. For many, a move to cloud-based analytics (IoT) for groundwater monitoring may be disruptive. On the other hand, the benefits in terms of better data, faster responses to adverse conditions, lower cost, and greater safety, security, and sustainability seems undeniable. 


\section{CHAPTER 3.}

\section{ESTIMATION OF NATURAL SOURCE ZONE DEPLETION WITHOUT BACKGROUND CORRECTION}

\subsection{Chapter Synopsis}

Real-time monitoring of subsurface temperatures and use of the heat generated by natural depletion of petroleum-based light nonaqueous phase liquids (LNAPLs) is a promising approach for resolving natural source zone depletion (NSZD) rates. The primary limitation of developed computational methods for transforming temperature data into NSZD rates is background correction of subsurface temperature. A new method "single stick" is advanced to convert continuous temperature data into NSZD rates without background correction. With respect to numerically synthesized surface and subsurface values of heat sources, 0.617 and 0.017 absolute percentage errors of estimated values by single stick method support the validity of mathematical formulations and computational algorithm. At three location with no LNAPL, the average of NSZD rates resulted by single stick method is lower than background correction approaches by a factor of 0.5 to 7.5 , indicating the accuracy of the single stick method. In addition, the resulting 13,100 L/ha/year average NSZD rate obtained by single stick method for 14 LNAPL-impacted locations suggests the ability of the single stick method in estimation of NSZD rates at LNAPL areas. Compared to background correction methods, the promising aspect of the single stick method is that background temperature data are not required for resolving the heat associated with NSZD. As a future vision, combined soil oxidation reduction potential data and water level data with temperature data and artificial intelligence will lead to a better understanding of NSZD processes in managing LNAPL sites. 


\subsection{Introduction}

In almost every part of the world, vast amounts of petroleum have been produced, transported, refined, stored, and/or used as fuel or feedstock. Correspondingly, inadvertent releases of petroleum liquids have occurred and large amounts of petroleum liquids have been released into soil and groundwater. Fortunately, as natural losses (melting) controls the extent of glaciers, natural losses (biodegradation) control the extent of risks associated with subsurface petroleum liquids (Mahler et al., 2012; Sale et al., 2018). The corollary of the extent of glacier and LNAPL bodies being controlled by natural losses is advanced in Figure 3.1 .
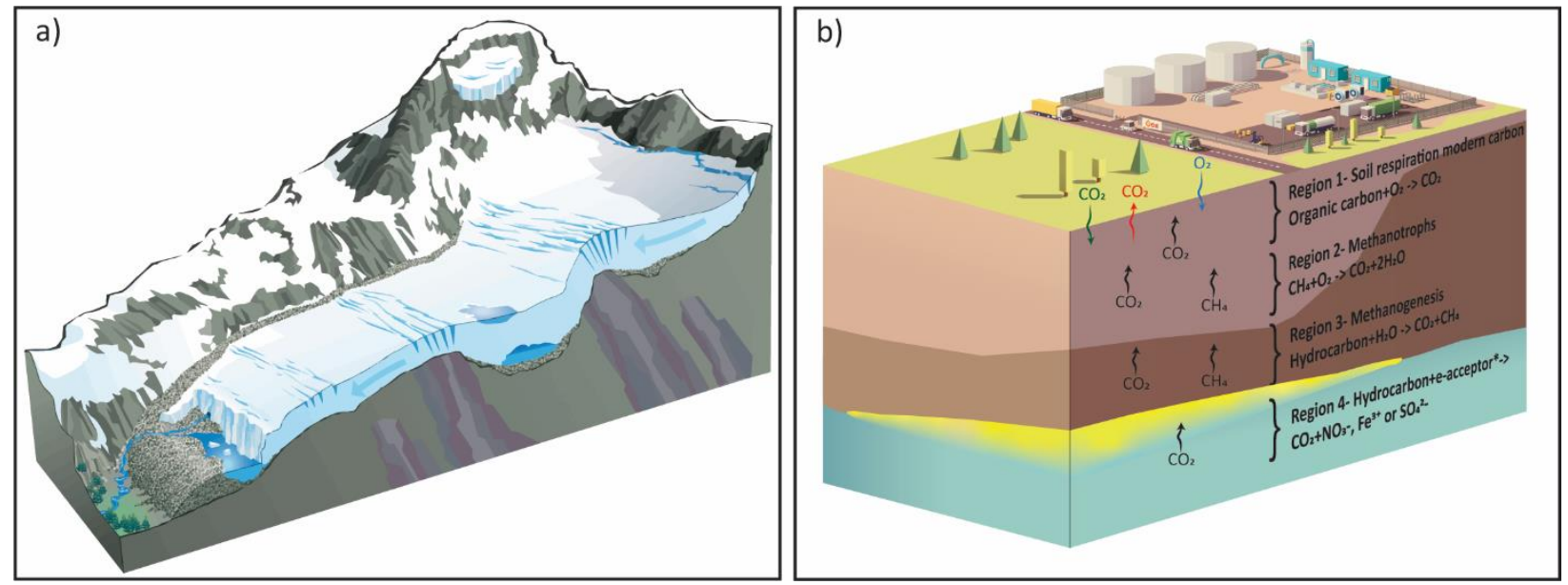

Figure 3.1. a) Extent of glacial ice limited by melting ice and b) Extent of LNAPL limited by NSZD

NSZD losses are part of the natural short-term biological organic carbon cycle, wherein organic carbon is introduced into shallow subsurface setting and subsequently returned to the atmosphere as gases. Following Atekwana and Atekwana (2010), Irianni Renno et al. (2016), and Garg et al. (2017), released LNAPLs commonly concentrate about the water table, available electron acceptors are depleted by percent concentrations of LNAPL, and methanogenesis ensues. Albeit slow, methanogenesis has the advantage over electron acceptor based NSZD 
processes of not being limited by the availability of electrons acceptors (e.g., $\mathrm{O}_{2}, \mathrm{Fe}^{+3}, \mathrm{SO}_{4}^{-2}$ ). Generation of NSZD $\mathrm{CO}_{2}$ and $\mathrm{CH}_{4}$ leads to exceedances of aqueous-phase gas solubility and upward fluxes of $\mathrm{CO}_{2}$ and $\mathrm{CH}_{4}$ through the unsaturated zone. Typically, methane encounters a downward flux of oxygen (Amos et al., 2005), and methane is exothermally converted into $\mathrm{CO}_{2}$ by methanotrophs (Stockwell, 2015; Irianni Renno et al., 2016; Garg et al., 2017).

Initial efforts to quantify NSZD rates focused on quantifying NSZD gas fluxes using different methods as explained in Chapter. 1. A common limitation of gas flux methods is that measurements are typically made over brief periods in systems where gas fluxes can be dynamic due to short-term barometric pumping and/or transient soil moisture (Karimi et al., 2018). More recently, temperature-based approaches for quantifying LNAPL NSZD rates have been advanced by Sale et al. (2015), Warren et al. (2015), and Karimi Askarani et al. (2018), involving: 1) continuously measuring vertical temperature profiles in background and LNAPL impacted areas 2) isolating NSZD heat from heat associated with surface heating by subtracting background temperatures from temperature in LNAPL impacted areas, 3) conducting an energy balance to resolve NSZD energy (e.g., $\mathrm{W} / \mathrm{m}^{2}$ ) and 4) estimating NSZD rates by dividing NSZD energy by the estimated NSZD heat of reaction. Continuous temperature monitoring addresses issues with temporally-sparse gas flux measurements (Karimi et al., 2018), and thermal properties of subsurface media are arguably far more uniform than gas-phase diffusion coefficients and soil permeability.

The primary limitation of published methods for transforming temperature to NSZD rates is that background correction for surface heating and cooling at LNAPL impacted locations constrains the accuracy of reported values. Manifestations of flawed background corrections can include occasionally implausible NSZD rates in areas where there is no LNAPL, negative NSZD 
rates, and/or improbably large NSZD rates in areas with LNAPL. Ideally, background locations needs to be largely similar to the LNAPL-impacted locations, through time, with respect to all factors controlling surface heating and cooling including albedo, infiltration/evaporation of precipitation, and incident radiation, to name a few. As an example, a background location with asphalt and direct sunlight is likely to yield flawed background-correction data for surface heating and cooling in an LNAPL-impacted area with direct sunlight and a natural vegetative cover.

While concerns can be raised with respect to the accuracy of all methods for quantifying NSZD rates, we can be confident that NSZD frequently plays an important role in constraining the extent of LNAPL and the associated risks. If this were not true, the extent of LNAPL bodies would be far larger than what we see today, much like the extent of glaciers would be much larger if they were not melting. The current challenge with respect to quantifying NSZD rates is that we are like a person with too many watches. We are never quite sure what time it is.

\subsection{Research Objective}

The main objective of this chapter is to explore a new "single stick" method for converting continuous temperature data into NSZD rates. Novel mathematical methods are advanced, the validly of the methods are tested using collaborative models, methods for converting temperature into NSZD rates are compared using data from three field sites, and merits-limitation of the single stick method are evaluated. The motivation for this study is to progress to having a widely-accepted "best" method for estimating NSZD rates and a greater confidence in our emerging reliance on NSZD to manage LNAPLs in soil and groundwater. 


\subsection{Methods}

The following section describes a novel mathematical approach to transforming subsurface temperature data into NSZD rates. Topics addressed include a mathematical derivation, methods used to test the derived solution, and background information regarding five study sites.

\subsubsection{Conceptual Model}

The two primary heat sources/sinks in a media impacted by petroleum LNAPL are surface heating and cooling and subsurface NSZD. Processes driving surface heating and cooling include incident solar radiation, black body radiation, incident precipitation, and evaporative cooling of soil water, to name a few. Heat moves into the subsurface when the net surficial inflow of energy is greater than the losses of energy. Conversely, heat moves out of the subsurface when the energy losses are greater than energy inputs (Jury and Horton 2004; Hillel 1980).

Reactions associated with subsurface NSZD are presented in Table 3.1. Following Johnson and Lundegard (2006), decane is used as representative "model" petroleum hydrocarbon. The first reaction (1) is mediated by methanogens under anaerobic conditions producing $\mathrm{CH}_{4}$ and $\mathrm{CO}_{2}$. Methanogenesis typically occurs in and about the space where LNAPLs are present (Irianni et al., 2015 and Garg et al., 2017). While the exergonic $\Delta G_{r}^{o}$ value for (1) favors the forward reaction, the $\Delta H_{r}^{o}$ value is positive indicating an endothermic reaction. In the second reaction (2), methanotrophs aerobically oxidize $\mathrm{CH}_{4}$ into $\mathrm{CO}_{2}$ and $\mathrm{H}_{2} \mathrm{O}$. Oxidation of $\mathrm{CH}_{4}$ occurs above the LNAPL body at a vertical position where the outward flux of $\mathrm{CH}_{4}$ meets an inward flux of atmospheric $\mathrm{O}_{2}$. Notably, the inward flux of $\mathrm{O}_{2}$ can vary with time due to temporally varying effective oxygen diffusion coefficient (controlled by soil water content) 
barometric pumping, and water table fluctuations (Karimi et al., 2018). Reaction (2) provides the primary source of heat for NSZD.

Table 3.1. Transformation of decane as a representative of petroleum hydrocarbon compound through NSZD process with change in free Gibbs energy and enthalpy. The values of change in Gibbs free energy $\left(\Delta G_{r}^{o}\right)$ and enthalpy $\left(\Delta H_{r}^{o}\right)$ under standard conditions for each reaction in Table 3.1 are calculated based on the values tabulated in Appendix A.

\begin{tabular}{|c|c|c|}
\hline Reaction & $\begin{array}{l}\Delta G_{r}^{o} \\
(\mathbf{k J} / \mathbf{m o l}- \\
\left.\mathrm{C}_{10} \mathbf{H}_{22}\right)\end{array}$ & $\begin{array}{l}\Delta H_{r}^{o} \\
(\mathbf{k J} / \mathbf{m o l}- \\
\left.\mathrm{C}_{10} \mathrm{H}_{22}\right)\end{array}$ \\
\hline 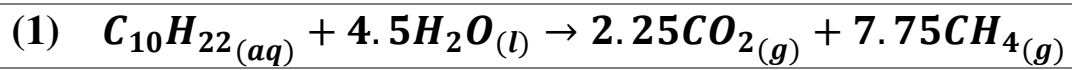 & -266 & 120 \\
\hline (2) $\mathrm{CH}_{4(g)}+2 \mathrm{O}_{2(g)} \rightarrow \mathrm{CO}_{2(g)}+2 \mathrm{H}_{2} \mathrm{O}_{(l)}$ & -6341 & -6902 \\
\hline (3) $\quad C_{10} H_{22}(a q)+15.5 O_{2_{(g)}} \rightarrow 10 \mathrm{CO}_{2_{(g)}}+11 H_{2} o_{(l)}$ & -6607 & -6782 \\
\hline
\end{tabular}

\subsubsection{Derivation}

The following method advances a solution for NSZD rates as a function of temperatures measured along a vertical subsurface profile at a single location. This method is referred to as the "single stick method". All other current methods of transforming temperature to NSZD rates rely on "background-temperature corrections," as described in Sale et al. (2015), Warren et al (2015), and Karimi et al. (2018).

Following Carslaw and Jaeger (1959); Jury and Horton (2004); and Hillel (2013), the governing equations for conductive heat transfer is:

$\frac{\partial}{\partial x}\left(K_{x} \frac{\partial T}{\partial x}\right)+\frac{\partial}{\partial y}\left(K_{y} \frac{\partial T}{\partial y}\right)+\frac{\partial}{\partial z}\left(K_{z} \frac{\partial T}{\partial z}\right)=\frac{\partial C \rho T}{\partial t}$

where $K\left(\mathrm{ML} / \mathrm{T}^{3} \theta\right)$ is thermal conductivity, $C\left(\mathrm{~L}^{2} / \mathrm{T}^{2} \theta\right)$ is heat capacity, $T$ is temperature $(\theta), t$ (T) is time, $\rho\left(\mathrm{M} / \mathrm{L}^{3}\right)$ is sediment density, and $(x, y, z)(\mathrm{L})$ are spatial coordinates. As shown in Figure 3.2, the surface heat source/sink $q_{s}\left(\mathrm{M} / \mathrm{T}^{3}\right)$ occurs at $x=0$. The subsurface heat source/sink $q_{s s}\left(\mathrm{M} / \mathrm{T}^{3}\right)$ occurs across a horizontal plane at a temporally varying position $x=x^{\prime}$. At any point in the domain, temperature is a function of the temporal values of $q_{s}, q_{s s}$, and $x$. 


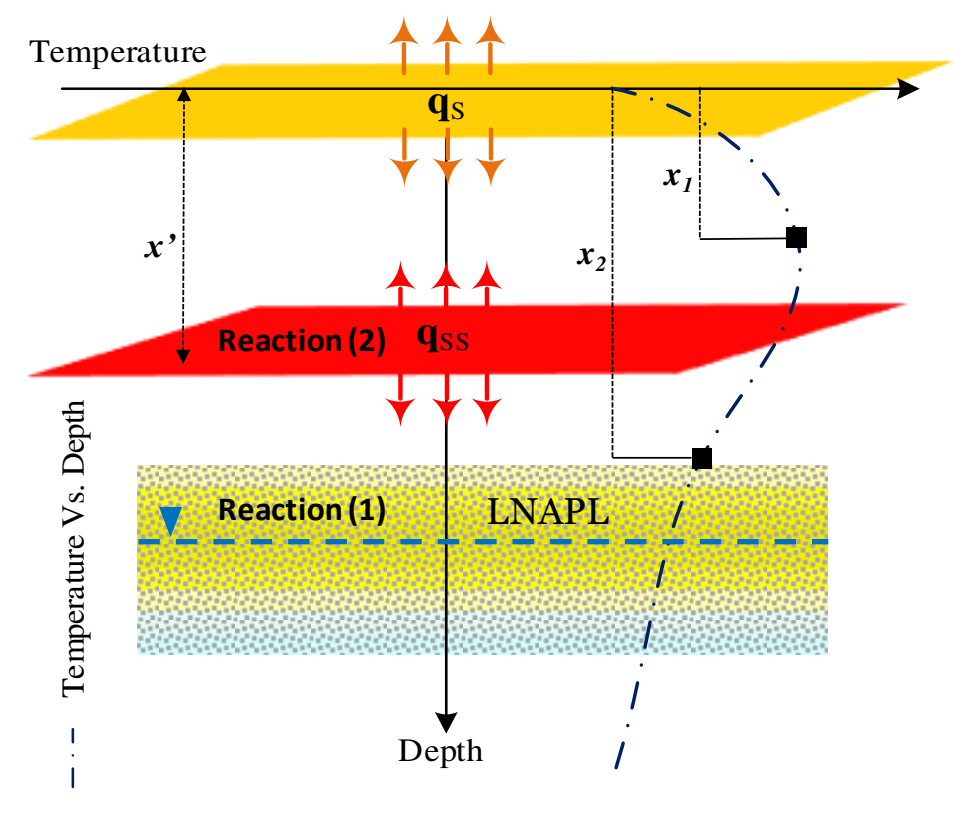

Figure 3.2. Conceptual model for primary heat sources in a LNAPL-impacted area

Additional assumptions used to derive a solution include:

1. Surface and subsurface heat sources/sinks can be approximated as planar features.

2. Thermal properties of soil are independent of position, direction, temperature, and time.

3. Horizontal heat fluxes are negligible (Stockwell, 2015).

4. Temporally-varying surface and subsurface heat source/sink can be approximated using a succession of steady state (e.g., daily) values.

5. The surface heating and cooling term addresses all processes controlling surface heating and cooling including, but not limited to solar radiation, black body radiation, incident precipitations, evaporative cooling, and composting shallow soil organic compounds.

6. The subsurface heat source/sink has a temporally-varying position $\dot{x}$ (approximated using a succession of steady-state values) and an image source/sink symmetrically located at position $-\dot{x}$ 
7. Net gain or of loss of biomass, precipitation or dissolution of minerals, or changes in thermodynamic states do not contribute significantly to subsurface heating and cooling (Karimi et al., 2018).

8. Geothermal temperature gradients are negligible (Stockwell, 2015; Karimi et al., 2018).

9. Observed near-constant temperatures at depth are a basis for initial condition temperature conditions.

10. The energy produced from mineralization of decane is representative of the energy produced through NSZD of the hydrocarbons of concern.

\subsubsection{Solution}

Applying the stated assumptions to Equation (3.1), the governing equation reduces to:

$\frac{\partial^{2} T}{\partial x^{2}}=\frac{1}{\kappa} \frac{\partial T}{\partial x}$

Boundary and initial conditions include:

$q_{s}=-\left.K \frac{d T}{d x}\right|_{x=0}$

$T( \pm \infty, t)=T_{0}$

$T(x, 0)=T_{0}$

where $T_{0}$ is initial temperature, and $\kappa=K / \rho c$ is thermal diffusivity $\left(\mathrm{L}^{2} / \mathrm{T}\right)$.

A solution for Equation (3.2) is obtained by superimposing separate solutions for temperatures associated with $q_{s}$ and $q_{s s}$. Following Carslaw and Jeager (1959), a solution for temperature as a function of $q_{s}$ is:

$T(x, t)-T_{0}=\frac{2 q_{s}}{K}\left\{\sqrt{\frac{\kappa t}{\pi}} \exp \left(-\frac{x}{4 \kappa t}\right)-\frac{x}{2} \operatorname{erfc}\left(\frac{x}{\sqrt{4 \kappa t}}\right)\right\}$ 
Equation (3.6) satisfies all conditions of Equations (3.3), (3.4), and (3.5). Again, following Carslaw and Jeager (1959), a solution for temperature as a function of $q_{s s}$ at $\dot{x}$ is:

$$
\begin{aligned}
& T(x, t)=\frac{q_{S S}}{\rho c}\left\{\sqrt{\frac{t}{\pi \kappa}} \exp \left(-\frac{(x-\dot{x})^{2}}{4 \kappa t}\right)-\frac{|x-\dot{x}|}{2 k} \operatorname{erfc}\left(\frac{|x-\dot{x}|}{\sqrt{4 \kappa t}}\right)\right\}+\frac{q_{S S}}{\rho c}\left\{\sqrt{\frac{t}{\pi \kappa}} \exp \left(-\frac{(x+\dot{x})^{2}}{4 \kappa t}\right)-\right. \\
& \left.\frac{(x+\dot{x})}{2 k} \operatorname{erfc}\left(\frac{(x+\dot{x})}{\sqrt{4 \kappa t}}\right)\right\}
\end{aligned}
$$

The first term in Equation (3.7) accounts for the real subsurface NSZD heat source. The second term in Equation (3.7) is an imaginary source located in imaginary space, at a position equidistant to the real subsurface heat source above the ground surface. Summation of Equations (3.6) and (3.7) yields:

$$
\begin{aligned}
& T(x, t)-T_{0}=\frac{2 q_{s}}{\mathrm{~K}}\left\{\sqrt{\frac{\kappa t}{\pi}} \exp \left(-\frac{x}{4 \kappa t}\right)-\frac{x}{2} \operatorname{erfc}\left(\frac{x}{\sqrt{4 \kappa t}}\right)\right\}+\frac{q_{s s}}{\rho c}\left\{\sqrt{\frac{t}{\pi \kappa}} \exp \left(-\frac{(x-\dot{x})^{2}}{4 \kappa t}\right)-\right. \\
& \left.\frac{|x-\dot{x}|}{2 k} \operatorname{erfc}\left(\frac{|x-\dot{x}|}{\sqrt{4 \kappa t}}\right)\right\}+\frac{q_{s s}}{\rho c}\left\{\sqrt{\frac{t}{\pi \kappa}} \exp \left(-\frac{(x+\dot{x})^{2}}{4 \kappa t}\right)-\frac{(x+\dot{x})}{2 k} \operatorname{erfc}\left(\frac{(x+\dot{x})}{\sqrt{4 \kappa t}}\right)\right\}
\end{aligned}
$$

In net, the combination of real surface and subsurface heat sources and an imaginary subsurface heat sources leads to a mathematical framework in which NSZD heat can leave the real model domain at $x=0$.

A solution accounting for temporal variations in $q_{s}, q_{s s}$, and $\dot{x}$ is obtained using a succession of steady states:

$T(x, t)-T_{0}=\sum_{i=1}^{n}\left(q_{s}^{i}-q_{s}^{i-1}\right) F\left(x, t-t_{i-1}\right)+\left(q_{s s}^{i}-q_{s s}^{i-1}\right) G\left(x, t-t_{i-1}, \dot{x}\right)$

where $q_{s}, q_{s s}$, and $\dot{x}$ are assumed constant between consecutive time steps $\left(t_{n-1}<t \leq t_{n}\right)$,

$$
F\left(x, t-t_{i-1}\right)=\frac{2}{K}\left\{\sqrt{\frac{\kappa\left(t-t_{i-1}\right)}{\pi}} \exp \left(-\frac{x}{4 \kappa\left(t-t_{i-1}\right)}\right)-\frac{x}{2} \operatorname{erfc}\left(\frac{x}{\sqrt{4 \kappa\left(t-t_{i-1}\right)}}\right)\right\}
$$

and 
$G\left(x, t-t_{i-1}, x^{\prime}\right)=\frac{1}{\rho c}\left\{\sqrt{\frac{\left(t-t_{i-1}\right)}{\pi \kappa}} \exp \left(-\frac{\left(x-x^{2}\right)^{2}}{4 \kappa\left(t-t_{i-1}\right)}\right)-\frac{\left|x-x^{\prime}\right|}{2 k} \operatorname{erfc}\left(\frac{\left|x-x^{\prime}\right|}{\sqrt{4 \kappa\left(t-t_{i-1}\right)}}\right)\right\}+$

$\frac{1}{\rho c}\left\{\sqrt{\frac{\left(t-t_{i-1}\right)}{\pi \kappa}} \exp \left(-\frac{(x+\dot{x})^{2}}{4 \kappa\left(t-t_{i-1}\right)}\right)-\frac{(x+\dot{x})}{2 k} \operatorname{erfc}\left(\frac{(x+\dot{x})}{\sqrt{4 \kappa\left(t-t_{i-1}\right)}}\right)\right\}$

By measuring temperature in the subsurface at two different positions (Figure 3.2), Equation (3.9) can be solved in the following two-equation, two-unknown system for determining the values of $q_{s}$ and $q_{s s}$ :

$\left\{\begin{array}{l}T\left(x_{1}, t\right)=\sum_{i=1}^{n}\left(q_{s}^{i}-q_{s}^{i-1}\right) F\left(x, t-t_{i-1}\right)+\left(q_{s s}^{i}-q_{s s}^{i-1}\right) G\left(x, t-t_{i-1}, x\right) \\ T\left(x_{2}, t\right)=\sum_{i=1}^{n}\left(q_{s}^{i}-q_{s}^{i-1}\right) F\left(x, t-t_{i-1}\right)+\left(q_{s s}^{i}-q_{s s}^{i-1}\right) G\left(x, t-t_{i-1}, \dot{x}\right)\end{array}\right.$

As expressed in Equation (3.8), except for $q_{s}$ and $q_{s s}, x^{\prime}$ is unknown. In the single stick model, this term $(\dot{x})$ is determined using an iteration approach that will be explained in the following section.

Finally, the values of subsurface heat source $\left(q_{s s}\right)$ are converted to NSZD rates, on a volumetric basis, using:

$N \dot{S Z D}=\frac{-q_{S S}}{\Delta H_{\text {decane }} \rho_{\text {decane }}}$

where $N \dot{S Z D}$ is the rate of NSZD (L/T), $\Delta H_{\text {decane }}$ is the enthalpy of complete mineralization $\left(\mathrm{ML}^{2} / \mathrm{T}^{2} / \mathrm{mol}\right)$, and $\rho_{\text {decane }}$ is the molar density of decane $=5.14(\mathrm{~mol} / \mathrm{L})$.

\subsubsection{Algorithm}

Estimates of NSZD rates $(N \dot{S Z D})$ through time are obtained using an algorithm programmed in MATLAB ${ }^{\circledR}$ (The MathWorks Inc., Natick, Massachusetts). The primary input in this algorithm are vertical profiles of subsurface temperatures measured in LNAPL-impacted areas. Measured temperatures at any vertical position in the subsurface are averaged on a daily basis. Key steps for transforming daily average temperature data to NSZD rates using this algorithm are illustrated in Figure 3.3. In more detail: 
1. The daily average of measured subsurface temperatures, thermal properties of soil profile, and number of positions for evaluating the subsurface heat source are considered as input values.

2. In a fixed time step $(i)$, the algorithm selects a position for subsurface heat source $\left(\dot{x}_{j}\right)$.

3. A system of two equations (3.12) is solved for determining the values of $q_{s j}^{i}$ and $q_{s s}{ }^{i}$ based on the selected position for subsurface heat source.

4. The simulated temperature distribution $\left(T_{P r d}\right)$ is obtained using Equation (3.9).

5. The conformity of simulated temperature distribution $\left(T_{P r d}\right)$ to the observed temperature distribution $\left(T_{O b S}\right)$ is evaluated using a $R^{2}$ value.

6. After the subsurface heat source is evaluated at all specified positions $(j=n)$, the algorithm goes to the next step. Otherwise, it goes back to step 2 to consider another position for subsurface heat source.

7. The values of $q_{s}{ }^{i}, q_{s s}{ }^{i}$, and $\dot{x}$ are concluded for the fixed time step $(i)$ based on the simulated temperature profile.

8. Lastly, the estimated value of the subsurface NSZD heat source is converted into an NSZD rate using Equation (3.13).

9. The program iterates through time until all of the temperature data have been transformed into NSZD rates. 


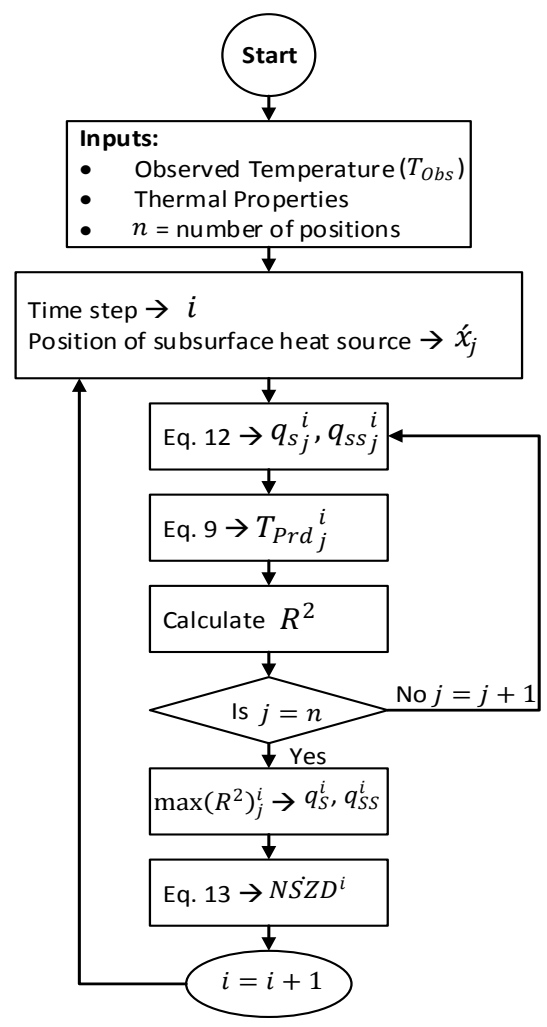

Figure 3.3. Flowchart of the single stick model

\subsubsection{Confirmation of Solution and Algorithm}

The following section describes three approaches used to test the validity of the solution and computational algorithm.

Numerical Model Test - A two-step process was used to test the validity of the analytical solution (Equation (3.8)) and to check the computational algorithm. Firstly, daily prescribed values for $q_{s}$ and $q_{s s}$ were imposed on surface and subsurface of a soil profile modeled using a finite element approach programmed in MATLAB ${ }^{\circledR}$ to simulate temperature distribution throughout the soil profile for a 50-day period (see Figure 3.4). Secondly, the single stick model was employed to estimate $q_{s}$ and $q_{s s}$ using the synthetic temperatures of the soil 
profile. Agreement between imposed and estimated values of $q_{s}$ and $q_{s s}$ are used to evaluate the validity of the mathematical solution and the MATLAB code.

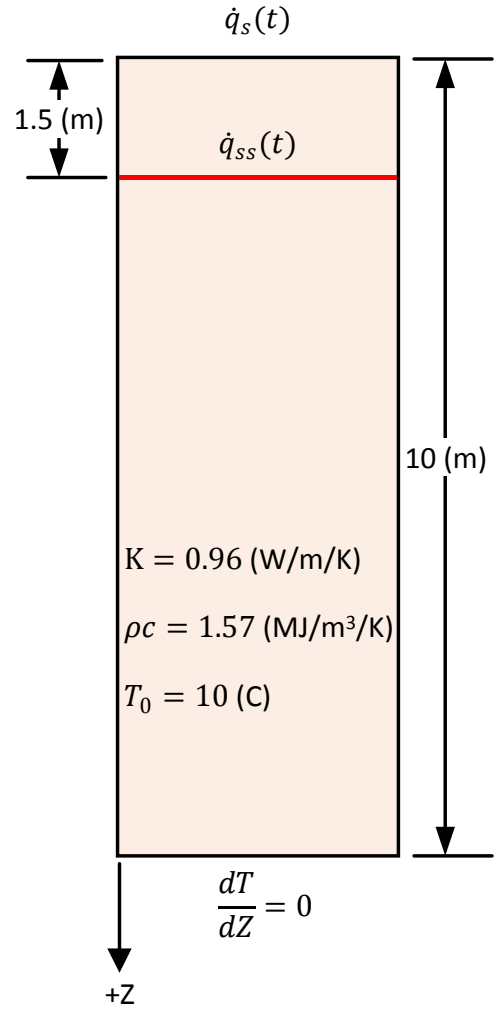

(a)

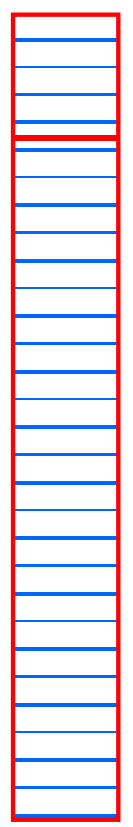

(b)

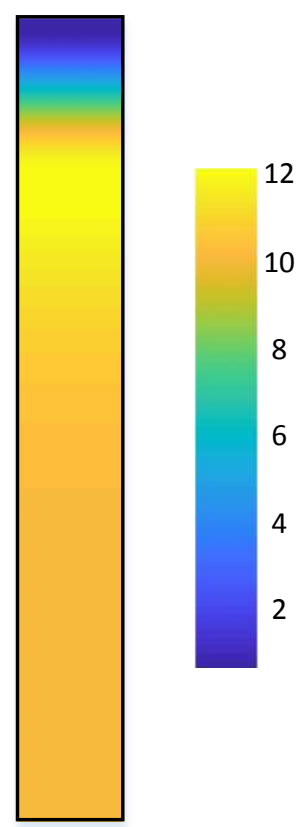

(c)

Figure 3.4. Finite element approach: (a) physical model of soil profile, (b) discretization of soil profile, and (c) temperature distribution.

Model performance is assessed using 1) Root Mean Square Error (RMSE), 2) coefficient

of determination $\left.\left(R^{2}\right), 3\right)$ Nash-Sutcliffe Efficiency (NSE; Nash and Sutcliffe, 1970), 4) index of agreement (d; Willmott, 1981), 5) Percent Error (PE), 6) mean $(\mu)$, and 7) standard deviation $(\sigma)$ of residuals (observed minus modeled).

Comparison of observed and predicted temperature profiles - To investigate how the single stick model describes subsurface temperature distribution, the simulated subsurface temperature profile by the single stick model are compared to the actual subsurface temperature 
profile measured in a field site. The ability of estimated $q_{s}$ and $q_{s s}$ to reproduce observed subsurface temperature provides an additional means of evaluating the validity of the mathematical solution and the MATLAB code.

Triplicate Test - Three thermal monitoring systems were installed in a LNAPL area (Site 4), approximately $2 \mathrm{~m}$ apart in an equilateral triangle. The triplicate values from the single stick method are compared to the values derived from the $\mathrm{CO}_{2}$ trap method for a different field site (McCoy, 2015) to evaluate the coefficient of variation (the ratio of the standard deviation to the mean value) due to local spatial variations and measurement accuracy.

\subsubsection{NSZD Rate}

Comparisons of Single Stick and Background Correction Methods - The merits of the single stick computational approach are evaluated by comparing results from three field sites (Sites 1, 2, and 3) using single stick and background-correction methods. Background-correction methods include methods presented in Sale et al. (2015), 2) Warren and Bekins (2015), and 3) Karimi Askarani et al. (2018). Background correction methods are predicated on using subsurface temperature data at a representative background (no LNAPL) location to isolate heat associated with surface heating and cooling from heat associated with NSZD.

In addition, since each of the sites considered in this study has two background locations, applications of the background correction methods include considering one background location as an LNAPL-impacted location and the other background location as a background location. NSZD rates at background locations (using both background and single stick methods) are calculated to provide a basis for evaluating the ability of all methods to capture zero NSZD rates at background locations. 
NSZD Rate at a LNAPL-Impacted Location in a Site with No Background Data - To show the main advantage of the single stick method, estimation of NSZD rates in LNAPL areas with no need for background correction, NSZD rate at a LNAPL-impacted location in a former refinery (Site-5) where there is no background location is calculated. This location has also been characterized and monitored by collecting cryogenic cores following the method described in Kiaalhosseini et al. (2017).

Negative Rates - Site-wide monthly average of NSZD rates calculated by the single stick method for Site-3 are provided to show not only the seasonal behavior with NSZD rates, but more importantly the occurrence of negative NSZD rates through time for the study period.

\subsubsection{Study Sites}

Data from five field sites are used to evaluate the single stick method. Relevant attributes of each site are presented in Table 3.2. Sites 1 through 3 are equipped with vertical strings (referred to as "sticks") of type-T copper-constant thermocouples, and Sites 4 and 5 are equipped with digital temperature sensors (Dallas DS18b20). Vertical position of the thermocouples in the subsurface and the period of data collection at each study site are provided in Table 3.2. The fabrication and installation of thermal monitoring systems at sites 1 through 3 are the same as the systems explained in Chapter 2 (2.4.2). The new generation of the monitoring system, used at Sites 4 and 5, is described in Chapter 4 (4.4.1) in detail.

Table 3.2. Relevant attributes of study sites

\begin{tabular}{|c|c|c|c|c|c|}
\hline Location & Site-1 & Site-2 & Site-3 & Site-4 & Site-5 \\
\hline Facility & $\begin{array}{l}\text { Fuel terminal - } \\
\text { Former } \\
\text { refinery }\end{array}$ & $\begin{array}{l}\text { Active } \\
\text { refinery }\end{array}$ & $\begin{array}{l}\text { Former natural } \\
\text { gas plant }\end{array}$ & $\begin{array}{l}\text { Former } \\
\text { refinery }\end{array}$ & $\begin{array}{l}\text { Former } \\
\text { refinery }\end{array}$ \\
\hline Setting & $\begin{array}{l}\text { Basin Fill - } \\
\text { Heterogeneous } \\
\text { fine to }\end{array}$ & $\begin{array}{l}\text { Braided } \\
\text { Stream - } \\
\text { Sand }\end{array}$ & $\begin{array}{l}\text { Texas Gulf } \\
\text { Coast- } \\
\text { Heterogeneous }\end{array}$ & $\begin{array}{l}\text { Missouri } \\
\text { River- } \\
\text { Clayey }\end{array}$ & $\begin{array}{l}\text { Lower Great } \\
\text { Miami River } \\
\text { Glacial }\end{array}$ \\
\hline
\end{tabular}




\begin{tabular}{|c|c|c|c|c|c|}
\hline & $\begin{array}{l}\text { medium- } \\
\text { grained } \\
\text { sediments }\end{array}$ & $\begin{array}{l}\text { grading } \\
\text { from fine } \\
\text { to coarse } \\
\text { with depth }\end{array}$ & $\begin{array}{l}\text { fine to } \\
\text { medium- } \\
\text { grained } \\
\text { sediments }\end{array}$ & $\begin{array}{l}\text { sand } \\
\text { grading to } \\
\text { sand with } \\
\text { depth }\end{array}$ & $\begin{array}{l}\text { outwash silt } \\
\text { grading to sand } \\
\text { and gravel } \\
\text { with depth }\end{array}$ \\
\hline $\begin{array}{l}\text { Average } \\
\text { depth to } \\
\text { water }(\mathrm{m})\end{array}$ & 5 & 1 & 2 & 5 & 8 \\
\hline $\begin{array}{l}\text { Vertical } \\
\text { position of } \\
\text { temperature } \\
\text { measurement } \\
\mathrm{s}(\mathrm{m} \text { bgs })\end{array}$ & $\begin{array}{l}0.15,0.61, \\
1.22,1.83, \\
3.05,5.8,8.53, \\
\text { and } 12.2\end{array}$ & $\begin{array}{l}0.15,0.3, \\
0.46,0.61, \\
1.22,1.83, \\
2.43 \text {, and } \\
3.05\end{array}$ & $\begin{array}{l}0.3,0.61,1.22, \\
2.44,3.66,6.1 \\
8.53, \text { and } 10.67\end{array}$ & $\begin{array}{l}0.08,0.23, \\
0.53,0.84, \\
1.14,1.75, \\
2.34,2.95, \\
3.56,4.17, \\
4.78,5.36, \\
5.97,6.58, \\
7.19,7.80, \\
8.41, \text { and } \\
9.02\end{array}$ & $\begin{array}{l}0.15,0.30 \\
0.61,1.83, \\
2.44,3.66 \\
4.88,6.10 \\
7.32,8.53 \\
9.75,10.67\end{array}$ \\
\hline $\begin{array}{l}\text { No. of sticks } \\
\text { at LNAPL } \\
\text { impacted } \\
\text { locations }\end{array}$ & 4 & 4 & 4 & 3 & 1 \\
\hline $\begin{array}{l}\text { No. of sticks } \\
\text { at } \\
\text { background } \\
\text { locations }\end{array}$ & 2 & 2 & 2 & - & - \\
\hline $\begin{array}{l}\text { Data } \\
\text { collection } \\
\text { frequency } \\
(\mathrm{min})\end{array}$ & 1 & 0.5 & 1 & 60 & 60 \\
\hline $\begin{array}{l}\text { Length of } \\
\text { record } \\
\text { (years) }\end{array}$ & 1.67 & 1.67 & 1.75 & 0.35 & 0.33 \\
\hline
\end{tabular}

Based on prior site investigations and studies, the thermal conductivity and heat capacity of unsaturated and saturated areas in all the study sites are assumed $0.96(\mathrm{~W} / \mathrm{m} / \mathrm{K}), 1.57$ $\left(\mathrm{MJ} / \mathrm{m}^{3} / \mathrm{K}\right), 1.46(\mathrm{~W} / \mathrm{m} / \mathrm{K})$, and $2.51\left(\mathrm{MJ} / \mathrm{m}^{3} / \mathrm{K}\right)$, respectively (Stockwell, 2015). The sediment density in the study sites is $2.65\left(\mathrm{gr} / \mathrm{cm}^{3}\right)$. The heat of full oxidation of decane $(6791 \mathrm{~kJ} / \mathrm{mol}$ (Stockwell, 2015)) is used to convert NSZD energy into estimates of LNAPL depletion rates. 


\subsection{Results}

\subsubsection{Confirmation of Solution and Algorithm}

Numerical Model Test - Figure 3.5 presents imposed and predicted values of $q_{s}$ and $q_{s s}$ for a 50-day computational test period. Predicted values are based on the single stick method. A statistical analysis of imposed and predicted values is provided in Table 3.3. Favorable agreement between imposed and temperature-derived $q_{s}$ and $q_{s s}$ values supports the validity of the single stick analytical solution and the computational algorithm.
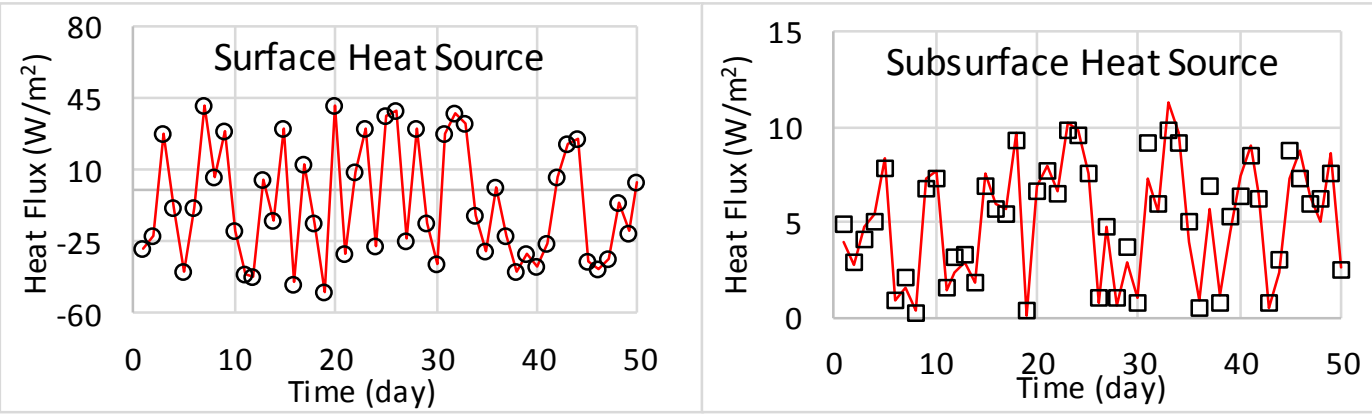

Figure 3.5. a) Prescribed values (black circles) and predicted values (red line) of $q_{s}$, b) prescribed values (black squares) and predicted values (red line) of $q_{s s}$

Table 3.3. Statistical evaluation of the performance of the single stick model

\begin{tabular}{|c|c|c|}
\hline Statistic & Surface heat source & Subsurface heat source \\
\hline RMSE & 0.021 & 0.700 \\
\hline $\mathbf{R}^{2}$ & 1.000 & 0.952 \\
\hline NSE & 1.000 & 0.944 \\
\hline d & 0.999 & 0.896 \\
\hline PE & -0.612 & 0.017 \\
\hline$\mu$ & -0.036 & -0.001 \\
\hline$\sigma$ & 0.021 & 0.704 \\
\hline
\end{tabular}

Comparison of observed and predicted temperature profiles - Figure 3.6 presents measured subsurface versus predicted subsurface temperature at Site-1 at three-month intervals over a one-year period. The predicted temperatures are based on daily estimates of $q_{s}$ and $q_{s s}$ 
obtained using the single stick method applied to Equation (3.9) and temporal best estimates of the position of the subsurface heat source. Table 3.4 provides a statistical analysis of agreement between simulated temperatures by the single stick method and the measured field temperature data from 0.15 and $1.83 \mathrm{~m}$ (bgs) for a 639-day period.

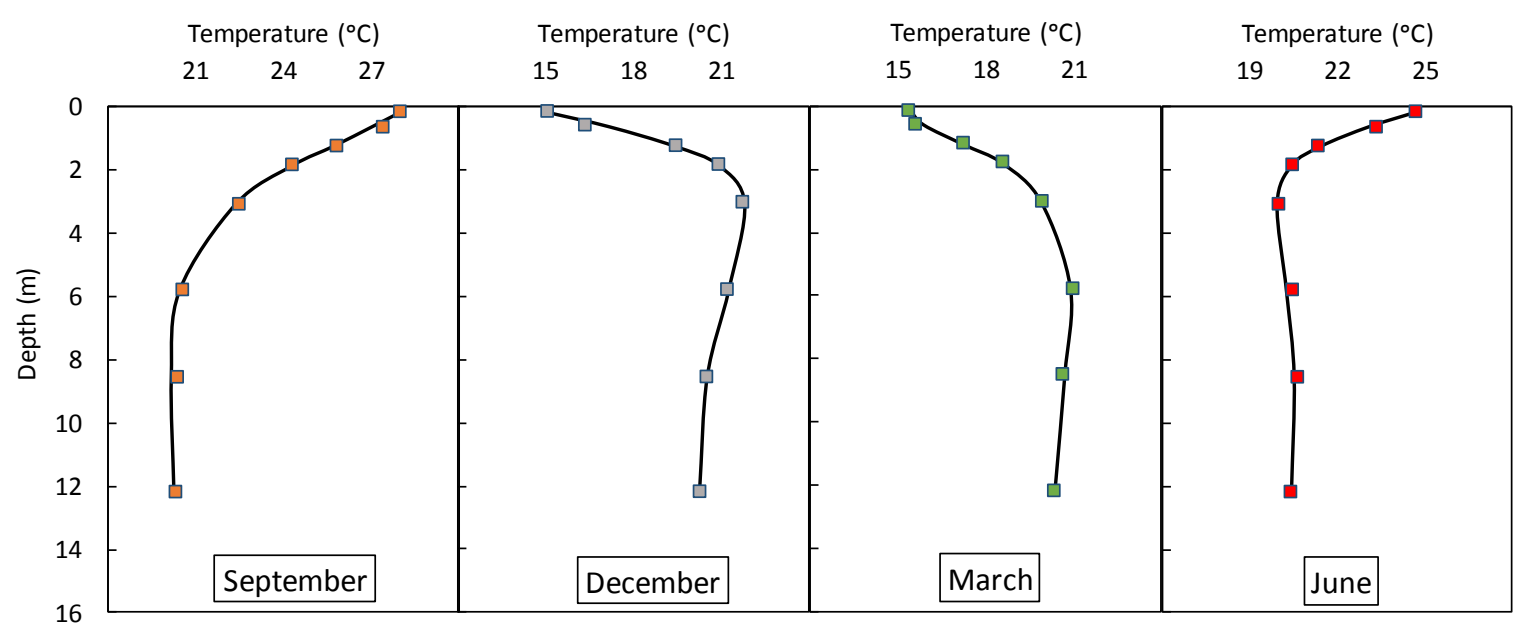

Figure 3.6. Measured subsurface temperature profile (squares) in a LNAPL-impacted location at Site-1 and simulated subsurface temperatures (solid line) from the single stick algorithm

Table 3.4. Statistical evaluation of the agreement between measured and simulated temperature data by the single stick algorithm

\begin{tabular}{|c|c|c|}
\hline \multirow{2}{*}{ Statistic } & \multicolumn{2}{|c|}{ Subsurface temperature } \\
\hline & $0.15(\mathrm{~m})$ & $1.83(\mathrm{~m})$ \\
\hline RMSE & 0.003 & 0.006 \\
\hline $\mathbf{R}^{2}$ & 1.000 & 1.000 \\
\hline NSE & 1.000 & 1.000 \\
\hline d & 0.999 & 0.998 \\
\hline PE & 0.000 & 0.001 \\
\hline$\mu$ & 0.004 & 0.006 \\
\hline$\sigma$ & 0.000 & 0.000 \\
\hline
\end{tabular}

Triplicate Test - Table 3.5 presents tabulated NSZD rates from three monitoring sticks at Site-4. As noted in Methods (3.4), the sticks are approximately $2 \mathrm{~m}$ apart in an equilateral 
triangle and, as such, they are considered to be a triplicate data set from a single location. Table 3.5 indicates the NSZD rates from the single stick method range from 24300 to $27100 \mathrm{~L} / \mathrm{ha} /$ year with a coefficient of variation equal to $6 \%$. In comparison, the coefficient of variation associated with a $\mathrm{CO}_{2}$ trap triplicate test, reported in McCoy et al. (2015), is $200 \%$ greater than the coefficient from the single stick method.

Table 3.5. Triplicate NSZD rates from $\mathrm{CO}_{2}$ trap and the single stick method for a 42-day period

\begin{tabular}{lll}
\hline Area & \multicolumn{2}{c}{ NSZD (L/Ha/year) } \\
\cline { 2 - 3 } & CO$_{2}$ Trap & single stick \\
\hline LNAPL (Triplicate 1 of 3) & 90900 & 25300 \\
\hline LNAPL (Triplicate 2 of 3) & 130000 & 24300 \\
\hline LNAPL (Triplicate 3 of 3) & 120000 & 27100 \\
\hline Average \pm Standard deviation & $113600 \pm 20300$ & $25600 \pm 1420$ \\
\hline
\end{tabular}

\subsubsection{NSZD Rate}

Comparisons of Single Stick and Background-Correction Methods - Figure 3.7 presents NSZD rates for the three sites using background-corrected and single stick methods. In general, all methods are in agreement within an order of magnitude. On average, estimated NSZD rates at LNAPL-impacted locations using background-correction methods advanced by Sale et al. (2015), Warren et al. (2015), and Karimi et al (2018), are respectively $11 \%$ and $44 \%$ lower and $155 \%$ greater than NSZD rates obtained using the single stick method. On average, estimated NSZD rates at background locations using Sale et al. (2015), Warren et al. (2015) and Karimi et al. (2017) are 4700, 3700, and $19000 \mathrm{~L} / \mathrm{ha} /$ year greater than the ideal value of zero liters per hectare per year. In contrast, the average NSZD rate at background locations obtained using the single stick method is $1900 \mathrm{~L} / \mathrm{ha} / \mathrm{year}$. It is plausible that the low single stick value of $1900 \mathrm{~L} / \mathrm{ha} / \mathrm{year}$ is due to the heat associated with natural attenuation of dissolved-phase petroleum compounds. 

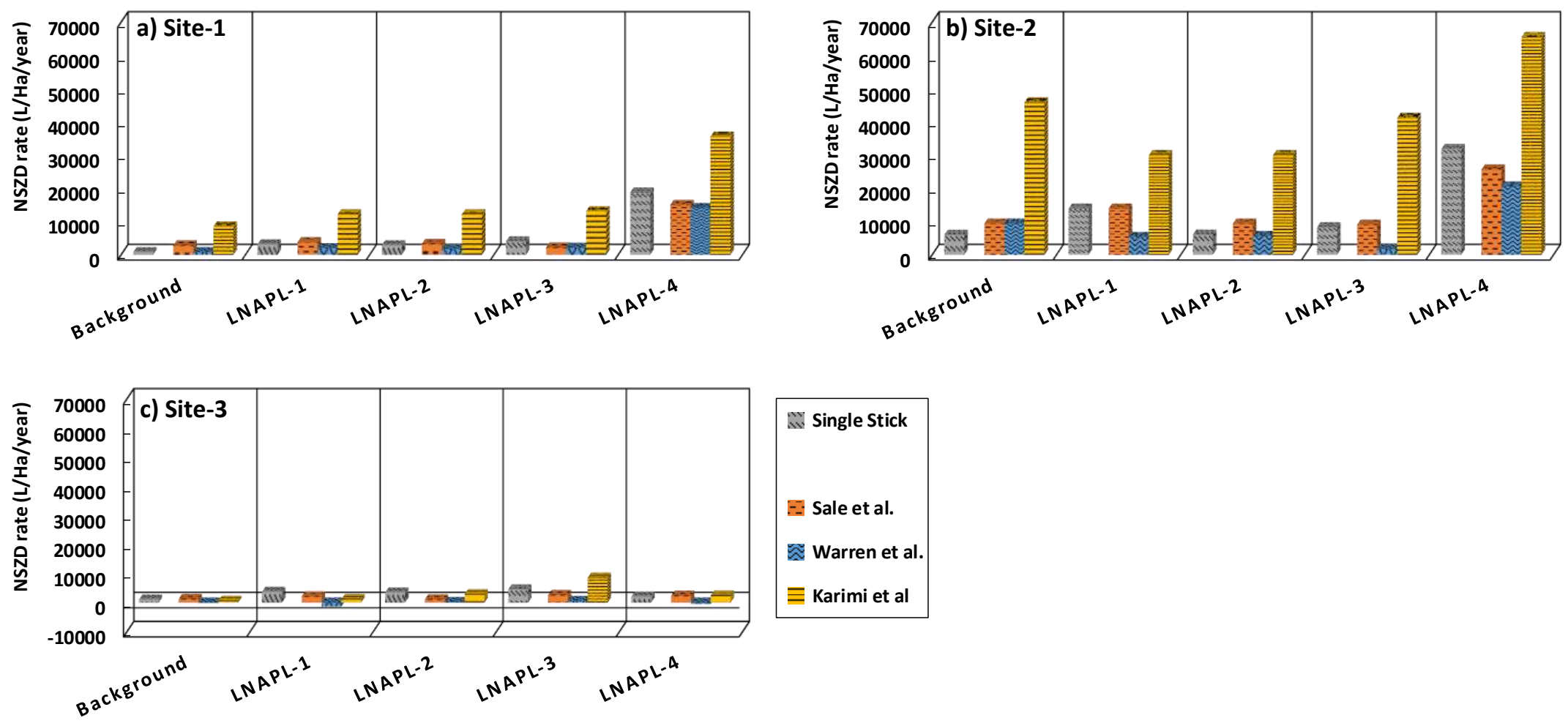

Figure 3.7. Annual average NSZD rate in background and LNAPL-impacted areas at a) Site-1, b) Site-2, and c) Site-3 


\section{NSZD Rate at a LNAPL-Impacted Location in a Site with No Background Location}

- Figure 3.8 presents average monthly NSZD rates based on daily values derived by the single stick method for an LNAPL location at Site-5. Average NSZD loss rate over a 100-day study period for this site is $13,000 \mathrm{~L} / \mathrm{ha} /$ year. Due to the absence of a representative LNAPL-impacted location with no LNAPL (i.e., a background location), the single stick method is the only approach applicable for estimation of NSZD rate in this location.

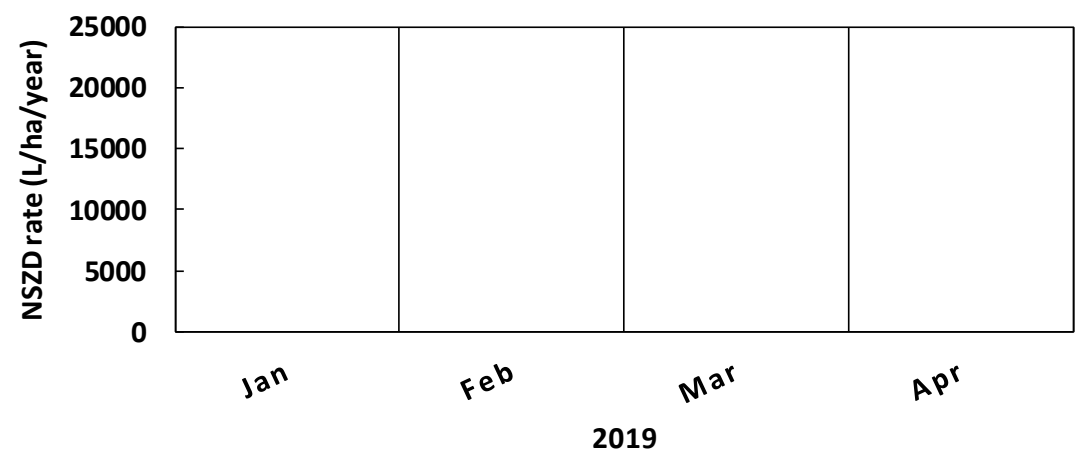

Figure 3.8. Average monthly NSZD rates by the single stick method in an LNAPLimpacted area at Site-5

Negative Rates - Figure 3.9 illustrates the site-wide monthly average of NSZD rates from the single stick method for Site-3 based on daily values. The periodic behavior of NSZD rates indicates the apparent NSZD rate increase during warmer/dryer seasons and decrease through the cooler/wetter seasons. The monthly average of NSZD rates demonstrates apparent negative values of NSZD rates for October 2017 to February 2018, when the monthly average water content in shallow soil and evapotranspiration (ET) approached their maximum and minimum values, respectively (Figure 3.9). The water content and evapotranspiration data were obtained from Giovanni online data system, developed and maintained by the NASA GES DISC (Xia et al., 2012a, 2012b). 


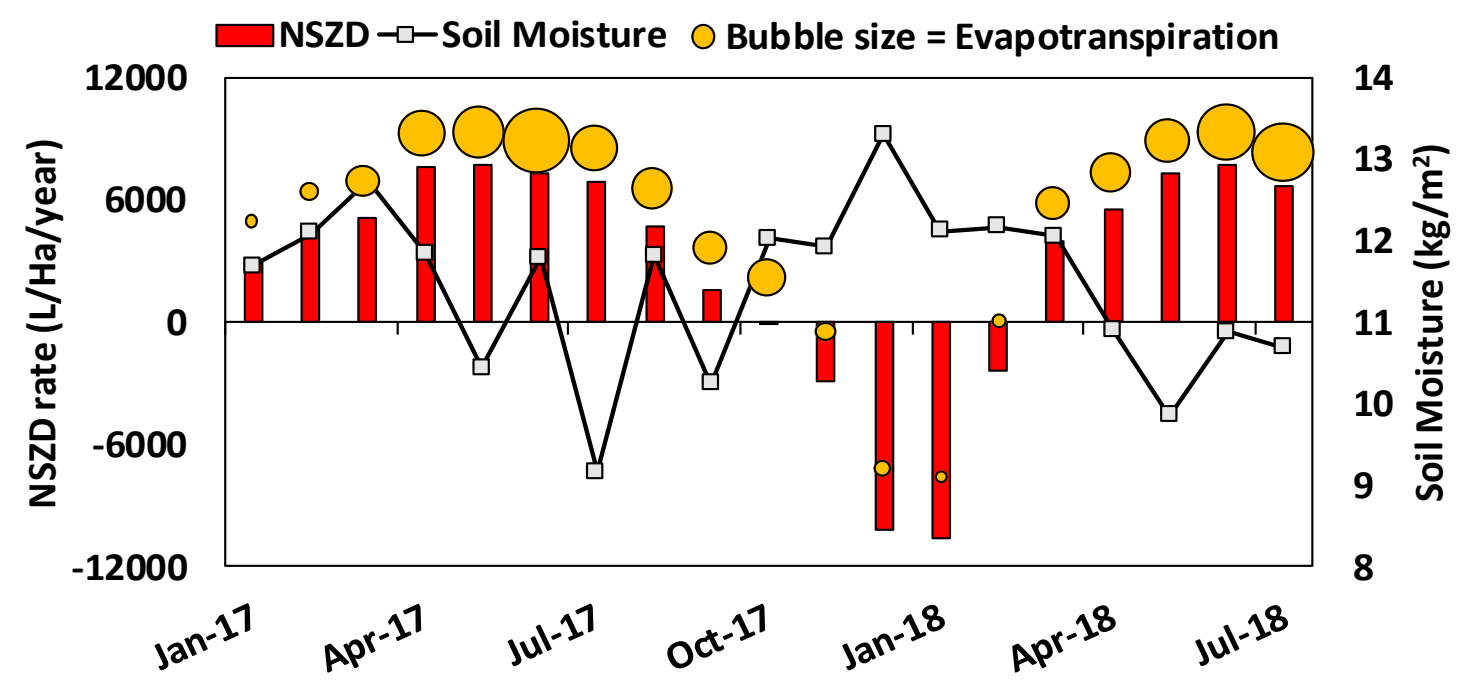

Figure 3.9. Average of evapotranspiration, shallow soil moisture, and site-wide monthly average of NSZD rates calculated by the single stick method in Site-3

\subsection{Discussions}

\subsubsection{Confirmation of Solution and Algorithm}

Three lines of evidence were considered to evaluate the validity of the single stick method and supporting computational algorithms. Collectively, close agreement is seen between 1) estimated and numerically synthesized $q_{s}$ and $q_{s s}$ values, 2) observed and modeled subsurface temperature profiles, and 3) NSZD rates at three co-located sticks. Based on the three analyses, it seems likely that the single stick method (including underpinning assumptions), mathematical formulations, and computational algorithms, are largely valid. Perhaps the most compelling argument for validity is that, absent accurate estimates of $q_{s}$ and $q_{s s}$, it seems improbable that the close agreement between modeled and observed subsurface temperatures in Figure 3.6 and Table 3.4 could be achieved. 


\subsubsection{NSZD Rate}

Development of the single stick method was motivated by concerns regarding occasionally 1) implausible NSZD rates in areas where there is no LNAPL, 2) negative NSZD rates, and/or 3) improbably large NSZD rates in areas with LNAPL. The ability of the single stick method to address these concerns is explored in the following discussion.

With respect to implausible NSZD rates in areas where there is no LNAPL, continuous cryogenically collected core (following the methods of Kiaalhosseni et al. (2017)) was collected at the background location in Site-1. No LNAPL and $\mathrm{mg} / \mathrm{L}$ dissolved-phase hydrocarbon concentrations in groundwater were observed at the background location in Site-1. Based on Figure 3.7, temperature-based estimates of annual average NSZD rates for the background location in Site-1 are 4,700, 9,400, 9,400, and 46,000 liter per hectare per year using the single stick method, Sale et al. (2015), Warren et al. (2015), and Karimi et al (2018), respectively. Although the lowest NSZD rate at the background location in Site-1 resulted from the single stick method, the rates from both background-correction and single stick methods at this location are apparently high. The high apparent NSZD rates at background location in Site-1 can be explained by: 1) produced warm water in the subsurface due to different processes occurring in an active refinery, 2) the heat produced through natural attenuation of dissolved-phase petroleum compounds in groundwater, and 3) insufficient subsurface temperature data.

Figure 3.10 presents the average of predicted NSZD rates from all background locations in Site 1,2, and 3. The data indicate that estimated average NSZD rate by the single stick method is $55 \%, 106 \%$, and $750 \%$ lower than NSZD rates obtained using Warren et al. (2015), Sale et al. (2015), and Karimi et al. (2018), respectively. Our hypothesis is that the lower, more plausible, NSZD results at background locations using the single stick method are attributed to elimination 
of background corrections that can be flawed in space and/or time. Overall, an ability to achieve low NSZD rates at locations where LNAPL is absent suggests that the single stick method is more accurate than background-correction methods.

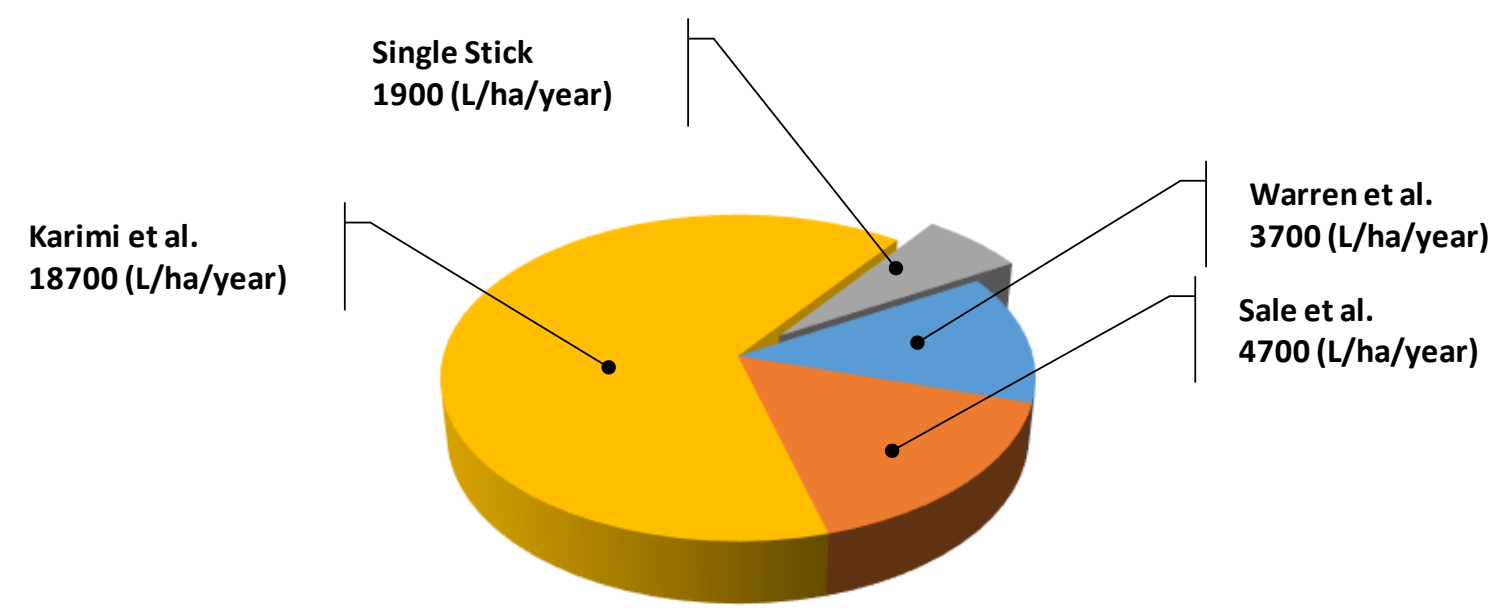

Figure 3.10. Average of NSZD rates calculated by the single stick method and background correction method for all background locations.

With respect to negative NSZD rates, negative rates have been a chronic concern with temperature-based estimates of NSZD rates. A primary hypothesis for negative NSZD rates has been flawed background correction, wherein surface heating and cooling at background locations are occasionally significantly different than surface heating and cooling at impacted locations. The method of Karimi et al. (2018) addresses negative NSZD rates by treating them as zero rates based on implausibility. The methods of Sale et al. (2015) and Warren et al. (2015) include negative NSZD rates in averaged rates. Inclusion of negative rates can be justified based on an assumed normal distribution of errors in the estimated NSZD rates.

Unfortunately, per Figure 3.9, the single stick method elimination of the background correction has not eliminated occasional negative NSZD rates. This result has led to an 
additional hypothetical explanation for negative NSZD rates. Based on Table 3.1, NSZD consists of two reactions. First, methanogenesis is an endothermic reaction that occurs primarily in the LNAPL zone. Second, methane is oxidized above the LNAPL zones via an exothermic reaction occurring at an interface where oxygen encounters methane. An argument can be advanced that sites and/or times with negative NSZD rates correlate to shallow soil with high water content, including frozen ground that precludes oxygen entry into the subsurface (Figure 3.9). Exclusion of oxygen could lead to methanogenesis being the primary reaction and endothermic cooling producing apparent negative NSZD rates. Support for the hypothesis of endothermic cooling can be found in ongoing methanogenic laboratory column studies where the column soils are consistently 0.2 to $0.6{ }^{\circ} \mathrm{C}$ cooler than room temperatures. Given endothermic cooling, negative rates are not a basis for invalidating temperature-based NSZD rates, and negative rates should be included in cumulative estimates of NSZD rates. Further work is needed to fully resolve the basis for apparent negative NSZD rates obtained from temperature data and the implications of negative rates with respect to the accuracy of temperature-based estimates of NSZD rates.

With respect to large NSZD rates in areas with LNAPL, mean values from all data sets are 21,500, 4,700, 7,500, and 8,400 L/ha/year, using the methods of Karimi et al. (2018), Warren et al. (2015), Sale et al. (2015), and single stick, respectively. The highest values coming from the methods of Karimi et al (2018) is attributed to exclusion of negative rates, as described in the preceding paragraph. On average, the remaining three approaches provide lower and similar results. Unfortunately, variation between high and low values as large as a factor of -4.4 to 18.5 (Figure 3.7) at individual locations for the same time period indicate that the methods of Sale et al. (2015), Warren et al. (2015), and single stick are not equivalent. Based on technical rigor, 
including elimination of background correction errors, an argument can be advanced that the single stick method is likely to provide the best estimates of NSZD rates.

Unfortunately, technical rigor alone is an insufficient basis for resolving which method provides the best estimates of NSZD rates. Currently, work is ongoing to collect and analyze cryogenic core at benchmark locations at all of the sites considered in this study. Observed changes in subsurface LNAPL concentration over time (e.g., 3 to 5 years) will be used to independently verify NSZD rates and further resolve the merits of available methods for transforming temperature data into NSZD rates.

\subsubsection{Merits-Limitation of the Single Stick Method}

As stated in the introduction, a primary objective of the paper is to resolve meritslimitation of the single stick method with respect to other temperature-based methods of estimating NSZD rates. To the positive, eliminating a need for background temperature is valuable. Background correction requires additional data collection at a sufficient number of locations to capture surface heating and cooling at impacted locations. Furthermore, at many sites, finding representative background locations is difficult or infeasible. In addition, eliminating background corrections eliminates the errors that are inherent with imperfect background correction. Lastly, an ability to provide lower (near zero) estimates of NSZD rates in areas where there is no LNAPL is a positive. Arguably, methods that predict higher NSZD rates where LNAPL is absent are less valid than methods that yield lower NSZD rates where LNAPL is absent.

To the negative, the single stick method is computationally complex as compared to the methods of Sale et al. (2015) and Warren et al. (2015). Currently, the single stick code requires access to MATLAB $^{\circledR}$, and the single stick code is not publically available. Given the ambiguity 
as to the merits of the single stick method versus background correction methods, it is difficult to argue that the benefits of the single stick method outweigh the costs of more complicated single stick computational methods. To resolve access to the single stick method, efforts are ongoing to move collected data and the single stick code to a cloud-based computing space where it will be combined with soil redox, water level, and climate data to provide a comprehensive sensor-based data set for monitoring subsurface conditions.

\subsection{Conclusion}

Herein, a novel single stick computational approach is advanced for transforming subsurface temperature data from LNAPL zones into NSZD rates. Reliance on temperature data to resolve NSZD rates has the advantage over gas fluxes methods of providing continuous NSZD rates in potentially dynamic systems where sparse temporal data can be poor indictors of average rates. Also, the single stick method has the advantage over other thermal methods of not requiring background temperature data to resolve heat associated with NSZD. The benefits of eliminating background correction are two-fold, including eliminating 1) the need for collecting background data and 2) the errors that can be inherent to background-correction approaches.

Arguments supporting the validity of the single stick method include its strong foundation in first principles, favorable results from computational tests that show close agreement between imposed and predicted heating fluxes, favorable agreement between observed and predicted subsurface temperatures, and lower NSZD rates at background locations. While the merits of the single stick method can be advanced, it is difficult to argue that the single stick method is clearly the best approach to obtaining NSZD rates. Certainly, the computational methods for temperature data of Sale et al. (2015) and Warren et al. (2015) are computationally more practical and, in the big picture, tell a similar story of NSZD rates of 1000s to 10000s of 
L/ha/year. Also noteworthy, following arguments advanced in Cohen (2013), there is a tendency for averaged NSZD rates to move to similar values, using the methods described in this paper, as the number of measured values gets large.

Much work is ongoing to further resolve the accuracy of estimated NSZD rates and processes. These developments include using cryogenic coring methods to independently validate measured NSZD rates. Unfortunately, it will take time for NSZD to deplete enough LNAPL for accurate quantification of NSZD rates using cryogenic coring methods. On another path, nascent efforts are ongoing to combine soil oxidation reduction potential (SORP) data (Burge, 2018) and water-level data with temperature data. Synergistically, in a world of big data; artificial intelligence; and machine learning, interdependencies of SORP, water-level, and temperature data are leading to a better understanding of NSZD processes and the appropriate niche for NSZD in managing LNAPL sites. 


\section{CHAPTER 4.}

\section{REAL-TIME, IN-SITU THERMAL CONDUCTIVITY MEASUREMENT OF SOIL}

\subsection{Chapter Synopsis}

Soil thermal conductivity is an essential parameters in subsurface heat transfer models including methods for calculating natural source zone depletion (NSZD) rates at petroleum hydrocarbon sites. This chapter proposes new Internet of Things (IoT) equipment and a computational method for measuring real-time, in-situ thermal conductivity of soil. An experiment was conducted at a field site with different soil textures with depth. The results indicate that thermal conductivity is strongly influenced by soil water content and soil particle size. The greatest values of thermal conductivity were measured in the saturated soil containing gravelly sand with quartz, while the smallest values were associated with unsaturated soil including silt and clay. The agreement between thermal conductivities derived from this experiment and prior studies supports the validity of the IoT device and the computational method. Overall, this newly-developed approach for estimating in-situ thermal conductivity values offers the potential for better data at lower cost as compared to conventional methods.

\subsection{Introduction}

Knowledge of the thermal properties of soils is significant for determination of heat flow and modeling heat transport in subsurface media. Determination of in-situ thermal conductivity has been well studied because of considerable applications in geophysics (Jolivet and Vasseur, 1982; Kristiansen, 1982), super-deep drill hole studies (Burkhardt et al., 1990, 1995), geothermal energy exploration (Behrens et al., 1980; Mussmann and Kessels, 1980), ground heat exchangers researches, and nuclear waste disposal, as well as other studies in different types of industrial 
waste materials with thermal relevance or heat generation (Chan and Jeffrey, 1983; Tan and Ritchie, 1997; Askarani et al., 2016; Ghazizadeh et al., 2018; Ghazizadeh et al., 2019). In addition, ground thermal conductivity is a crucial parameter for assessing NSZD rates using subsurface temperatures, since all available methods for transforming temperature data to NSZD rates rely on Fourier's law (Karimi et al., 2018).

One of the simplest ways to determine in-situ thermal conductivity that can reduce measurement error is to insert a needle sensor into a sample of a solid or porous material to measure the temperature increase in response to an input heat with controlled rate along the probe (Choudary, 1976; Komle, 2011; Knight et al., 2016). This idea was first introduced by Schleiremachen in 1833 and was developed to the point of being practical in the 1950's (Austin, 1995). The primary analytical direct models used to calculate thermal properties by evaluating thermal-response data are line-source (Mogensen, 1983) and cylinder-source (Ingersoll, 1954) approaches (Bristow et al., 1994; Różański et al., 2013).

In-situ measurement of thermal conductivity has some advantages over laboratory assessment, such as the ability to measure thermal properties in the prevailing ambient condition and thereby helping to evaluate thermal conductivity of heterogeneous soil without the need for core drilling (Kukkonen, 1999). However, some limitations associated with the probes and setups used for measuring in-situ thermal properties include: difficulties with fabrication and installation, long-term test time, mechanical weakness of probes, measurement error associated with less favorable length to diameter ratios, instantaneous measurement, and cost.

\subsection{Research Objective}

The central objective of this chapter is to introduce cost-effective IoT equipment and a simple computational method that resolves real-time, in-situ thermal conductivity of soil profiles. 
The approach addresses the primary limitations of conventional techniques (e.g., laboratory studies) for measuring in-situ thermal conductivity of soil.

\subsection{Methods}

This section describes the equipment, derived computational model, and the study site where the in-situ thermal conductivity of soil profile has been calculated.

\subsubsection{Equipment}

A vertical string of digital temperature sensors referred to as "sticks" were used to acquire subsurface temperature. The use of digital temperature sensors (DS18B20, Adafruit Industries, NY) with $+/-0.5{ }^{\circ} \mathrm{C}$ accuracy allows for the implementation of large number of sensors $(10$ - 100) on a single cable of three wires, as compared to traditional thermocouples. As shown in Figure 4.1, the temperature sensors are soldered on custom carrier printed circuit boards (PCBs) and to specific wire lengths with a custom 3D-printed plug attached. In a 3/8-inch SCH40 clear PVC tube containing the sensors, each sensor is potted in clear epoxy $\left(3 \mathrm{M}^{\mathrm{TM}}\right.$ Scotch-Weld ${ }^{\mathrm{TM}}$ Epoxy Potting Compound/Adhesive DP270; at $43{ }^{\circ} \mathrm{C}$ on $0.006 \mathrm{~m}$ samples $\mathrm{K}=17.7 \mathrm{~W} / \mathrm{m} / \mathrm{K}$ ), to protect the electronics from the outside environment and permanently hold the sensor in place. A heating strip (heat trace wire) is attached to the outside of the PVC stick with zip-ties to secure it in place during installation. The heating element is a $7.3 \mathrm{~m}$ long strip with an output of $33 \mathrm{~W} / \mathrm{m}$ and a maximum temperature of $149{ }^{\circ} \mathrm{C}$ (Arctic Trace ${ }^{\circledR}$, du Alaska Incorporated, Anchorage, Alaska). The heat trace wire can be powered remotely by a $120 \mathrm{~V}$ generator or direct current. 


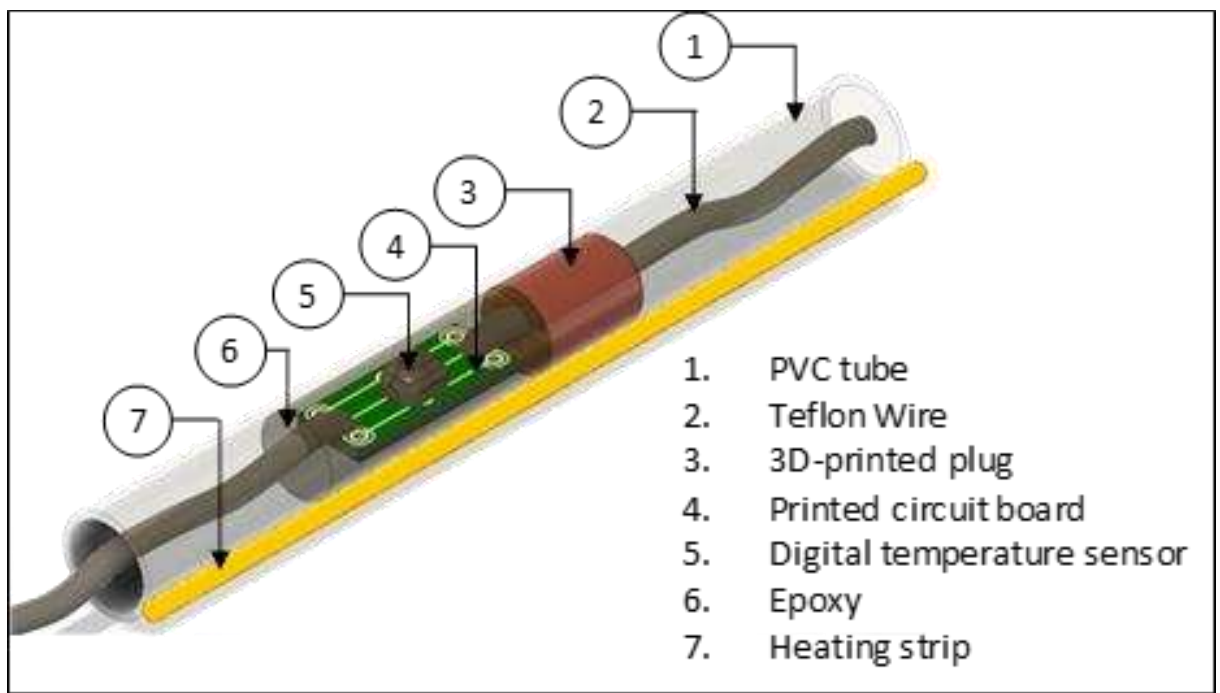

Figure 4.1. Scheme of a sensor in a stick with attached heating strip

The sensors are connected to a cellular micro-controller (Particle Electron), running on a 3.7V 4400mAh lithium-ion battery (Adafruit Industries, NY), that is charged through a solar charger (Adafruit Industries, NY) powered by a 2W 6V solar panel (Voltaic Systems, Brooklyn, NY) (Figure 4.2). The monitoring system reads temperature data every five minutes and sends the data over a cellular network to an online database for storage, analysis, and visualization. The cellular micro-controller, solar charger, and battery are housed inside a NEMA4 weatherproof enclosure (Nema Enclosures, Houston, TX). The solar panel is mounted directly on top of the enclosure.

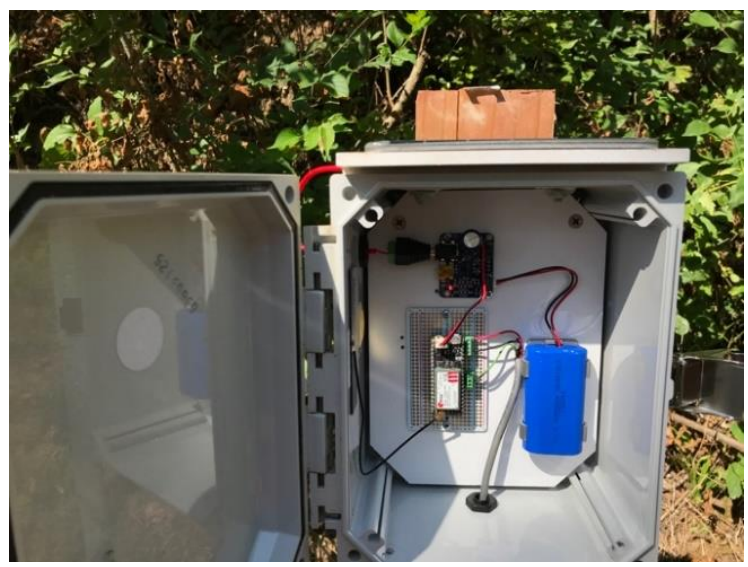

Figure 4.2. Data acquisition system 
Laboratory studies were conducted to test the uniformity of digital temperature sensors. In this laboratory test, each digital temperature sensor was submerged in a 10-inch PVC pipe, with a pump constantly circulating water for a 24 -hour period. The actual sensors used in the thermal monitoring stick fell within $\pm 0.15^{\circ} \mathrm{C}$ of the group mean temperature.

\subsubsection{Temperature Data Collection}

The stick was installed in soil below an asphalt access road, as shown in Figure 4.3. The stick consists of 18 digital temperature sensors at $0.15,0.30,0.61,0.91,1.22,1.83,2.44,3.05$, $3.66,4.27,4.88,5.49,6.10,6.71,7.32,7.92,8.53$, and $9.14 \mathrm{~m}$ below ground surface (bgs). The stick was installed in a $0.21 \mathrm{~m}$ diameter borehole completed using hollow stem auger. The annular space between the borehole and the formation was backfilled with medium sand and a bentonite seal was placed at the surface. The weatherproof enclosure was mounted to a $1.23 \mathrm{~m}$ fencepost in the roadside. Collection of temperature data at the site began on August 1, 2018. The heating strip was powered on for about 100 minutes and then shut off.

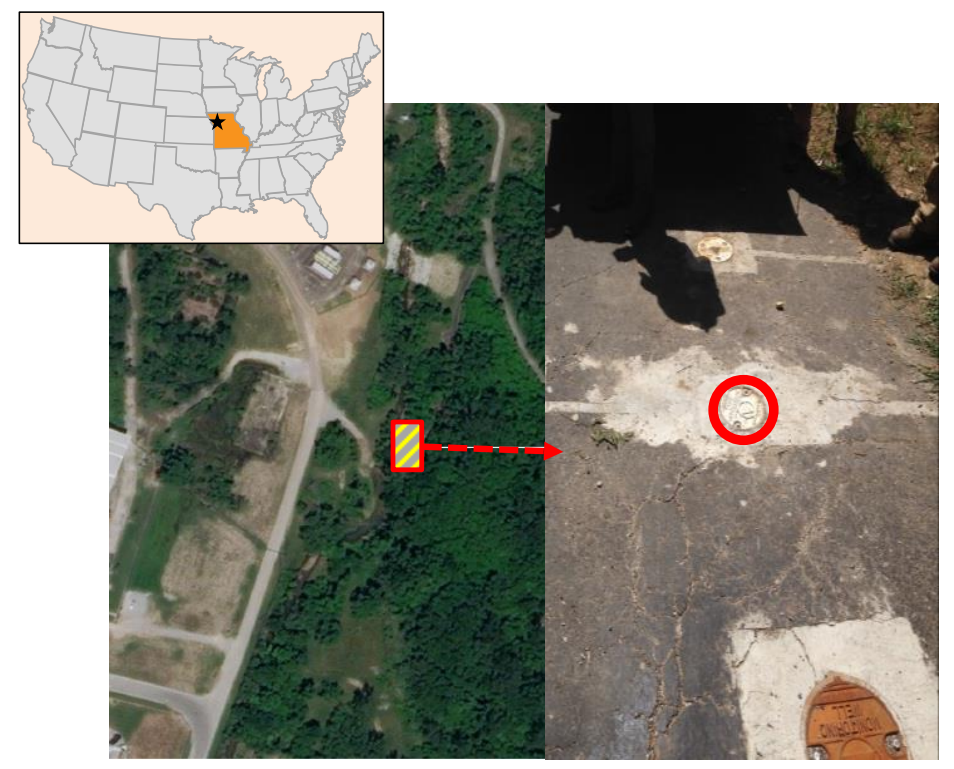

Figure 4.3. Study site with location of temperature monitoring stick 


\subsubsection{Computational Model}

In the following section, the solution of heat conduction equation for axisymmetric configurations that supports estimation of thermal conductivity is explained.

The heat conduction equation in a solid body with homogenous structure is described by:

$\frac{\partial^{2} T}{\partial x^{2}}+\frac{\partial^{2} T}{\partial y^{2}}+\frac{\partial^{2} T}{\partial z^{2}}=\frac{1}{\kappa} \frac{\partial T}{\partial t}$

where $T$ is temperature at position $(x, y, z)$ and time $t$, and $\kappa$ is thermal diffusivity $\left(\mathrm{m} / \mathrm{s}^{2}\right)$.

Following Carslaw and Jaeger (1959), the temperature in a three-dimensional space at any position and time in response to an instantaneous point source of heat at $(\dot{x}, \dot{y}, z ́)$ is derived as a solution of Equation (4.1) by:

$T(x, y, z, t)=T_{0}+\frac{S_{\text {point }}}{8(\pi \kappa t)^{3 / 2}} \exp \left(-\frac{(x-\dot{x})^{2}+(y-\dot{y})^{2}+(z-\dot{z})^{2}}{4 \kappa t}\right)$

where $T_{0}$ is the temperature of the medium before the release of the heat pulse, and $S_{\text {point }}$ is the instantaneous point source strength $\left(\theta \mathrm{L}^{3}\right)$.

Integration of Equation (4.2) over $z$ can describe the temperature distribution caused by an instantaneous line heat source along $\mathrm{z}$-axis in a medium as:

$T(r, t)=T_{0}+\frac{S_{\text {line }}}{4 \pi \kappa t} \exp \left(-\frac{r^{2}}{4 \kappa t}\right)$

where $r$ is the radial distance of a point from the line source $\left(r=\sqrt{(x-\dot{x})^{2}+(y-\hat{y})^{2}}\right)$, and $S_{\text {line }}$ is instantaneous line source strength $\left(\theta \mathrm{L}^{2}\right)$. If the line source releases constant heat from $\mathrm{t}=0$ to $\mathrm{t}=\mathrm{t}$, by integrating Equation (4.3) over the time interval, the temperature distribution is expressed as:

$T(r, t)=T_{0}-\frac{Q}{4 \pi K} E i\left(-\frac{r^{2}}{4 \kappa t}\right)$ 
where $Q$ is the rate of heat emission from the line source per unit length $\left(\mathrm{ML} / \mathrm{T}^{3}\right)$, and $-E i\left(-\frac{r^{2}}{4 \kappa t}\right)=-\gamma-\ln \left(\frac{r^{2}}{4 \kappa t}\right) \cdot \gamma$ is Euler's constant, which is equal to 0.577216. Thus, Equation (4.4) can be written as:

$T(r, t)-T_{0}=\frac{Q}{4 \pi K}\left(-\ln \frac{r^{2}}{4 \kappa t}-0.5772\right)$

The temperature increase $\left(s(t)=T(r, t)-T_{0}\right)$ in response to the heat released from a line source can be approximated by the Cooper-Jacob method (1946) as:

$s(t)=\frac{2.3 Q}{4 \pi K} \log \left(\frac{2.25 \kappa t}{r^{2}}\right)$

Finally, the residual temperature after turning off the heat source is expressed by:

$\dot{S}(t)=\frac{2.3 Q}{4 \pi K} \log \left(\frac{t}{\hat{t}}\right)$

where $t$ is the time after the release of heat is stopped.

The gradient of semi-log of $s$ versus $t / t$ is equal to $\frac{2.3 Q}{4 \pi K}$. As a result, thermal conductivity can be determined by measuring temperature decay in a medium after the release of heat from a line source when the rate of $Q$ is zero.

Note that the above solution is valid for the evaluation of thermal conductivity in a thermal response test if the following assumptions are fulfilled:

1. Conduction is the only mechanism governing the heat transfer in the ground.

2. Convective heat transfer is negligible.

3. The flow of heat is symmetric in the radial direction perpendicular to the line source.

4. Conductive heat transfer in the vertical direction is negligible.

5. The ratio of length to radius of heat trace wire is large enough to represent an infinite line source.

6. Heat is released with a constant rate along the line source. 
7. The backfilled annular space between stick and soil profile is negligible.

\subsubsection{Study Site}

The study site is a former refinery located within the Missouri River basin along the

south shore of the Missouri River in the central United States, as illustrated in Figure 4.3. Analysis of collected core using cryogenic technique (Kiaalhosseini et al., 2016) demonstrates that the vadose zone is comprised of primarily clayey silt to silty clay, underlying silts and clay with occasional sands, and some gravel advancing to the saturated zone with occasional interbedded sands and gravels. Groundwater flows to the east and discharges to a local creek. Based on the site-specific hydraulic conductivity, porosity, and horizontal gradients, the estimated average horizontal groundwater flow velocity ranges from 0.006 to 0.017 (m/d).

\subsection{Results and Discussion}

\subsubsection{Temperature Data}

Figure 4.4 shows measured temperature data from multiple positions in the subsurface in response to turning the heat trace wire on and off. Subsurface temperature increased in the heating period. Right after the heat release terminated, temperature decay began. As illustrated in Figure 4.4, no change in subsurface temperatures exists in the depths below the heating strip (i.e., $7.92,8.53$, and $9.14 \mathrm{~m}(\mathrm{bgs})$ ), supporting the validity of assumption that conduction of heat in the vertical direction is negligible. The significant difference between temperature responses at 1.75 , 2.36, and $2.97 \mathrm{~m}$ (bgs) reflect differences in water content, entrapped air, and soil texture throughout the soil profile. 


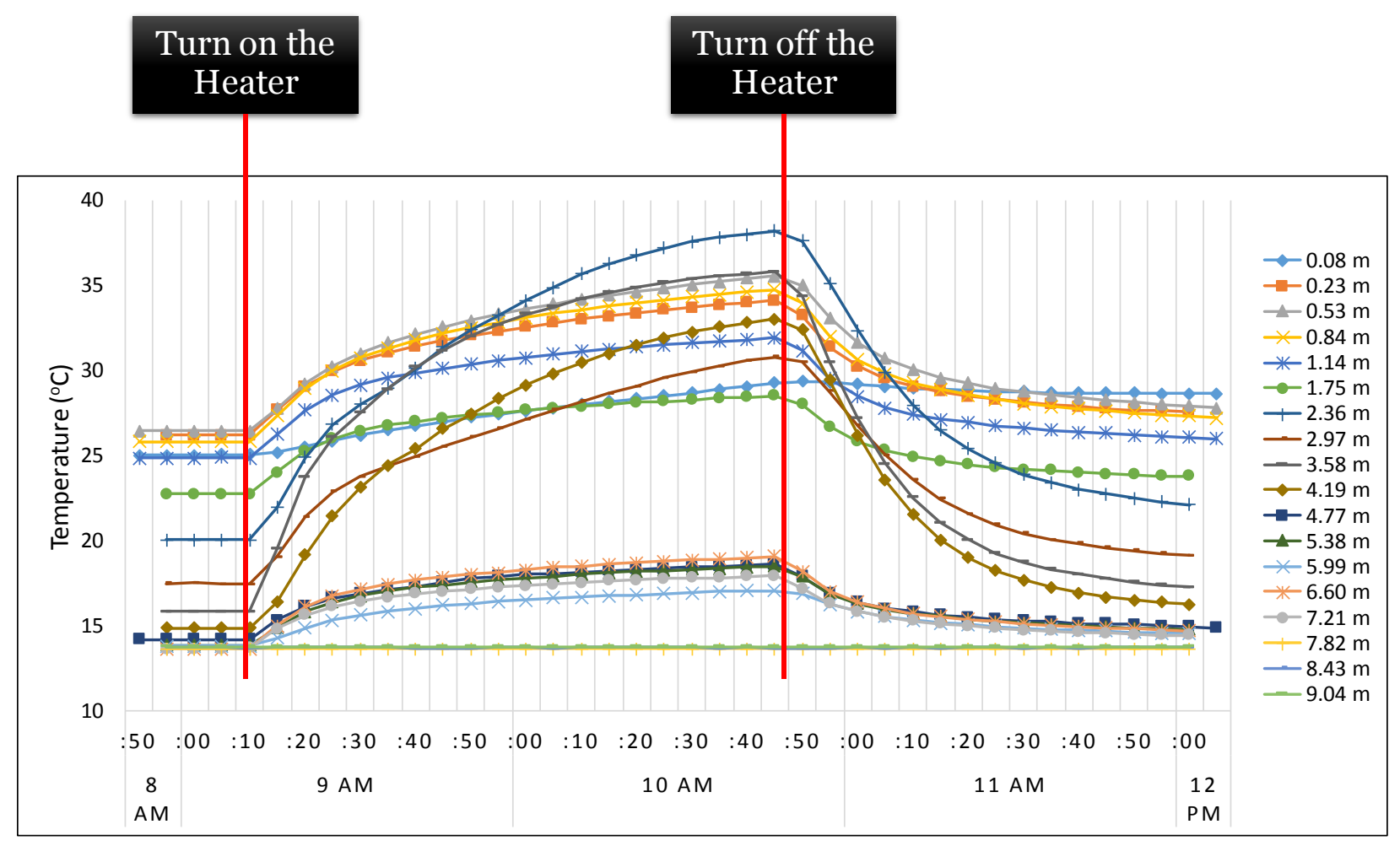

Figure 4.4. Measured subsurface temperatures at multiple positions during and after heating test

\subsubsection{Heating and Cooling Period}

The change in subsurface temperatures during and after the heating test is identical to the drawdown and recovery curve versus time in an aquifer test where water levels are measured at the well, as shown in Figure 4.5a. To use the temperature responses measured during the injection and dissipation of heat in the Cooper-Jacob method, the temperature decay curve in a semi-log scale for each position is required. Figure $4.5 \mathrm{~b}$ indicates the semi-log of residual temperature versus $(t / \hat{t})$ at $0.61 \mathrm{~m}$ (bgs). The plots related to other depths are provided in Appendix B. 


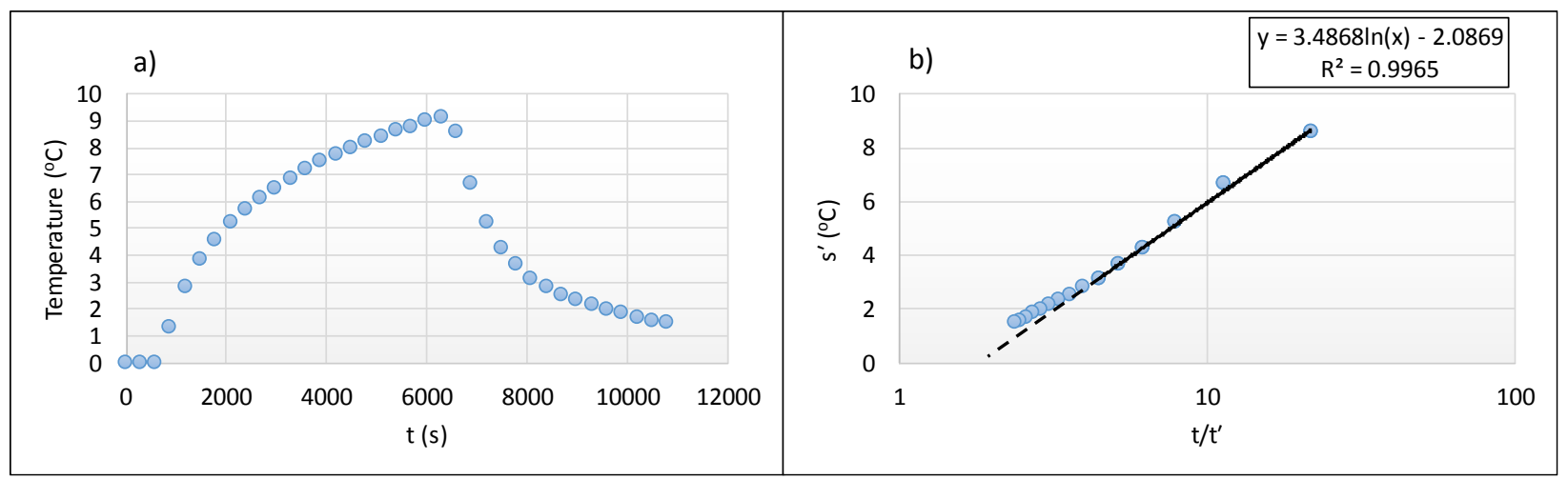

Figure 4.5. a) Change in subsurface temperature through the heating and dissipation of heat at $0.61 \mathrm{~m}$ (bgs) and b) semi-log of residual temperature versus $(t / t)$ at $0.61 \mathrm{~m}(\mathrm{bgs})$

\subsubsection{Thermal Conductivity}

Substituting the gradient of linear regression over the linear part of $s$ versus $t / t$ (Figure 4.5b) in Equation (4.7), at any depth where the temperature is measured, yields in-situ thermal conductivity of soil profile, as shown in Figure 4.6. In the upper $1.83 \mathrm{~m}$ of the soil profile containing silt and clay with low plasticity (CL and ML), thermal conductivity ranges from 1.7 to $2.8(\mathrm{~W} / \mathrm{m} / \mathrm{C})$. Although the expected values of thermal conductivity for dry fine-grain soils are lower than calculated values by an order of magnitude, the soil water content can affect this difference. Increasing water content replaces the poor contact between dry soil particles due to filled pores with air $\left(\mathrm{K}_{\mathrm{air}}=0.023 \mathrm{~W} / \mathrm{m} / \mathrm{C}\right)$ with highly conductive water bridges $\left(\mathrm{K}_{\text {water }}=0.58\right.$ $\mathrm{W} / \mathrm{m} / \mathrm{C}$ ) (Nikoforova et al., 2013). As shown in Figure 4.6, thermal conductivity of the middle part of the soil profile (2.44 to $4.27 \mathrm{~m}(\mathrm{bgs}))$ is $0.79(\mathrm{~W} / \mathrm{m} / \mathrm{C})$ on average, which is in agreement with the derived values from previous studies for fine-grain soils with the water content around 25\% (Tarnawski et al, 2015; Fricke et al., 1997; Kersten et al., 1949). As illustrated in Figure 4.6, in the middle part of the soil profile the soil moisture obtained using cryogenic cores is around $29 \%$ in average. 


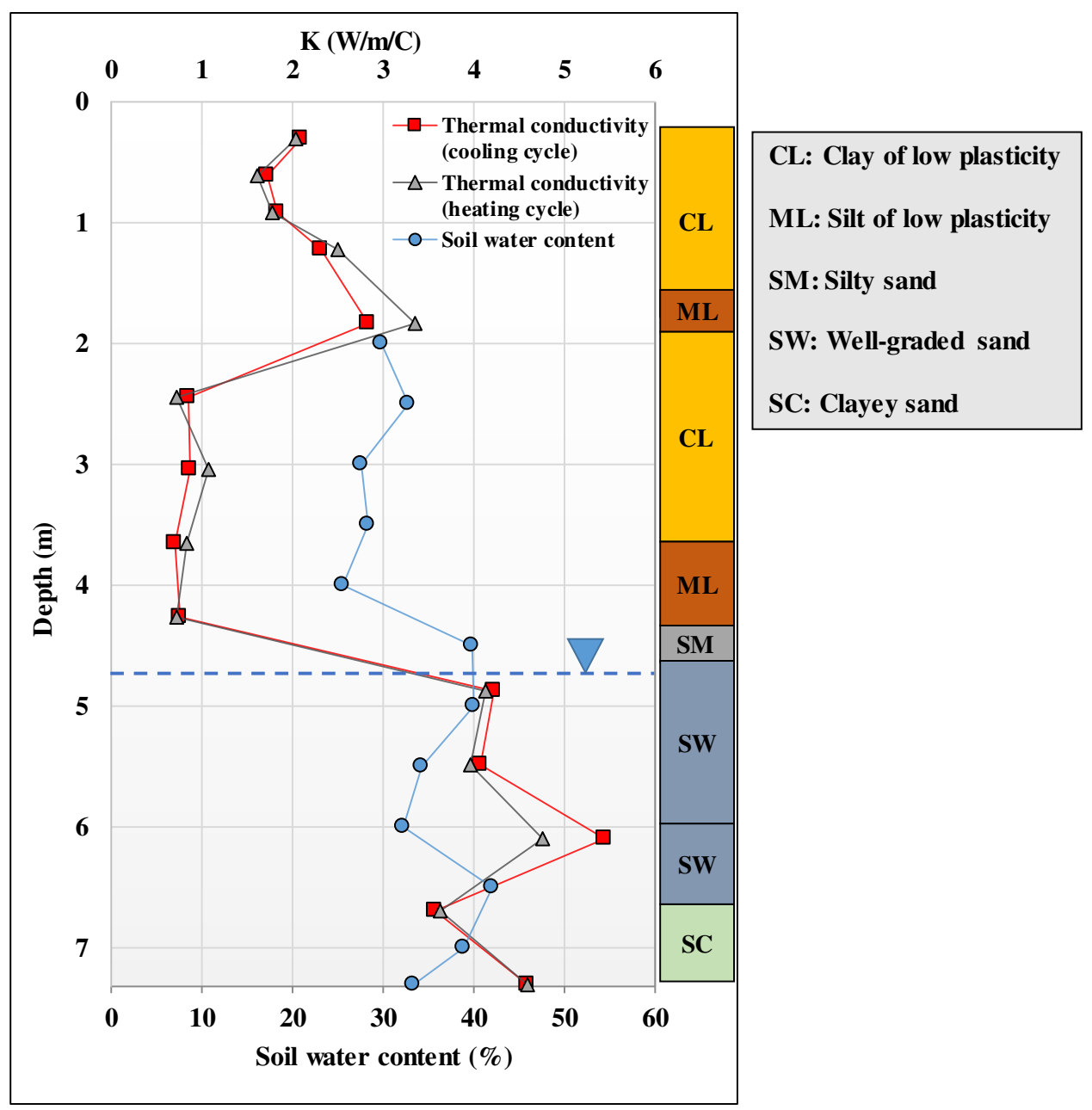

Figure 4.6. In-situ thermal conductivity of the soil profile

Figure 4.6 illustrates the highest values of thermal conductivity were obtained in the saturated area containing coarse-grain soils. The highest values of thermal conductivity in the saturated area can be explained by the fact that as the grain size increases, less particles are necessary for the same porosity leading to less thermal contact resistance. Moreover, investigation of cryogenic cores collected from this location shows the presence of quartz $(\mathrm{K}=$ 7.7 W/m/C) in the saturated soils, making the thermal conductivity higher (Tarnawski, 2015).

In addition to derived thermal conductivities using temperature responses in cooling period (i.e., residual temperature), following ASTM D5334-05 thermal conductivity of soil 
profile was calculated using the temperature responses in heating period substituted in Equation (4.7) as shown in Figure 4.6. A $0.66 \%$ difference between the averages of calculated thermal conductivities obtained based on temperature responses in heating and cooling cycles supports the accuracy of the calculations.

\subsection{Conclusion}

New hardware and a computational method were tested in a field site to determine in-situ thermal conductivity. The obtained thermal conductivity profile shows the main factors controlling thermal conductivity are soil texture and water content. The agreement between the measured thermal conductivities in the field site and the values from previous studies supports the validity of the equipment and model used for this research. In comparison to conventional devices and techniques, this IoT-based device offers benefits in terms of lower cost, remote dataacquisition, and real-time measurement. Furthermore, this IoT device suggests taking advantage of automatically triggering the heating events throughout a year to observe temporal variation in thermal conductivity. 


\section{CHAPTER 5.}

SUMMARY

This chapter provides a summary of the preceding chapters. First, the major findings of this Ph.D. research are stated. Second, suggestions for future work are presented.

\subsection{Major Findings}

Natural depletion of petroleum hydrocarbon in the subsurface has emerged as a viable and cost-effective remedy for mature LNAPL releases (Sale et al., 2018). Given this, quantification of NSZD rates at petroleum hydrocarbon sites is essential for LNAPL risk management and remediation decision making. The NSZD rates quantified by the methods relying on measuring the consumption of $\mathrm{O}_{2}$ or generation of $\mathrm{CO}_{2}$ through NSZD process are limited to the finite period of gas flux measurement and are significantly influenced by temporally variable environmental factors. An alternative approach to address this issue is to quantify NSZD rates by converting the subsurface temperature data to NSZD rates. All current methods for transforming temperature data into NSZD rates rely on background correction of temperature data to separate the heat associated with NSZD process.

Background-correction methods used for transforming the NSZD-related heat to rates have drawbacks and limitations including 1) incomplete energy balance 2) ignoring the effect of water table fluctuation, and 3) linear projection of temperature data. To overcome these limitations and flaws, a new regression-based algorithm was developed. Running this algorithm using 42 million temperature measurements provides not only accurate NSZD rates but also insights from long-term temporal variability in the NSZD rates. The agreement between the NSZD rates from the regression-based algorithm and the $\mathrm{CO}_{2}$ trap method supports the validity 
of this computational method. Based on the derived empirical correlation, rising the water table pushes more $\mathrm{CH}_{4}$ from saturated area to vadose zone leading to producing more NSZD-related heat, while increasing the water content at shallow soil causes a reduction in apparent NSZD rates due to constraining the inward diffusing $\mathrm{O}_{2}$ from atmosphere to subsurface. More importantly, thermal NSZD rates offer some advantages compared to the rates from $\mathrm{CO}_{2}$ trap method, including real time NSZD, lower cost, and sustainability.

Although the regression-based algorithm provides a more rigorous computational method for converting temperature data to NSZD rates based on background correction, the backgroundcorrection method still calculates over-/under-estimated NSZD rates due to an imperfect background location. A new computational method is presented in Chapter 3 to eliminate the need for background correction for transforming temperature data to NSZD rates. The validity of this method is supported by three different tests. In the first test, the agreement of results from a numerical model and the single stick model validated the performance of the single stick method for estimation of surface and subsurface heat sources. The second test indicated the ability of the single stick method in simulation of subsurface temperatures. The third test presented that estimations of NSZD rates by the single stick method are less sensitive to spatial variation compared to the rates obtained by $\mathrm{CO}_{2}$ trap methods. Comparison of NSZD rates from background-correction and single stick methods at background locations demonstrated that the single stick method yields the lowest rates at these locations with no LNAPL. In general, per the comparisons and tests carried out, it seems the single stick method can be considered as a preferred method for transforming temperature data to NSZD rates.

Thermal conductivity is a key input parameters in all published and introduced computational methods in this dissertation used for estimation of NSZD rates by subsurface 
temperatures. A new integrated hardware and computational method for measuring real-time, insitu thermal conductivity of soil profile is presented in Chapter 4. The agreement between thermal conductivities and the values from previous studies suggest the validity of this new instrument and computational model. This IoT-based measurement hardware overcomes the disadvantages of conventional approaches for measuring in-situ thermal conductivities, including cost, difficulties with installation and running the instruments, uncertainties associated with measuring instruments, and short-term measurement.

\subsection{Future Work}

The results described here suggest that the single stick method is a promising computational method for transforming temperature data to real-time NSZD rates. However, plenty of opportunities and interesting questions remain for future research. Briefly, here are some future directions.

Optimization Algorithm. Optimization approach is one of the most rigorous methods for solving non-linear equations. A work is in progress to solve the derived equation of the single stick method using optimization approaches. In addition, such an algorithm could help to understand how many measuring point in the subsurface are required to quantify NSZD rates by the single stick method.

Negative NSZD Rates. Although the thermodynamic calculations in Chapter 3 show the negative NSZD rates could be due to endothermic methanogenic process, this hypothesis needs to be validated by a laboratory study. A preliminary laboratory study is in progress to evaluate this phenomenon.

Sensitivity Analysis. There are plenty of uncertainties associated with input parameters of the computational methods used for quantifying NSZD rates and the instruments used for 
measuring subsurface temperature data. All these uncertainties can cause over or under estimation of NSZD rates. Therefore, a work is in progress to evaluate the sensitivity of NSZD rates to these source of uncertainties using the Monte Carlo technique.

Artificial Intelligence. In addition to temperature, oxidation reduction potential and water level are the primary parameters to characterize/monitor contaminated water, soils, and sediment. Many employed durable sensors have been streaming large multiple parameter data sets to cloud-based data storage. AI should be used to: 1) predict the rate of natural depletion, 2) find the correlation between NSZD rate and redox, and 3) detect new releases of contaminants.

Temporal Variability in Thermal Conductivity. The influence of different factors on thermal conductivity of soils has been well studied on a laboratory scale. However, difficulties with fabrication and installation, long-term test time, and cost prevented to investigate the temporal variation in thermal conductivity of soils under ambient situation. Using the IoT instrument, scheduled heating events throughout a one-year period can be triggered remotely to provide real-time, in-situ thermal conductivity of a soil profile that evaluates the temporal and spatial variation in thermal conductivity under environmental conditions. 


\section{REFERENCES}

American Petroleum Institute (API). (2017). Qualification of vapor phase-related natural source zone depletion processes. American Petroleum Institute.

Amos, R. T., K.U. Mayer, B.A. Bekins, G.N. Delin, and R.L. Williams. (2005). Use of dissolved and vapor-phase gases to investigate methanogenic degradation of petroleum hydrocarbon contamination in the subsurface. Water Resources Research, 41(2). doi:10.1029/2004WR003433.

Askarani, K.K. and Pakbaz, M.S. (2016). Drained shear strength of over-consolidated compacted soil-cement. Journal of Materials in Civil Engineering, 28(5), 04015207. https://doi.org/10.1061/(ASCE)MT.1943-5533.0001510

ASTM International. D5334-05 Standard Test Method for Determination of Thermal Conductivity of Soil and Soft Rock by Thermal Needle Probe Procedure. West Conshohocken, PA, 2005. doi: https://doi.org/10.1520/D5334-05

Atekwana, E.A. and E.A. Atekwana. (2010). Geophysical signatures of microbial activity at hydro-carbon contaminated sites: A review. Surveys in Geophysics, 31(2), 247- 283. https://doi.org/10.1007/s10712-009-9089-8

Austin III, W. A. (1998). Development of an in situ system for measuring ground thermal properties. Doctoral dissertation, Oklahoma State University.

Beck, J.V., Blackwell, B. and St Clair Jr, C.R. (1985). Inverse Heat Conduction: Ill-Posed Problems. A Wiley-Interscience, New York. 
Becker, B., Fricke, B. (1997). Effects of saturation and dry density on soil thermal conductivity. In Proceedings of the 3rd International Conference on Heat Pumps in Cold Climates, Wolfville, NS, Canada (pp. 11-12).

Behrens, J., Roters, B. and Villinger, H. (1980). In situ determination of thermal conductivity in cased boreholes. In: A.S. Strub and P. Ungemach (eds.), Advances in European Geothermal Research, Second International seminar on the Results of EC Geothermal Energy Research, March 4-6, 1980, Strasbourg, France. D. Reidel Publ., Dordrecht, 525534.

Bristow, K.L., White, R.D. and Kluitenberg, G.J. (1994). Comparison of single and dual probes for measuring soil thermal properties with transient heating. Soil Research, 32(3), 447464. https://doi.org/10.1071/SR9940447

Burge, Scott R., Russell G. Burge, and David A. Hoffman. (2018). Microbial sensor system for the assessment of subsurface environments. U.S. Patent Application No. 15/237,230.

Burkhardt, H., Honarmand, H. and Pribnow, D. (1990). First results of thermal conductivity measurements with a borehole tool for great depths. KTB report, 90, 245-259.

Burkhardt, H., Honarmand, H. and Pribnow, D. (1995). Test measurements with a new thermal conductivity borehole tool. Tectonophysics, 244, 161-165. https://doi.org/10.1016/0040-

\section{1(94)00224-W}

Carslaw, H.S. and J.C. Jaeger. (1959). Conduction of Heat in Solids, 2nd ed., Clarendon Press, Oxford.

Chan, T. and Jeffrey, J.A. (1983). Scale and water saturation effects for thermal properties of low-porosity rocks. In: Proceedings of the 24th U.S. Symposium on Rock Mechanics, June 20-23, 1983, College Station, Texas, 287-301. 
Choudhary, A. (1976). An approach to determine the thermal conductivity and diffusivity of a rock in situ” Ph.D. dissertation, Oklahoma State University.

Coffin, R.B., J.W. Pohlman, K.S. Grabowski, D.L. Knies, R.E. Plummer, R.W. Magee, and T.J. Boyd. (2008). Radiocarbon and stable carbon isotope analysis to confirm petroleum natural attenuation in the vadose zone. Environmental Forensics, 9(1), 75-84. https://doi.org/10.1080/15275920801888335

Cohen, J. (2013). Statistical power analysis for the behavioral sciences. Routledge.

Cooper, H. H., and Jacob, C. E. (1946). A generalized graphical method for evaluating formation constants and summarizing well-field history. Eos, Transactions American Geophysical Union, 27(4), 526-534. https://doi.org/10.1029/TR027i004p00526

Dean, J. A. (1999). Lange's handbook of chemistry. New york; London: McGraw-Hill, Inc..

Garg, S., C.J. Newell, P.R. Kulkarni, D.C. King, D.T. Adamson, M. Irianni-Renno, and T. Sale. 2017. Overview of natural source zone depletion: processes, controlling factors, and composition change. Groundwater Monitoring \& Remediation, 37(3), 62-81. https://doi.org/10.1111/gwmr.12219

Ghazizadeh, S. and Bareither, C.A. (2019). Temperature Effects on the Peak and LargeDisplacement Shear Strength of Needle-Punched Reinforced GCLs. Geosynthetics Conference, Houston, TX, USA.

Ghazizadeh, S. and Bareither, C.A. (2018). Stress-controlled direct shear testing of geosynthetic clay liners I: Apparatus development. Geotextiles and Geomembranes, 46(5), 656-666. https://doi.org/10.1016/j.geotexmem.2018.06.003 
Gieg, L.M., Fowler, S.J. and Berdugo-Clavijo, C. (2014). Syntrophic biodegradation of hydrocarbon contaminants. Current opinion in biotechnology, 27, 21-29. https://doi.org/10.1016/j.copbio.2013.09.002

Haynes, W.M. (2014). CRC Handbook of Chemistry and Physics. CRC Press, Boca Raton, Florida.

Hillel, D. (2013). Fundamentals of Soil Physics. Academic Press, New York.

Ingersoll, L.R., O.J. Zobel and A.C. Ingersoll. (1954). Heat Conduction with Engineering Geological, and other Applications. New York: Mc Graw-Hill.

Irianni Renno, M., D. Akhbari, M.R. Olson, A.P. Byrne, E. Lefèvre, J. Zimbron, M. Lyverse, T.C. Sale, and S. K. De Long. (2016). Comparison of bacterial and archaeal communities in depth-resolved zones in an LNAPL body. Applied Microbiology and Biotechnology, 100(7), 3347-3360. https://doi.org/10.1007/s00253-015-7106-Z

ITRC. (2009). Evaluating Natural Source Zone Depletion at Sites with LNAPL. Washington, DC: Interstate Technology and Regulatory Council.

J. Simunek, M. Sejna, M. Sakai, and M.Th. van Genuchten. (2013). The HYDRUS-1D Software Package for Simulating the One-Dimensional Movement of Water, Heat, and Multiple Solutes in Variably Saturated Media, Version 4.17, HYDRUS Software Series 3, Department of Environmental Sciences, University of California Riverside, Riverside, California, USA, pp. 343, 2013.

Johnson, P., P. Lundegard, and Z. Liu. (2006). Source zone natural attenuation at petroleum hydrocarbon spill sites - I: site-specific assessment approach. Groundwater Monitoring \& Remediation, 26(4), 82-92. https://doi.org/10.1111/j.1745-6592.2006.00114.x 
Jolivet, J. and Vasseur, G. (1982). Sur un essai de mesure directe du flux geothermique in situ. Ann. Geophys., 38, 225-239.

Jury, W.A. and R. Horton. 2004. Soil Physics, John Wiley \& Sons, New York.

Karimi Askarani, K., Stockwell, E.B., Piontek, K.R. and Sale, T.C. (2018). Thermal Monitoring of Natural Source Zone Depletion. Groundwater Monitoring \& Remediation, 38(3), 4352. https://doi.org/10.1111/gwmr.12286

Kersten, M.S. (1949). Thermal properties of soils. Bulletin 28, Minneapolis, Engineering Experiment Station, University of Minnesota.

Kiaalhosseini, S., Johnson, R.L., Rogers, R.C., Renno, M.I., Lyverse, M. and Sale, T.C. (2016). Cryogenic core collection (C3) from unconsolidated subsurface media. Groundwater Monitoring \& Remediation, 36(4), 41-49. https://doi.org/10.1111/gwmr.12186

Knight, J.H., Kluitenberg, G.J. and Kamai, T. (2016). The dual probe heat pulse method: interaction between probes of finite radius and finite heat capacity. Journal of Engineering Mathematics, 99(1), 79-102. https://doi.org/10.1007/s10665-015-9822-x

Kömle, N.I., Hütter, E.S., Macher, W., Kaufmann, E., Kargl, G., Knollenberg, J., Grott, M., Spohn, T., Wawrzaszek, R., Banaszkiewicz, M. and Seweryn, K. (2011). In situ methods for measuring thermal properties and heat flux on planetary bodies. Planetary and Space Science, 59(8), 639-660. https://doi.org/10.1016/j.pss.2011.03.004

Kristiansen, J. I. (1982). Transient cylindrical probe method for determination of thermal parameters of earth materials. Denmark.

Kukkonen, I., and Suppala, I. (1999). Measurement of thermal conductivity and diffusivity in situ: literature survey and theoretical modelling of measurements (POSIVA--99-01). Finland. 
Kulkarni, P.R., King, D.C., McHugh, T.E., Adamson, D.T. and Newell, C.J. (2017). Impact of temperature on groundwater source attenuation rates at hydrocarbon sites. Groundwater Monitoring \& Remediation, 37(3), 82-93. https://doi.org/10.1111/gwmr.12226

LI-COR. (2010). LI-8100A Automated Soil CO2 Flux System \& LI-8150 Multiplexer Instruction Manual. Lincoln, NE: LI-COR, Inc.

Lundegard, P.D. and Johnson, P.C. (2006). Source zone natural attenuation at petroleum hydrocarbon spill sites-II: application to a former oil field. Groundwater Monitoring \& Remediation, 26(4), 93-106. https://doi.org/10.1111/j.1745-6592.2006.00115.x

Luo, H., Dahlen, P.R., Johnson, P.C. and Peargin, T. (2013). Proof-of-concept study of an aerobic vapor migration barrier beneath a building at a petroleum hydrocarbon-impacted site. Environ-mental science \& technology, 47(4), 1977-1984. https://doi.org/10.1021/es3045532

Mahler, Nicholas, Tom Sale, and Mark Lyverse. (2012). A mass balance approach to resolving LNAPL stability. Groundwater, 50(6), 861-871. https://doi.org/10.1111/j.1745$\underline{6584.2012 .00949 . x}$

Maier, M. and Schack-Kirchner, H. (2014). Using the gradient method to determine soil gas flux: A review. Agricultural and forest meteorology, 192, 78-95. https://doi.org/10.1016/j.agrformet.2014.03.006

MathWorks. MATLAB and Curve Fitting Toolbox Release 2015b. (2015). The MathWorks, Inc., Natick, MA, United States.

McCoy, K. (2012). Resolving natural losses of LNAPL using $\mathrm{CO}_{2}$ traps. Doctoral dissertation, Colorado State University. Libraries. 
McCoy, K., J. Zimbron, T. Sale, and M. Lyverse. (2015). Measurement of natural losses of LNAPL using $\mathrm{CO}_{2}$ Traps. Groundwater, 53(4), 658-667. https://doi.org/10.1111/gwat.12240

Mogensen, P. (1983). Fluid to Duct Wall Heat Transfer in Duct System Heat Storages. Proceedings of the International Conference on Subsurface Heat Storage in Theory and Practice, Swedish Council for Building Research. June 6-8.

Molins, S., Mayer, K.U., Amos, R.T. and Bekins, B.A. (2010). Vadose zone attenuation of organic compounds at a crude oil spill site-Interactions between biogeochemical reactions and multi-component gas transport. Journal of Contaminant Hydrology, 112(1), 15-29. https://doi.org/10.1016/j.jconhyd.2009.09.002

Mussman, G. and Kessels, W. (1980). An in-situ thermal conductivity probe. In: A.S. Strub and P. Ungemach (eds.), Advances in European Geothermal Research, Second International seminar on the Results of EC Geothermal Energy Research, March 4-6, 1980, Strasbourg, France. D. Reidel Publ., Dordrecht, 556-564.

Nash, J. E. and Sutcliffe, J. V. (1970). River Flow Forecasting through Conceptual Models. Part IA Discussion of Principles. Journal of Hydrology, 10(3), 282-290. https://doi.org/10.1016/0022-1694(70)90255-6

Nikiforova, T., Savytskyi, M., Limam, K., Bosschaerts, W., and Belarbi, R. (2013). Methods and results of experimental researches of thermal conductivity of soils. Energy Procedia, 42, 775-783. https://doi.org/10.1016/j.egypro.2013.12.034

Palaia, T. (2016). Natural source zone depletion rate assessment. Applied NAPL Science Review 6. 
Plyasunov, A. V. and Shock, E. L. (2000). Thermodynamic functions of hydration of hydrocarbons at 298.15 K and 0.1 MPa. Geochimica et Cosmochimica Acta, 64(3), 439468. https://doi.org/10.1016/S0016-7037(99)00330-0

Poulsen, T.G. and P. Møldrup. (2006). Evaluating effects of wind-induced pressure fluctuations on soil-atmosphere gas exchange at a landfill using stochastic modeling. Waste Management \& Research, 24(5), 473-481. https://doi.org/10.1177/0734242X06066363

Ramirez, J.A., A.J. Baird, T.J. Coulthard, and J.M. Waddington. (2015). Ebullition of methane from peatlands: does peat act as a signal shredder? Geophysical Research Letters, 42(9), 3371 - 3379. https://doi.org/10.1002/2015GL063469

Różański, A. and Sobótka, M. (2013). On the interpretation of the needle probe test results: thermal conductivity measurement of clayey soils. Studia Geotechnica et Mechanica, 35(1), 195-207. DOI: 10.2478/sgem-2013-0015

Sale, T., H. Hopkins, and A. Kirkman. (2018). Managing Risks at LNAPL Sites. 2nd Edition Bulletin 18, American Petroleum Institute

Sale, T. C., Stockwell, E. B., Newell, C. J., Kulkarni, P. R. (2015). U.S. Patent Application No. $14 / 625,570$.

Sihota, N.J. , J.J. Trost , B.A. Bekins , A. Berg, G.N. Delin , B. Mason , E. Warren , and K.U. Mayer . (2016). Seasonal variability in vadose zone biodegradation at a crude oil pipeline rupture site. Vadose Zone Journal, 15(5). https://doi.org/10.2136/vzj2015.09.0125

Sihota, N.J., O. Singurindy, and K.U. Mayer. (2011). CO2-efflux measurements for evaluating source zone natural attenuation rates in a petroleum hydrocarbon contaminated aquifer. Environmental Science \& Technology, 45(2), 482-488. https://doi.org/10.1021/es1032585 
Skinner, A. M. (2013). LNAPL longevity as a function of remedial actions: tools for evaluating LNAPL remedies. Master's thesis, Colorado State University, Fort Collins, CO.

Stockwell, E. 2015. Continuous NAPL loss rates using subsurface temperatures, Master's thesis, Colorado State University, Fort Collins, CO.

Sweeney, R.E. and G.T. Ririe. (2014). Temperature as a tool to evaluate aerobic biodegradation in hydrocarbon contaminated soil. Groundwater Monitoring \& Remediation, 34(3), 4150. https://doi.org/10.1111/gwmr.12064

Taler, J. and Duda, P. (2010). Solving direct and inverse heat conduction problems. Springer Science \& Business Media.

Tan, Y. and Ritchie, A.I.M. (1997). In situ determination of thermal conductivity of waste rock dump material. Water, Air and Soil Pollution, 98(3-4), 345-359. https://doi.org/10.1023/A:1026459011919

Tarnawski, V. R., Momose, T., McCombie, M. L., and Leong, W. H. (2015). Canadian field soils III. Thermal-conductivity data and modeling. International Journal of Thermophysics, 36(1), 119-156. https://doi.org/10.1007/s10765-014-1793-z

Tracy, M.K. (2015). Method comparison for analysis of LNAPL natural source zone depletion using $\mathrm{CO}_{2}$ fluxes. Master's thesis, Colorado State University.

TRC. (2012). LNAPL distribution and recoverability assessment. Project Report to the State of Kansas.

Warren, E. and B.B. Bekins. (2015). Relating surface temperature changes to microbial activity at a crude oil-contaminated site, Journal of Contaminant Hydrology, 182, 183-193. https://doi.org/10.1016/j.jconhyd.2015.09.007 
Wiedemeier, T. H., J.T. Wilson, J.E. Hansen, F.H. Chapelle, and M.A. Swanson. (1996). Technical protocol for evaluating natural attenuation of chlorinated solvents in groundwater. Revision 1. Air Force Center for Environmental Excellence. Brooks AFB TX.

Willmott, C. J. (1981). On the validation of models. Physical geography, 2(2), 184-194. https://doi.org/10.1080/02723646.1981.10642213

Wyatt, D.E., D.M. Richers, and R.J. Pirkle. (1995). Barometric pumping effects on soil gas studies for geological and environmental characterization. Environmental Geology, 25(4), 243-250. https://doi.org/10.1007/BF00766753

Xia, Y., et al., NCEP/EMC (2012). "NLDAS Noah Land Surface Model L4 Hourly 0.125 x 0.125 degree V002.” Edited by David Mocko, NASA/GSFC/HSL, Greenbelt, Maryland, USA, Goddard Earth Sciences Data and Information Services Center (GES DISC), Accessed: [Data Access Date], 10.5067/47Z13FNQODKV

Xia, Y., K. Mitchell, M. Ek, J. Sheffield, B. Cosgrove, E. Wood, L. Luo, C. Alonge, H. Wei, J. Meng, B. Livneh, D. Lettenmaier, V. Koren, Q. Duan, K. Mo, Y. Fan, and D. Mocko, (2012). "Continental-scale water and energy flux analysis and validation for the North American Land Data Assimilation System project phase 2 (NLDAS-2): 1. Intercomparison and application of model products." J. Geophys. Res., 117, D03109, doi:10.1029/2011JD016048.

Zimbron, J., T. Sale, and M. Lyverse. (2014). Gas flux measurement using traps, Pending U.S. Patent 8,714034 B2. May 6, 2014. 
Appendix A

SUPPORTING INFORMATION FOR THERMODYNAMIC CALCULATION ASSOCIATE WITH METHANOGENIC PROCESS 
Table A-1. Free energy and enthalpy of formation for reaction components

\begin{tabular}{lllll}
\hline Species & State & $\Delta \boldsymbol{G}_{\boldsymbol{f}}(\mathbf{k J} / \mathbf{m o l})$ & $\Delta \boldsymbol{H}_{\boldsymbol{f}}(\mathbf{k J} / \mathbf{m o l})$ & Source \\
\hline $\boldsymbol{C}_{\mathbf{1 0}} \boldsymbol{H}_{\mathbf{2 2}}$ & aq & 54.34 & -296.97 & $\begin{array}{l}\text { Plyasunov and Shock } \\
(2000)\end{array}$ \\
$\boldsymbol{H}_{\mathbf{2}} \boldsymbol{O}$ & $\mathrm{l}$ & -237.14 & -285.83 & Dean (1999) \\
$\boldsymbol{C O}_{\mathbf{2}}$ & $\mathrm{g}$ & -394.39 & -393.51 & Dean (1999) \\
$\boldsymbol{C H}_{\mathbf{4}}$ & $\mathrm{g}$ & -50.5 & -74.6 & Dean (1999) \\
$\boldsymbol{O}_{\mathbf{2}}$ & $\mathrm{g}$ & 0 & 0 & Standard \\
\hline $\begin{array}{l}\text { 1 = liquid } \\
\text { aq = aqueous }\end{array}$ & & & \\
$\mathrm{g}=$ gas & & &
\end{tabular}


Appendix B

SUPPORTING INFORMATION FOR CALCULATING IN SITU THERMAL CONDUCTIVITY OF SOIL PROFILE 


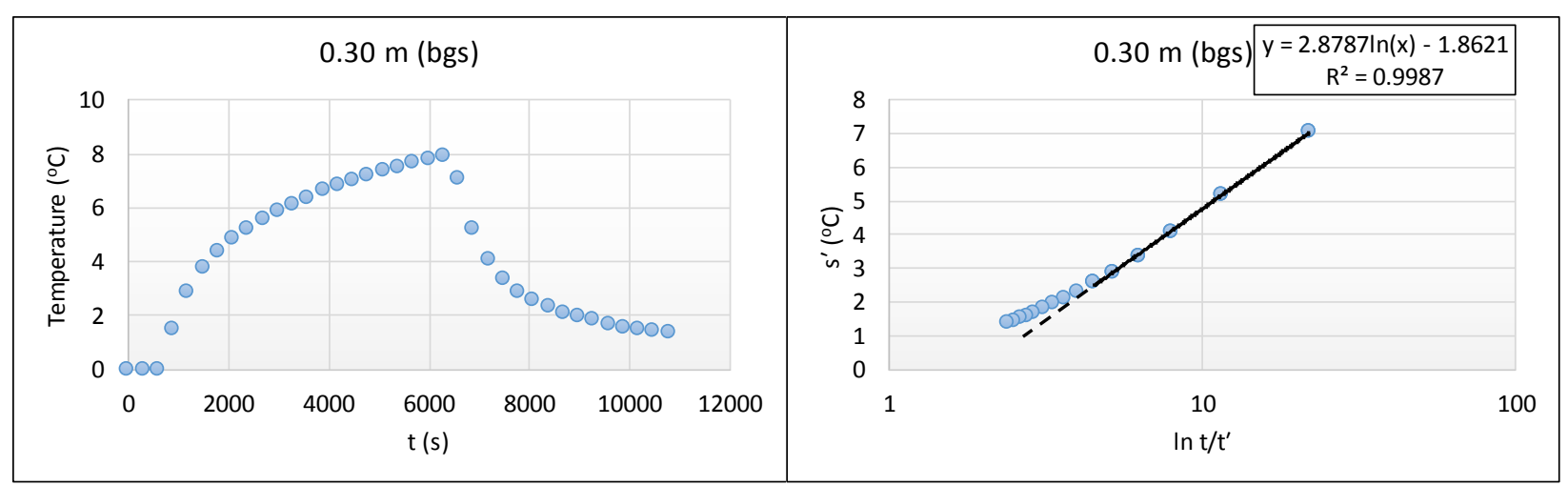

Figure B-1. Change in subsurface temperature through the heating and dissipation of heat and residual temperature versus $(t / t)$ at $0.30 \mathrm{~m}(\mathrm{bgs})$

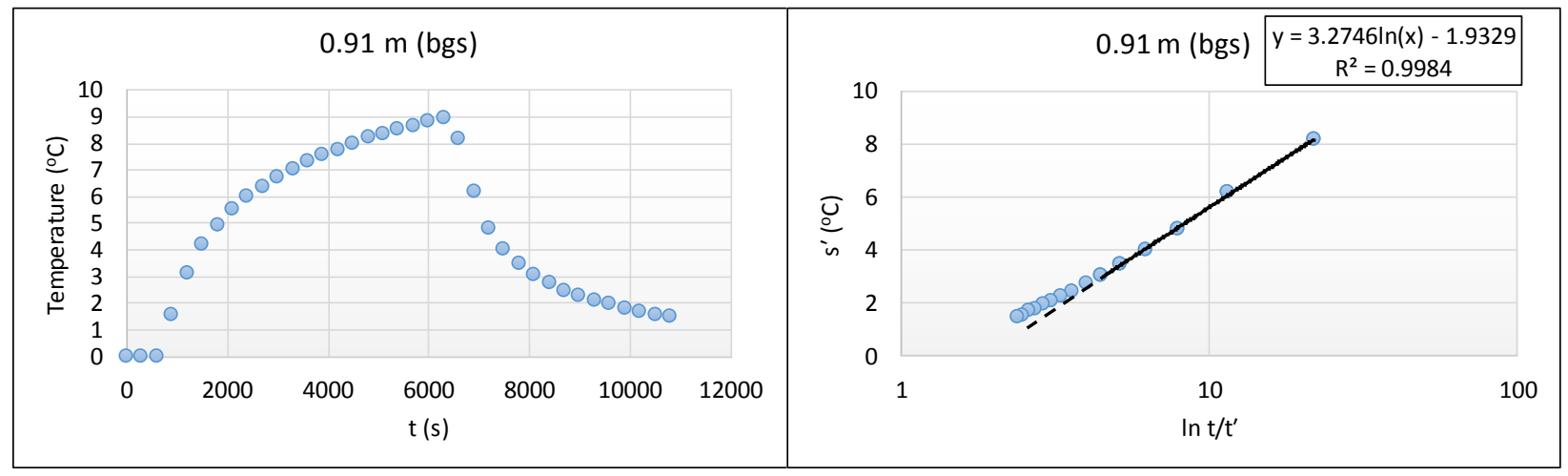

Figure B-2. Change in subsurface temperature through the heating and dissipation of heat and residual temperature versus $(t / t)$ at $0.91 \mathrm{~m}(\mathrm{bgs})$

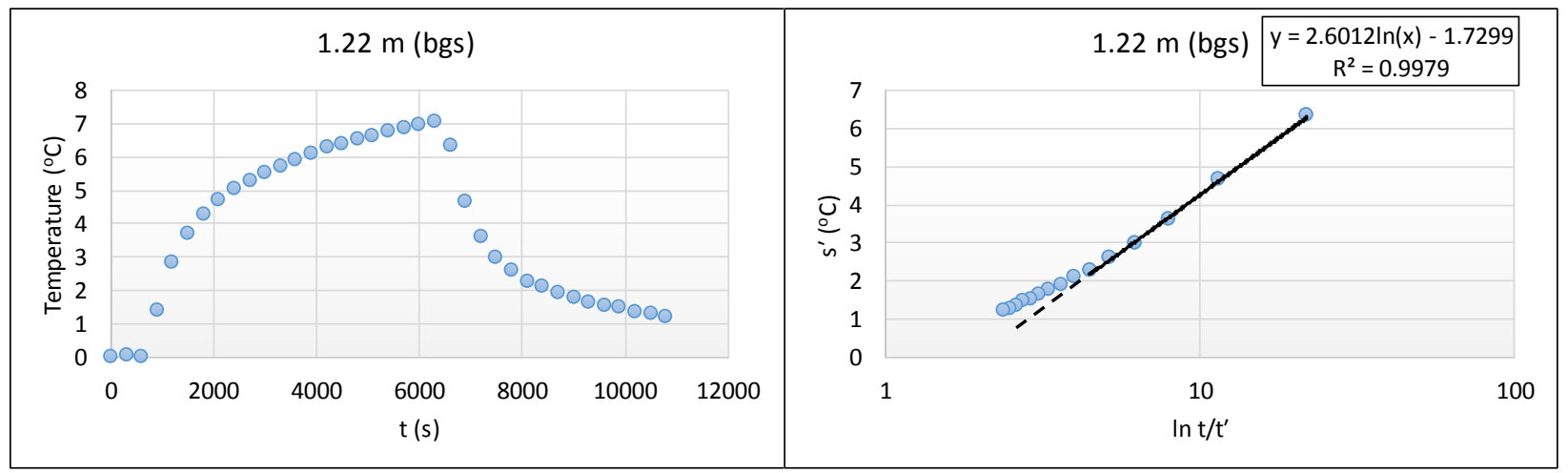

Figure B-3. Change in subsurface temperature through the heating and dissipation of heat and residual temperature versus $(t / t)$ at $1.22 \mathrm{~m}(\mathrm{bgs})$ 


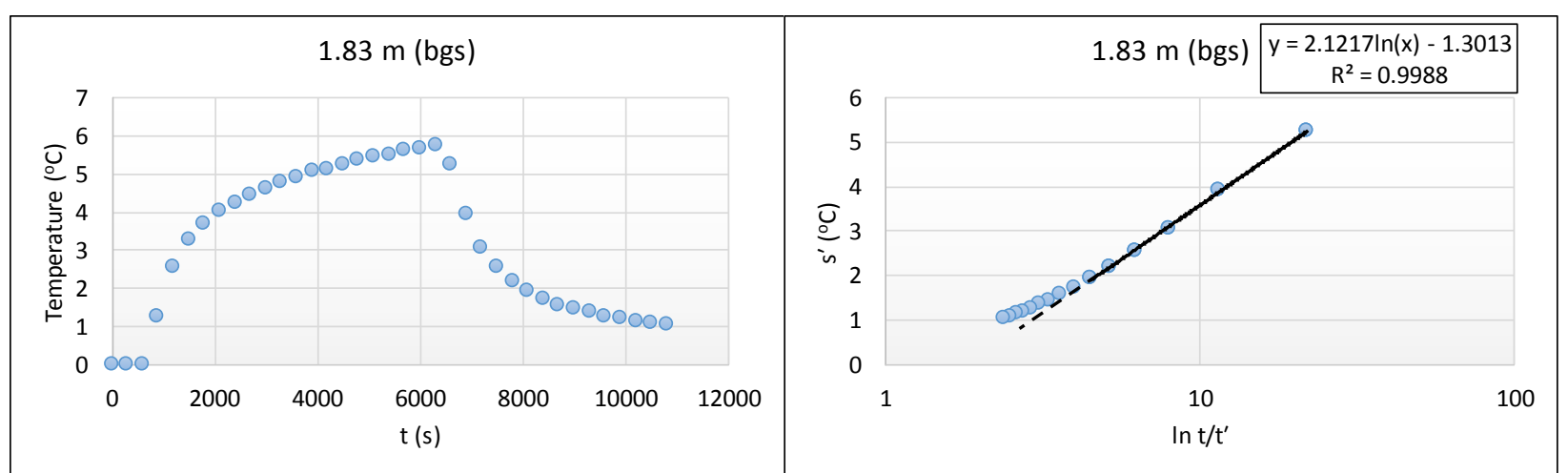

Figure B-4. Change in subsurface temperature through the heating and dissipation of heat and residual temperature versus $(t / t)$ at $1.83 \mathrm{~m}$ (bgs)
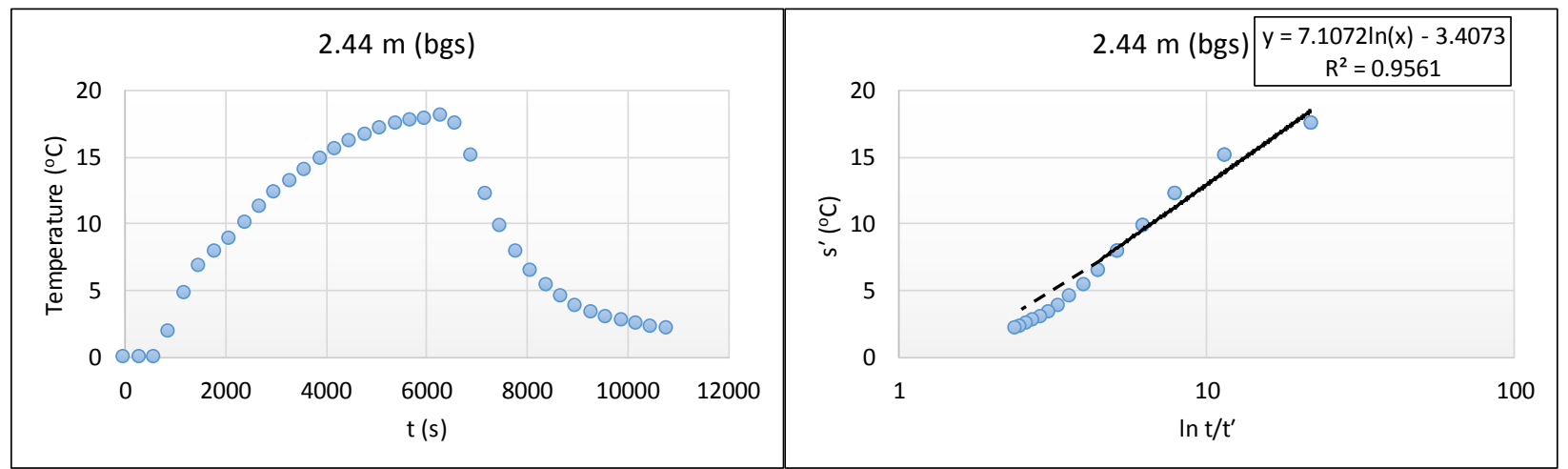

Figure B-5. Change in subsurface temperature through the heating and dissipation of heat and residual temperature versus $(t / t)$ at $2.44 \mathrm{~m}$ (bgs)
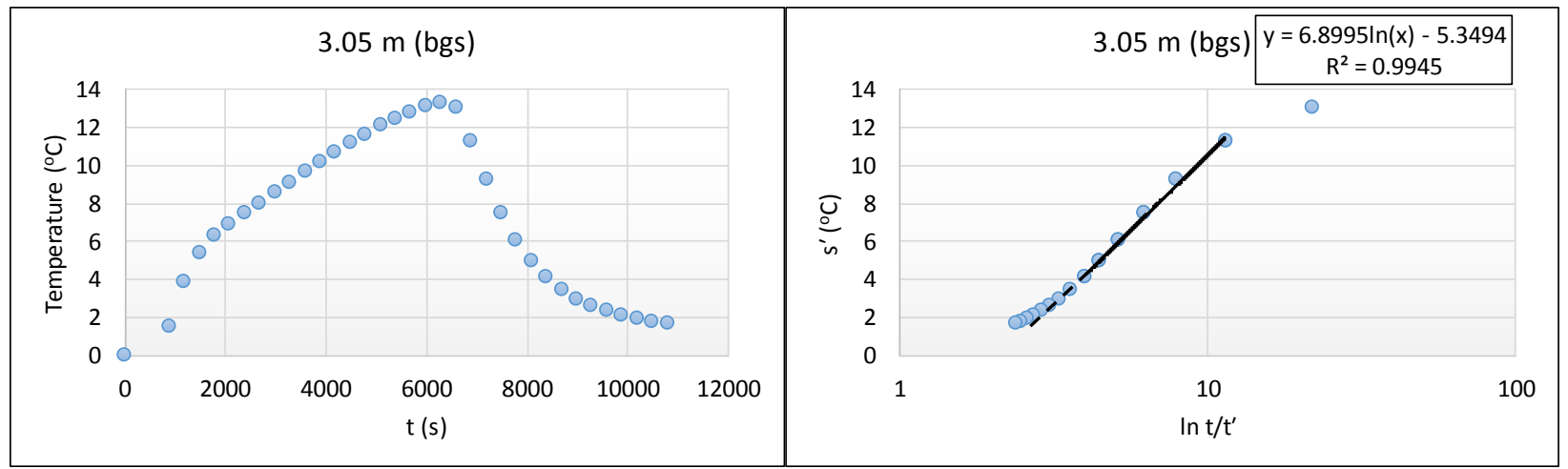

Figure B-6. Change in subsurface temperature through the heating and dissipation of heat and residual temperature versus $(t / t)$ at $3.05 \mathrm{~m}$ (bgs) 


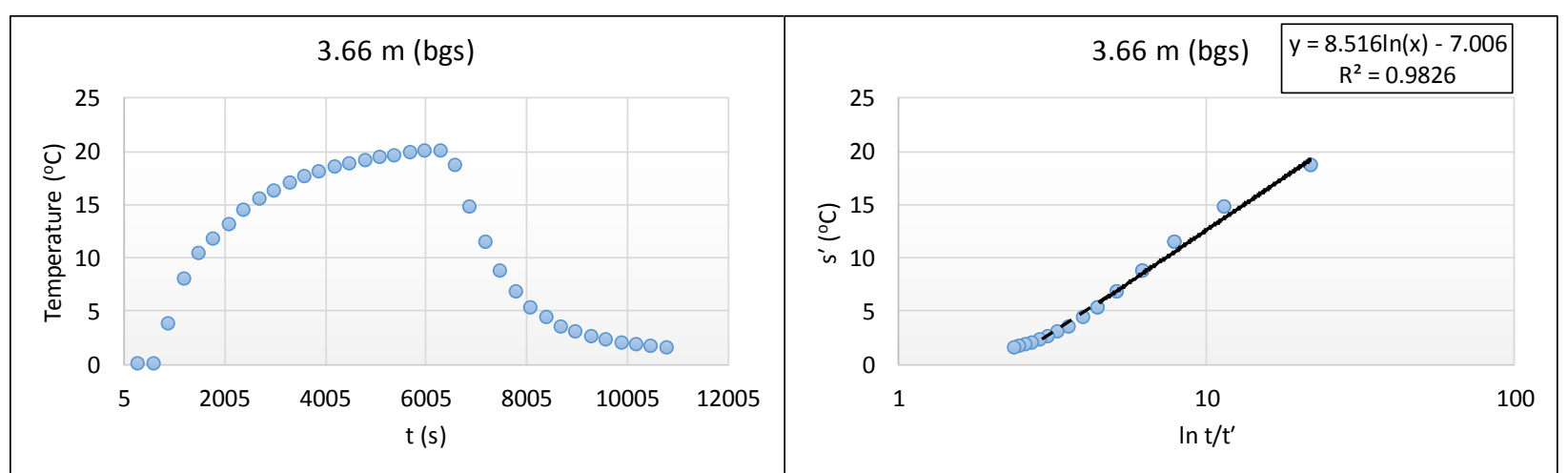

Figure B-7. Change in subsurface temperature through the heating and dissipation of heat and residual temperature versus $(t / t)$ at $3.66 \mathrm{~m}$ (bgs)

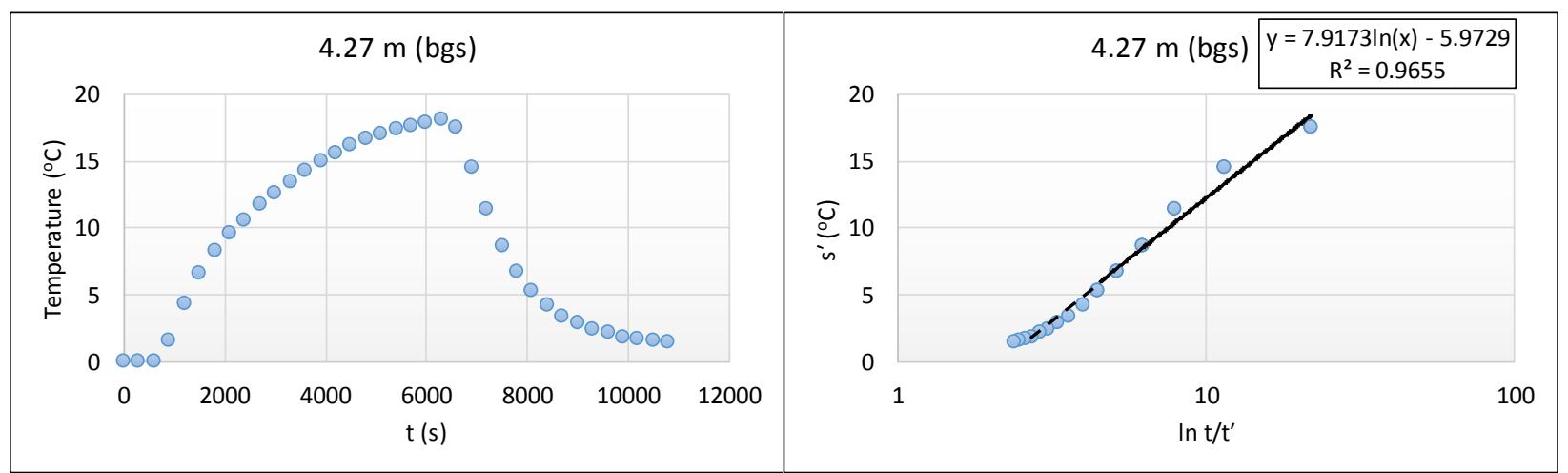

Figure B-8. Change in subsurface temperature through the heating and dissipation of heat and residual temperature versus $(t / t)$ at $4.27 \mathrm{~m}$ (bgs)
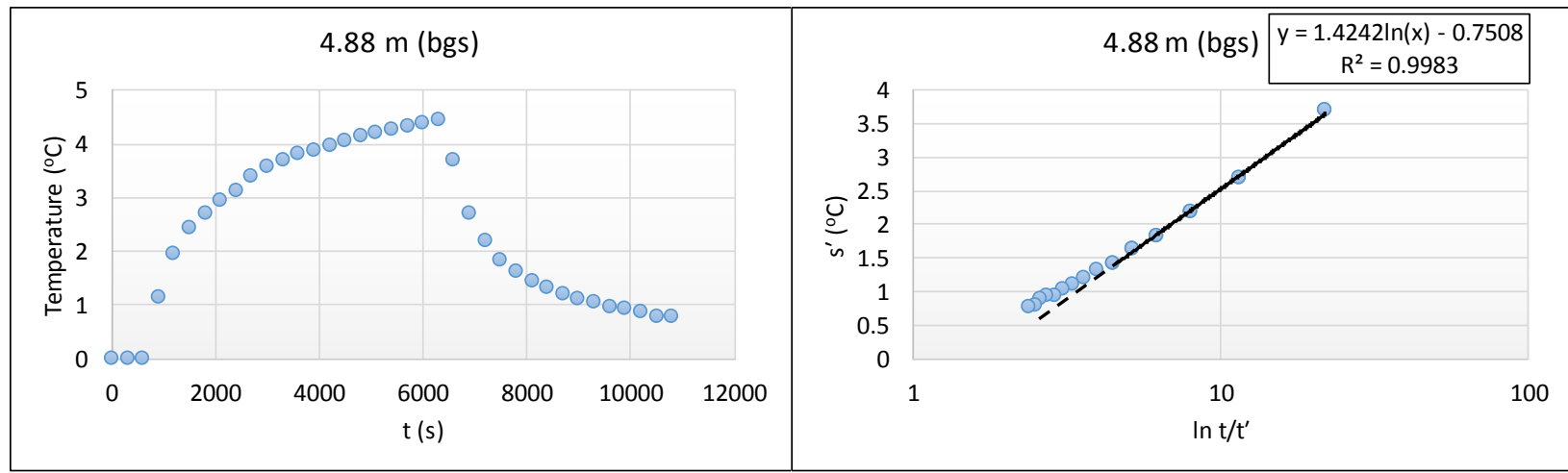

Figure B-9. Change in subsurface temperature through the heating and dissipation of heat and residual temperature versus $(t / t)$ at $4.88 \mathrm{~m}(\mathrm{bgs})$ 


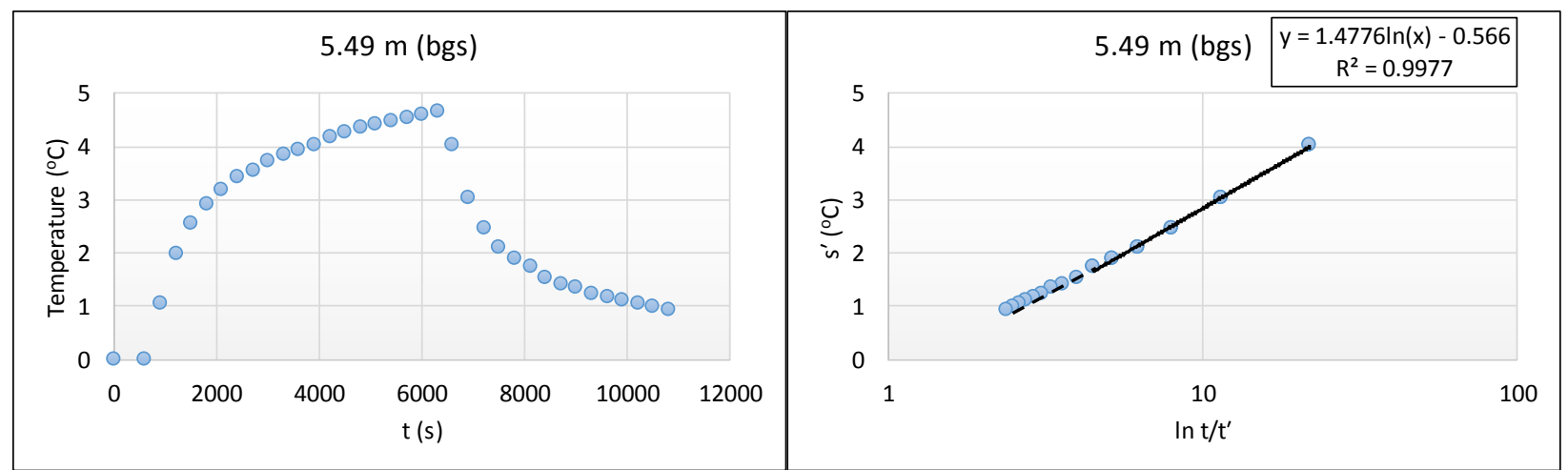

Figure B-10. Change in subsurface temperature through the heating and dissipation of heat and residual temperature versus $(t / t)$ at $5.49 \mathrm{~m}$ (bgs)

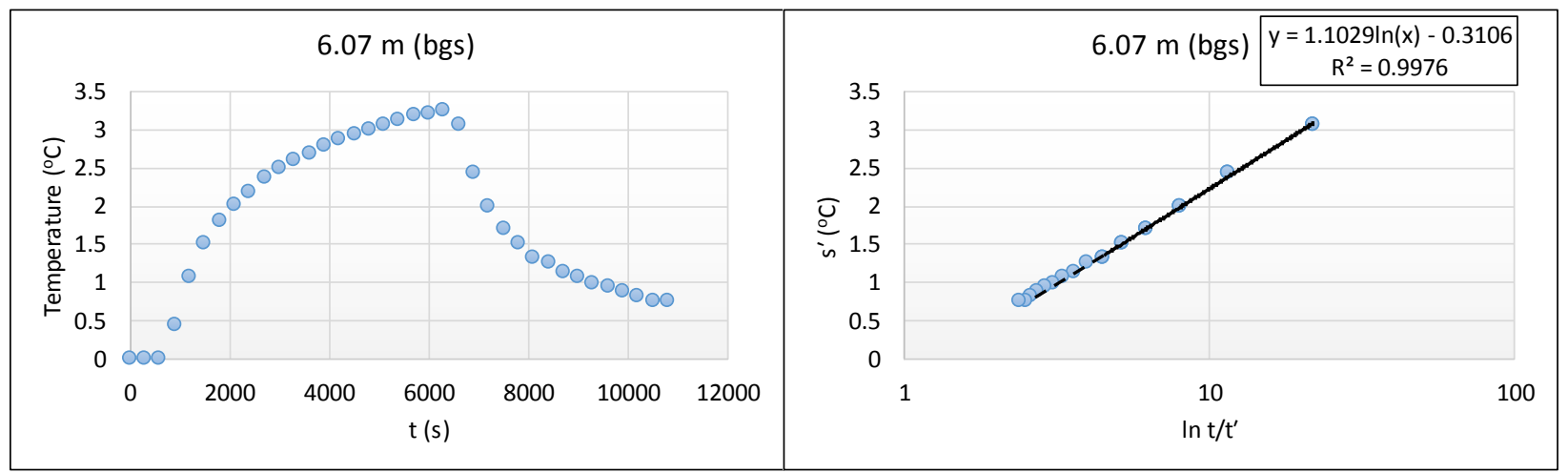

Figure B-11. Change in subsurface temperature through the heating and dissipation of heat and residual temperature versus $(t / t)$ at $6.07 \mathrm{~m}(\mathrm{bgs})$
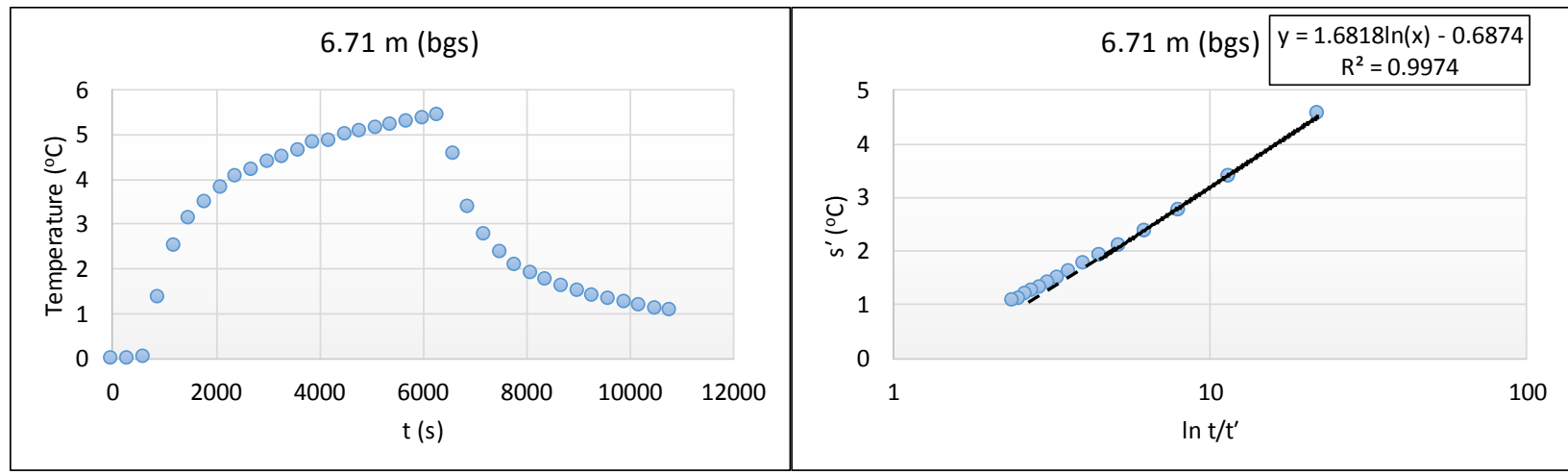

Figure B-12. Change in subsurface temperature through the heating and dissipation of heat and residual temperature versus $(t / t)$ at $6.71 \mathrm{~m}(\mathrm{bgs})$ 


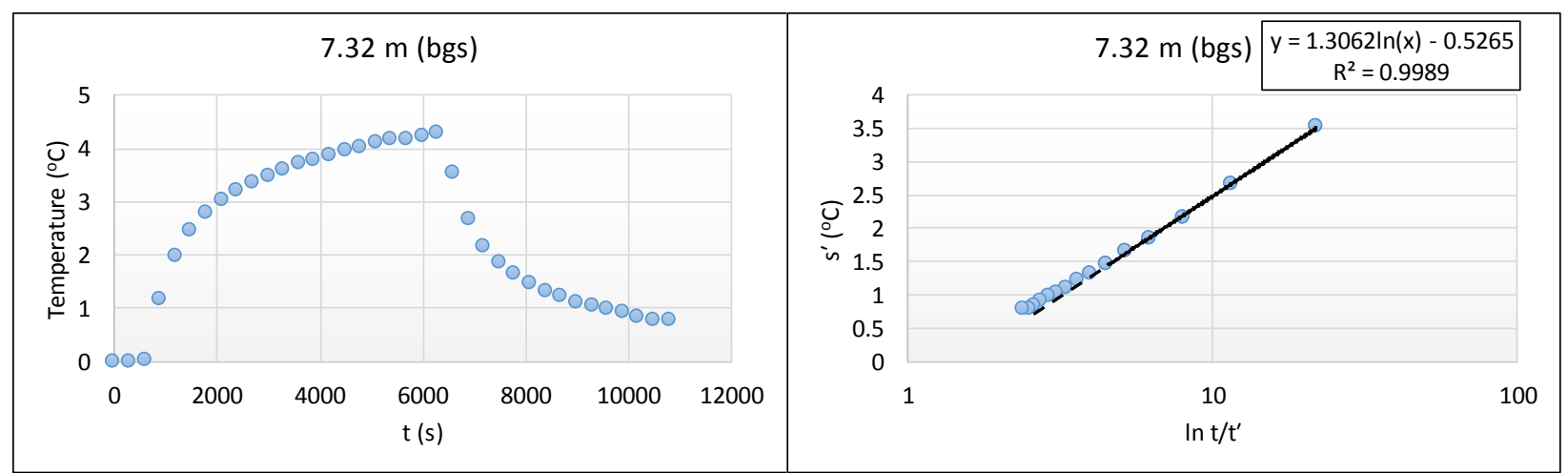

Figure B-13. Change in subsurface temperature through the heating and dissipation of heat and residual temperature versus $(t / t)$ at $7.32 \mathrm{~m}$ (bgs) 